\title{
ESTUDIOS DE CASO PARA LA DOCENCIA EN EMPRESA SOCIAL Y ECONOMÍA SOCIAL
}

\section{IGNACIO BRETOS ISABEL SAZ GIL}

Cátedra Cooperativas y Economía Social Caja Rural de Teruel Universidad de Zaragoza

\begin{tabular}{|c|c|}
\hline in & $\begin{array}{l}\text { Cátedra Cooperativas } \\
\text { y Economía Social }\end{array}$ \\
\hline 1542 & Universidad Zaragoza \\
\hline
\end{tabular}


(C) Ignacio Bretos e Isabel Saz-Gil

2019, $1^{\text {a }}$ Edición

Universidad de Zaragoza

Financiado por:

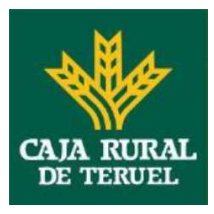

Con la colaboración de:

$$
\begin{aligned}
& \text { GESES } \\
& \text { UnivEASIDAD DE ZARAGozA } \\
& \text { Económicos destudios Sociales y }
\end{aligned}
$$

Grupo de Estudios Sociales y Económicos del Tercer Sector, Universidad de Zaragoza.

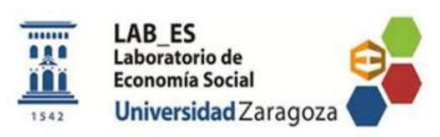

LAB_ES, Laboratorio de Economía Social, Universidad de Zaragoza.
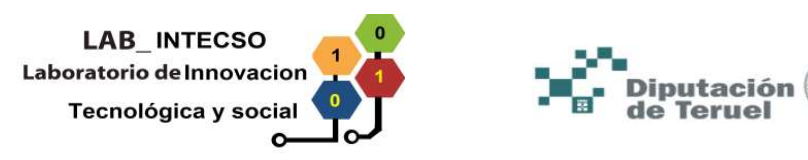

LAB_INTECSO, Laboratorio de Innovación Tecnológica y Social, Facultad de Ciencias Sociales y Humanas de Teruel.

\section{Edita y distribuye:}

Cátedra Cooperativas y Economía Social, Caja Rural de Teruel.

Facultad de Economía y Empresa, Universidad de Zaragoza.

Gran Vía 2, 50005, Zaragoza, España.

\section{Recurso electrónico}

ISBN: 978-84-948481-3-1

DOI: $10.26754 /$ uz.978-84-948481-3-1 
ÍNDICE DE CONTENIDOS

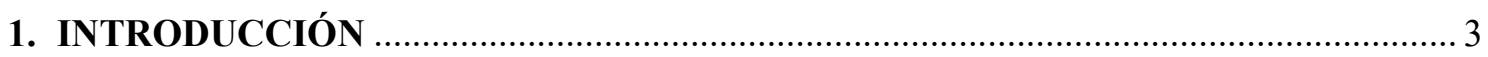

2. ARLA FOODS: LA VISIÓN GLOBAL DEL COOPERATIVISMO AGROALIMENTARIO

3. GRUPO UP: LA DIFUSIÓN DEL COOPERATIVISMO A TRAVÉS DE LA INTERNACIONALIZACIÓN.

4. GRUPO MONDRAGÓN: LA ADAPTACIÓN DEL COOPERATIVISMO A LA GLOBALIZACIÓN

5. RABOBANK: UNA EXPERIENCIA DE BANCA COOPERATIVA MULTINACIONAL

6. GRUPO ARCOÍRIS: LA FUERZA DEL COOPERATIVISMO AGROALIMENTARIO

7. ATADI: AGRUPACIÓN TUROLENSE DE ASOCIACIONES DE PERSONAS CON

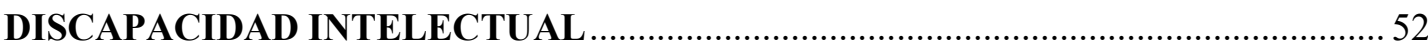

8. CEREALES TERUEL: SOCIEDAD COOPERATIVA DEL ALTO TERUEL ............. 62

9. KOOPERA: INNOVACIÓN SOCIAL Y MEDIOAMBIENTAL …............................... 72

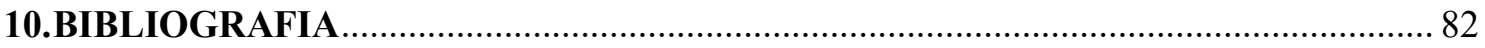




\section{INTRODUCCIÓN}

Desde la Cátedra Cooperativas y Economía Social Caja Rural de Teruel, de la Universidad de Zaragoza, uno de los objetivos clave que se persiguen es la promoción del conocimiento sobre las cooperativas y las organizaciones de la Economía Social en el ámbito de la comunidad universitaria. Una de las estrategias esenciales para avanzar en esta dirección consiste en fomentar una mayor inclusión y visibilidad de este tipo de organizaciones dentro de la docencia universitaria, con particular incidencia en las materias relacionadas con la economía y con la dirección y gestión de empresas.

En este contexto, el presente libro proporciona una colección de 8 estudios de caso de organizaciones entroncadas en el sector de la Economía Social con un doble objetivo. Por un lado, pretendemos difundir y visibilizar la labor de distintas empresas y organizaciones relevantes del sector que, desde enfoques, trayectorias y actividades diversas, contribuyen a transformar la realidad socio-económica de los territorios donde operan. Como parte de la Economía Social, estas organizaciones llevan a cabo sus actividades desde una posición diferente a los modelos tradicionales de empresa, en tanto que se basan en principios como la primacía de las personas y del fin social sobre el capital, la independencia y autonomía en la gestión con respecto a los poderes públicos, la adhesión voluntaria y abierta, la gestión democrática por parte de los miembros, o la defensa y aplicación de los principios de solidaridad y responsabilidad.

Por otro lado, la finalidad principal del libro es que los casos prácticos presentados ofrezcan material relevante y útil para la docencia no sólo en el ámbito específico de la economía social y solidaria, sino en disciplinas científicas más generales como la economía, la sociología y la dirección y gestión de empresas.

Los casos se han seleccionado con el objetivo de ofrecer una amplia variedad de organizaciones de la economía social en términos de diversas variables como el tamaño de la organización por número de empleos y facturación, el alcance local o internacional de la actividad económica y social, la madurez de la empresa, el sector de actividad o los servicios ofrecidos.

Cada uno de los estudios de caso se ha estructurado de la siguiente manera. El primer apartado, "Introducción", se dedica a presentar la organización correspondiente, así como la información o datos necesarios para aportar al potencial lector una idea clara de sus actividades, objetivos, etc. El segundo apartado, "Desarrollo del caso", estudia la actividad que, en el ámbito de la política de empresa de la organización, sobresale por su carácter más relevante, estrategias, responsabilidad social, calidad, etc. El tercer apartado, "Cuestiones para la discusión", incluye diversas preguntas sobre cada empresa que servirán para profundizar los temas y estimular el espíritu crítico de los lectores, y que pueden resultar particularmente útiles para discutir en clase. Finalmente, el cuarto apartado destaca las principales conclusiones sobre la empresa correspondiente, tratando de reflejar un juicio crítico y destacar la relevancia de las actuaciones de la misma. 


\section{ARLA FOODS: LA VISIÓN GLOBAL DEL COOPERATIVISMO AGROALIMENTARIO}

\section{RESUMEN:}

El sector agroalimentario ha sufrido una extraordinaria transformación en las tres últimas décadas en un marco de constante globalización económica. Las cooperativas no han sido ajenas a estas tendencias y han seguido estrategias de expansión internacional basadas en las fusiones, adquisiciones y otras fórmulas. El caso de la cooperativa láctea Arla Foods es un claro ejemplo. Nacida en 2001 de la fusión de la danesa Danish MD Foods y la sueca Swedish Arla, hoy en día, la cooperativa es propiedad de 11.300 agricultores distribuidos entre Dinamarca, Suecia, el Reino Unido, Alemania, Bélgica, Luxemburgo y los Países Bajos. El intenso proceso de reflexión en el que Arla Foods llevaba inmersa los últimos años ha dado lugar a la estrategia denominada "Good Growth 2020", basada en la consecución de un "crecimiento global socialmente responsable, cooperativo, saludable y natural". 


\subsection{INTRODUCCIÓN}

Arla Foods es una cooperativa dedicada a la producción y distribución de leche y productos lácteos. Es la quinta mayor empresa láctea del mundo y su estrategia de diferenciación con respecto a sus competidores se basa en la elaboración de productos lácteos $100 \%$ naturales.

Figura 1. Página web oficial de Arla Foods

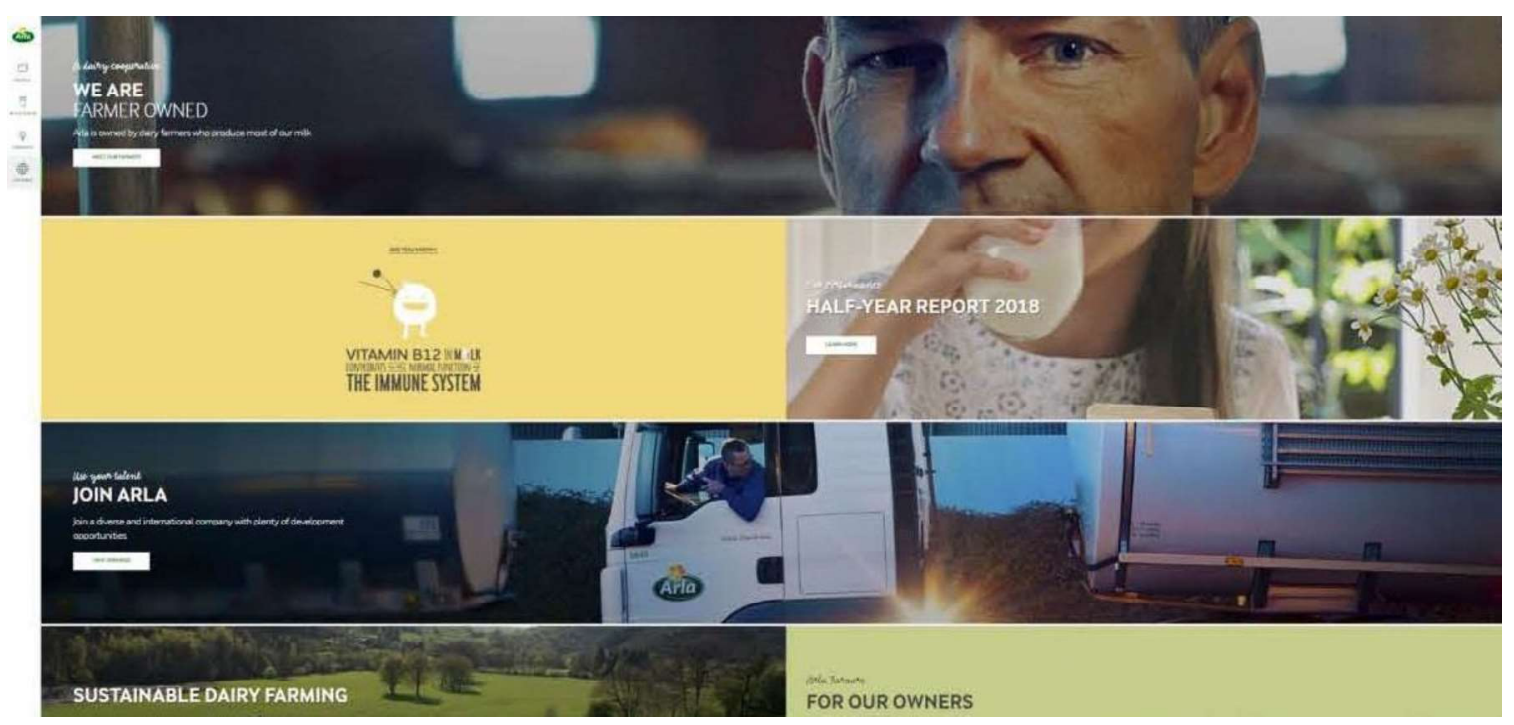

Fuente: https://www.arla.com/company/, accedido a 08/09/2018

La historia de Arla Foods se remonta a 1881, cuando las primeras cooperativas lácteas se fundan en Hjediing (Dinamarca) y en Vastmanland (Suecia). Tras diversos cambios y fusiones en el movimiento cooperativo agroalimentario sueco y danés, Arla Foods, tal y como la conocemos hoy en día, se constituye en el año 2001 mediante la fusión de la danesa Danish MD Foods y la sueca Swedish Arla. Actualmente, Arla Foods es propiedad de 11.262 ganaderos, repartidos entre Suecia (2.780), Dinamarca (2.675), Alemania (2.327), Reino Unido (2.395), Bélgica (815), Luxemburgo (215) y Holanda (55). En el año 2017, la cooperativa empleaba a un total de 18.973 personas en todo el mundo (alrededor del 70\% en Dinamarca y Suecia), produjo 13.900 millones de $\mathrm{kg}$ de leche y facturó 10.300 millones de euros, obteniendo beneficios por valor de 120 millones de euros.

\subsection{DESARROLLO DEL CASO DE ARLA FOODS}

Arla Foods destaca por ser una de las cooperativas agroalimentarias multinacionales de mayor importancia en el mundo. Ello lo ha conseguido generando un negocio sólido y rentable a largo plazo, para lo cual ha sido esencial su estrategia de expansión internacional, mientras ha llevado a cabo políticas esenciales para mantener su esencia cooperativa, expandir su base societaria y control democrático, y promover la sostenibilidad medioambiental. En los últimos años, Arla Foods ha diseñado la estrategia denominada "Good Growth", con el objetivo de seguir promocionando una 
expansión y crecimiento eficiente y rentable, a la vez que sostenible y socialmente responsable.

Figura 2. Modelo de gobernanza cooperativa en Arla Foods

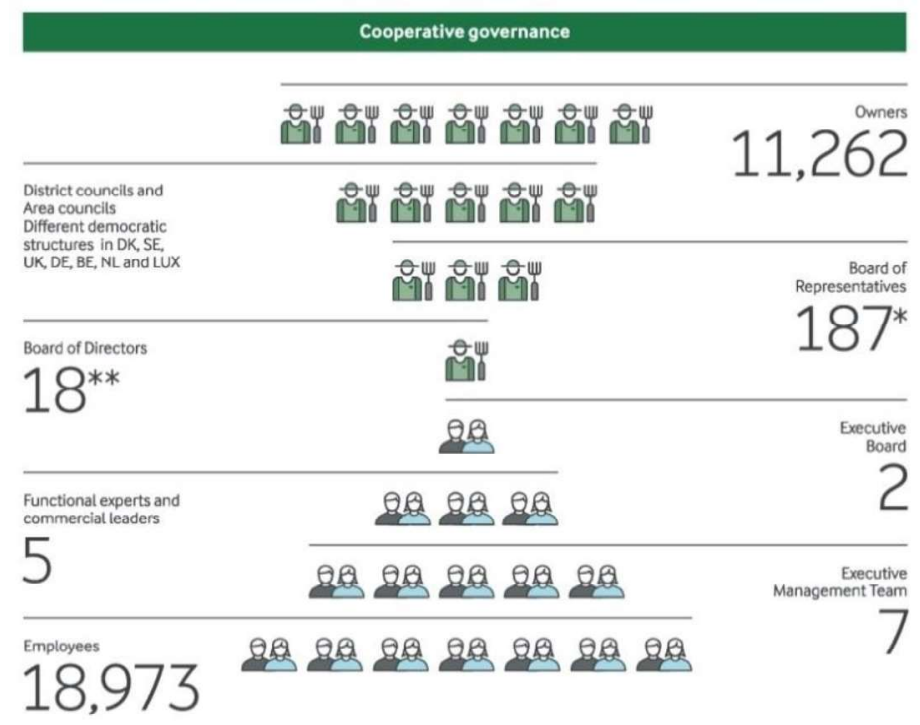

Fuente: Arla Foods (2018), Annual Report 2017, accedido a 08/09/2018

\section{Políticas de Ganadería Sostenible}

Como parte de la estrategia medioambiental de Arla, la Junta Directiva de Arla acordó la estrategia global para la Producción Lechera Sostenible en 2014. La estrategia se centra en tres áreas principales: clima, animales y naturaleza (Figura 3).

Figura 3. Estrategia de sostenibilidad medioambiental de Arla Foods

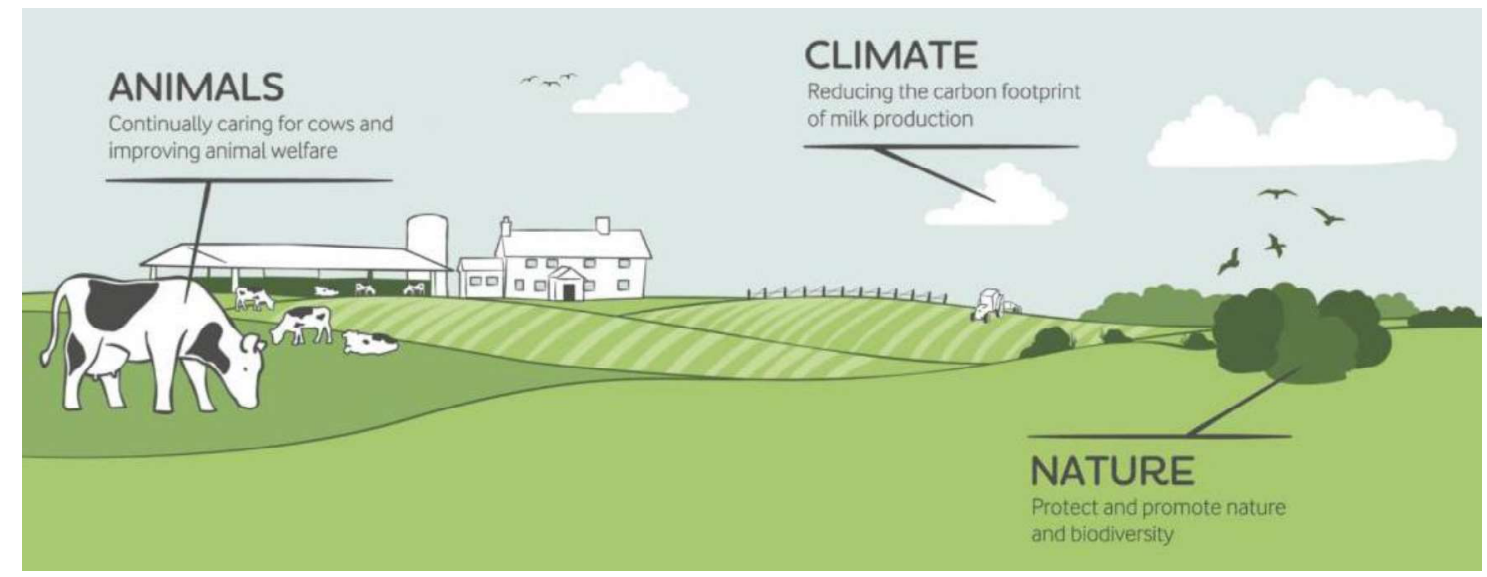

Fuente: Arla Foods (2018), Annual Report 2017, accedido a 08/09/201 
La reducción de la huella de carbono de la producción lechera es una parte esencial de la estrategia de sostenibilidad de Arla Foods. Tras completar más de 4.300 de evaluaciones de la huella de carbono en el Reino Unido, Suecia y Dinamarca, los socios de Arla acordaron reducir su huella de carbono en un 30\% en 2020. En 2015, la huella de carbono de las granjas de Arla se redujeron en un $23 \%$ con respecto a 1990. Desde 2017, los agricultores en Alemania y Benelux también se han unido a las evaluaciones de la huella de carbono.

Por otro lado, 370 granjas en Suecia y Dinamarca han realizado una evaluación energética que ha llevado a reducir el uso de electricidad. Se han realizado más de 295 talleres en el Reino Unido, Suecia y Dinamarca para compartir conocimientos entre los agricultores sobre el uso eficiente de alimentos y energía.

\section{Animales}

Los propietarios de granjas de Arla trabajan continuamente para aumentar los ya altos estándares de bienestar animal en sus granjas. Con base en los estándares del programa Arlagården, los propietarios de granjas de Arla utilizan talleres sobre bienestar animal como un foro de encuentro en el que compartir las mejores prácticas para mejorar el bienestar animal. En Suecia y el Reino Unido se han llevado a cabo casi 300 talleres en los últimos años.

Arlagården es el programa de garantía de calidad de Arla, que es obligatorio para todos los propietarios de granjas de Arla. Para asegurarse de que todas las granjas cumplan con los estándares, todas las granjas son evaluadas regularmente por auditores externos. Todos los agricultores de Arla en el Reino Unido también están adheridos a los estándares de "Red Tractor", pasando una evaluación cada 18 meses.

\section{Naturaleza}

El mantenimiento de la biodiversidad en las granjas es una prioridad en Arla. Muchos productores utilizan la soja como alimento para las vacas y, desde 2010, Arla ha sido miembro de la Mesa Redonda sobre Soja Responsable (RTRS). Desde 2014, Arla ha obtenido certificados RTRS que cubren el $100 \%$ de la soja utilizada en las granjas de Arla que no están cubiertas por Proterra.

Asimismo, en 2016, Arla se convirtió en socio comercial del proyecto 'Biodiversity Now', que está dirigido por Danmarks Naturfredningsforening, la ONG medioambiental más grande de Dinamarca. Biodiversity Now es el proyecto de ciencia ciudadana más grande de Dinamarca. Más de 29.000 ciudadanos participan en el registro de 30 especies y 12 hábitats daneses a través de la aplicación móvil llamada 'NaturTjek'. Mediante una versión "Arla" de la aplicación, la cooperativa anima a los propietarios daneses a inscribirse y registrar especies y hábitats en sus granjas lecheras. A cambio, los agricultores reciben noticias relevantes y apoyos para actividades de biodiversidad en las granjas. 


\section{La expansión internacional como sello de identidad de Arla Foods}

En las últimas décadas, el sector agroalimentario ha experimentado un intenso proceso de globalización mediante la creación de cadenas globales de productos básicos, potenciado por los avances tecnológicos en el transporte y conservación de los alimentos y por las reformas regulatorias orientadas a desmantelar las barreras comerciales, eliminar los subsidios a la producción y promover el libre mercado de productos agroalimentarios (Cheshire y Woods, 2013).

Este contexto explica la marcada orientación global que ha caracterizado a Arla Foods desde sus orígenes. La mayor cooperativa láctea de Dinamarca, Danish MD Foods, y su equivalente sueca, Swedish Arla, se fusionaron en 2001 creando Arla Foods con el objetivo de intensificar su proceso de expansión internacional. Entre los principales motivos tras la estrategia de internacionalización de la cooperativa, destacan la elevada integración vertical de las cadenas de valor en el sector agroalimentario, es decir, la mayoría de sus competidores ya operaban globalmente, la necesidad de alcanzar un mayor dimensionamiento y obtener economías de escala para mantener la competitividad, así como la importancia de lograr un mayor poder de negociación frente a las grandes cadenas empresariales de distribución alimentaria.

De hecho, ya en sus inicios, Arla Foods se establece en diversos países. Sólo en tres años, entre 2004 y 2007, la cooperativa inicia operaciones en Canadá (adquisición de National Cheese Company), China (joint venture con Mengniu Company), Estados Unidos (adquisición de White Clover), Finlandia (adquisición de Ingman Foods), Reino Unido (fusión con Express Dairies) y Rusia (joint venture con Artis).

Cabe mencionar que la estrategia de internacionalización ha variado significativamente a lo largo del tiempo. Durante décadas, su proceso de expansión se basó prioritariamente en el establecimiento alianzas estratégicas. Sin embargo, en los últimos años, la cooperativa ha tendido hacia una mayor integración vertical, adquiriendo y absorbiendo distintas empresas extranjeras. Los agricultores en cada país están vinculados a Arla Foods a través de sus filiales nacionales, la mayoría de las cuales operan bajo una fórmula societaria de capital (sociedades anónimas y de responsabilidad limitada).

No obstante, un aspecto especialmente relevante de Arla Foods, y que la diferencia a de otras cooperativas agroalimentarias multinacionales, es que ha abierto su base societaria al exterior. Inicialmente, los socios cooperativistas se localizaban en Suecia y Holanda, países de donde provenían las cooperativas que se fusionaron bajo Arla Foods. En los últimos años, sin embargo, ganaderos de Reino Unido, Alemania, Bélgica, Luxemburgo y los Países Bajos han pasado a ser socios cooperativistas de la cooperativa. Por ejemplo, en el caso de Reino Unido y Alemania, tras establecer joint ventures en estos países, Arla Foods absorbe las empresas e invita a los agricultores a integrarse como socios propietarios de la cooperativa, dando como resultado su integración. Estos países participan en el consejo de representantes de Arla Foods, dando como resultado una junta directiva altamente representativa. 
Actualmente, Arla Foods emplea a cerca de 19.000 personas en todo el mundo. Controla filiales productivas en 12 países (Estados Unidos, China, Canadá, Argentina, Brasil, Reino Unido, Dinamarca, Alemania, Polonia, Suecia, Finlandia y Arabia Saudí) y dispone de oficinas de ventas en 30 países en todos los continentes. Además, sus productos se venden en más de 100 países.

\section{Mirando al futuro: La Estrategia “Good Growth 2020”}

Arla Foods ha estado inmersa en un intenso proceso de reflexión estratégica durante los últimos años con el objetivo de adaptarse a los nuevos requerimientos competitivos del mercado global y a las crecientes exigencias que plantean los consumidores en el ámbito de la responsabilidad social y medioambiental. Dicha reflexión ha dado lugar a la estrategia denominada "Good Growth 2020" que, con un carácter transversal, abarca el desarrollo de la cooperativa, los productos, los mercados y la forma de trabajar (véase la Figura 3).

La estrategia se basa en 4 pilares relacionados con el crecimiento empresarial:

- Crecimiento responsable, en tanto que se persigue un crecimiento con visión a largo plazo, basado en la seguridad alimentaria y que tiene en cuenta el impacto de la actividad empresarial en la sociedad y el medioambiente.

- Crecimiento cooperativo, en tanto que se busca crecer internacionalmente manteniendo la fórmula cooperativa y el poder de decisión en los socios propietarios y extendiendo la cooperación e involucración de los diferentes stakeholders en busca del beneficio mutuo.

- Crecimiento saludable, basado en la promoción de la nutrición láctea con el objetivo último de fomentar una vida más saludable en la sociedad.

- Crecimiento natural, basado en la producción y distribución de productos de origen natural y elevada calidad.

Figura 3. Pilares de la Estrategia "Good Growth 2020"

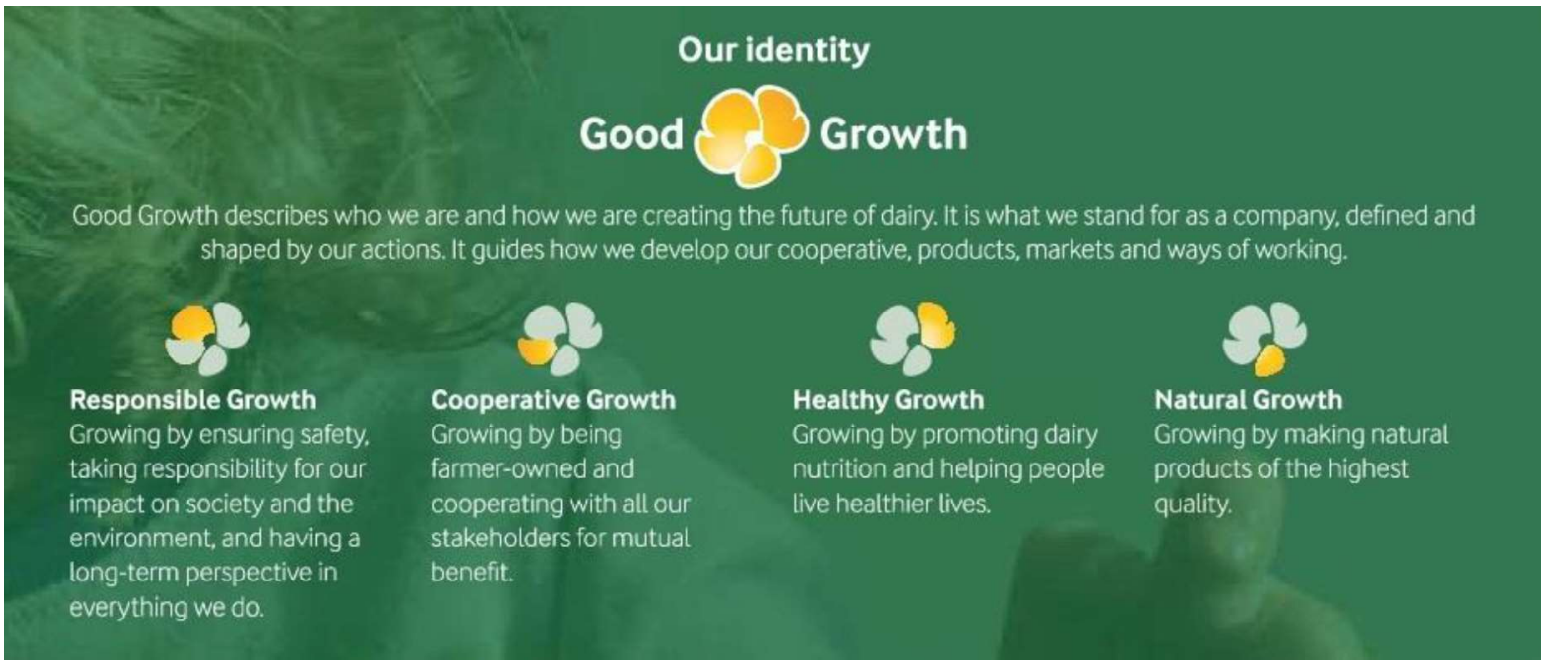

Fuente: Arla Foods (2018), Annual Report 2017, accedido a 08/09/2018 
Asimismo, con base en la misión de Arla Foods, esto es, "asegurar el mayor valor para la leche de nuestros granjeros y crear oportunidades para su crecimiento", la política empresarial "Good Growth 2020" focaliza la estrategia de la cooperativa en torno a tres ejes: producto, presencia global e integración empresarial. En cuanto al primer eje, Arla Foods pretende centrarse y sobresalir en ocho líneas de producto: leche y leche en polvo; bebidas lácteas; queso de untar; yogur; mantequilla y margarina; quesos de especialidad; y mozzarella. Con respecto a su estrategia de internacionalización, se busca mantener y fortalecer la presencia en 6 regiones clave del sector donde Arla Foods considera que tiene el mayor potencial para crear un negocio rentable a largo plazo. Estas regiones son Europa; África del Norte y Oriente Medio; África Subsahariana; China y Sudeste Asiático; Estados Unidos; y Rusia. Finalmente, en lo concerniente a la integración de negocios y bajo el eslogan "Un sólo Arla global", la cooperativa pretende aprovechar en mayor medida las potenciales sinergias entre negocios del grupo tras años de adquisiciones y fusiones, principalmente en Reino Unido, Suecia y Europa Central, así como avanzar hacia una cultura empresarial compartida por los cerca de 19.000 empleados del grupo.

\subsection{CUESTIONES PARA DISCUSIÓN}

Cuestión 1. ¿Qué diferencia a Arla Foods de sus competidores?

En primer lugar, Arla Foods se organiza como una cooperativa que es propiedad de más de 11.200 ganaderos, aspecto que le diferencia de muchas de las grandes empresas agroalimentarias del mundo. Además, Arla Foods sigue una estrategia de diferenciación de producto basada en la oferta de productos $100 \%$ naturales elaborados bajo sólidos criterios de responsabilidad social y medioambiental. Entre otras cuestiones, cabe destacar la Estrategia de Sostenibilidad Medioambiental de Arla Foods, basada en tres pilares clave: la reducción de la huella de carbono en las granjas de Arla, el bienestar animal y el compromiso con la protección de especies y hábitats en los entornos donde opera la cooperativa. Asimismo, la estrategia "Good Growth 2020", basada en la consecución de un "crecimiento global socialmente responsable, cooperativo, saludable y natural", refleja igualmente el compromiso de Arla Foods para crear un negocio rentable con una visión a largo plazo, a la vez que responsable y comprometido en términos sociales y medioambientales.

Cuestión 2. ¿Qué factores han impulsado la internacionalización de Arla Foods?

Como demuestran diversos trabajos, aunque las cooperativas tienden a estar fuertemente enraizadas en el territorio local y operar exclusivamente a nivel doméstico, las crecientes presiones de la globalización de los mercados han llevado a muchas de ellas a desarrollar estrategias de expansión internacional para mantener su competitividad y sobrevivir (Bretos et al. 2018a). En el sector agroalimentario en particular, la internacionalización se ha erigido como un elemento clave, viéndose favorecido por la supresión de las barreras comerciales y de los subsidios a la producción, así como por la 
promoción del libre comercio de productos agroalimentarios. Arla Foods se ha adaptado extraordinariamente a los requerimientos globales del sector, convirtiéndose en la quinta empresa láctea más grande del mundo. Así, entre las principales razones que explican la internacionalización de la cooperativa, se puede destacar la necesidad de obtener economías de escala o de adquirir un mayor poder de negociación frente a las grandes cadenas de distribución alimentaria.

Cuestión 3. ¿Cómo ha evolucionado el proceso de internacionalización de Arla Foods?

Inicialmente, la estrategia de internacionalización de Arla Foods se basó en el establecimiento de joint ventures y otros acuerdos de cooperación en el extranjero. Sin embargo, la creciente integración vertical del sector ha llevado a que Arla Foods haya desarrollado de manera prioritaria estrategias de adquisición y absorción de diversas empresas extranjeras. Un factor diferenciador de la expansión internacional de Arla Foods es que ha sido capaz de crecer internacionalmente y ampliar su base societaria al integrar diversas filiales y ofrecer a sus ganaderos convertirse en socios de la cooperativa, pasando a tener capacidad y poder en la toma de decisiones que afectan al grupo. Ello contrasta con diversos trabajos que ponen en relieve las dificultades para extender el modelo cooperativo al exterior en las empresas multinacionales (Bretos et al., 2018b) y las reticencias de los ganaderos a ampliar la propiedad de las cooperativas hacia las filiales extranjeras (Birchall, 2014). Por tanto, será particularmente relevante seguir de cerca la estrategia futura de internacionalización cooperativa de Arla Foods.

\subsection{CONCLUSIONES}

Arla Foods se erige como una de las cooperativas agroalimentarias europeas de mayor envergadura y con mayor éxito internacional, siendo además la quinta empresa láctea del mundo, y diferenciada de sus competidores directos al ofrecer productos lácteos $100 \%$ naturales y contar con una línea exclusiva de productos orgánicos. Su expansión global ha ido de la mano de la creciente globalización del sector agroalimentario, sabiendo adaptarse a los requerimientos económicos y competitivos del sector, al mismo tiempo que ha sido capaz de mantener su estructura de organización cooperativa y profundizar su sistema de gobernanza democrática.

La estrategia futura "Good Growth 2020" es buena muestra de ello, al combinar el crecimiento empresarial con su responsabilidad social y medioambiental. En este sentido, destaca su política de Ganadería Sostenible estructurada en torno a tres ejes: la reducción de la huella de carbono en las granjas, el bienestar animal y el compromiso con la protección de especies y hábitats. Asimismo, durante los últimos años, Arla Foods ha integrado verticalmente diversas filiales extranjeras de países como Reino Unido y Alemania, ofreciendo además a sus ganaderos incorporarse como socios cooperativistas. Hoy en día, es de hecho una de las pocas cooperativas agroalimentarias europeas cuya base societaria se compone de ganaderos de distintos países. 


\section{GRUPO UP: LA DIFUSIÓN DEL COOPERATIVISMO A TRAVÉS DE LA INTERNACIONALIZACIÓN}

\section{RESUMEN:}

El Grupo UP es un grupo empresarial especializado en soluciones empresariales y beneficios sociales para empleados. La empresa matriz, con sede en Francia, se estructura como una cooperativa propiedad de 664 trabajadores, siendo además la segunda cooperativa más grande de Francia en términos de facturación y número de socios. Como organización multinacional, el Grupo UP opera en 19 países y da empleo a cerca de 3.400 personas en todo el mundo. El $70 \%$ de la actividad productiva y el $60 \%$ del empleo total del grupo se concentran fuera de su país de origen, Francia. Un aspecto particularmente relevante en el caso del Grupo UP es que su Plan Estratégico de 2018 contempla la difusión global del modelo cooperativo en todas sus filiales. De momento, tres filiales francesas ya han sido integradas en la matriz cooperativa UP, convirtiéndose 250 trabajadores en nuevos socios cooperativistas. 


\subsection{INTRODUCCIÓN}

Grupo UP es un grupo empresarial conformado por su matriz cooperativa, con sede en Francia, y diversas filiales localizadas en Francia y el resto del mundo. En 2016, el grupo facturó 445 millones de euros, alcanzó una cuota de 1,3 millones de clientes y 24,5 millones de personas fueron beneficiarios de sus servicios. Actualmente, UP es la segunda cooperativa más grande de Francia en términos de facturación y número de socios.

Figura 1. Página web oficial del Grupo UP

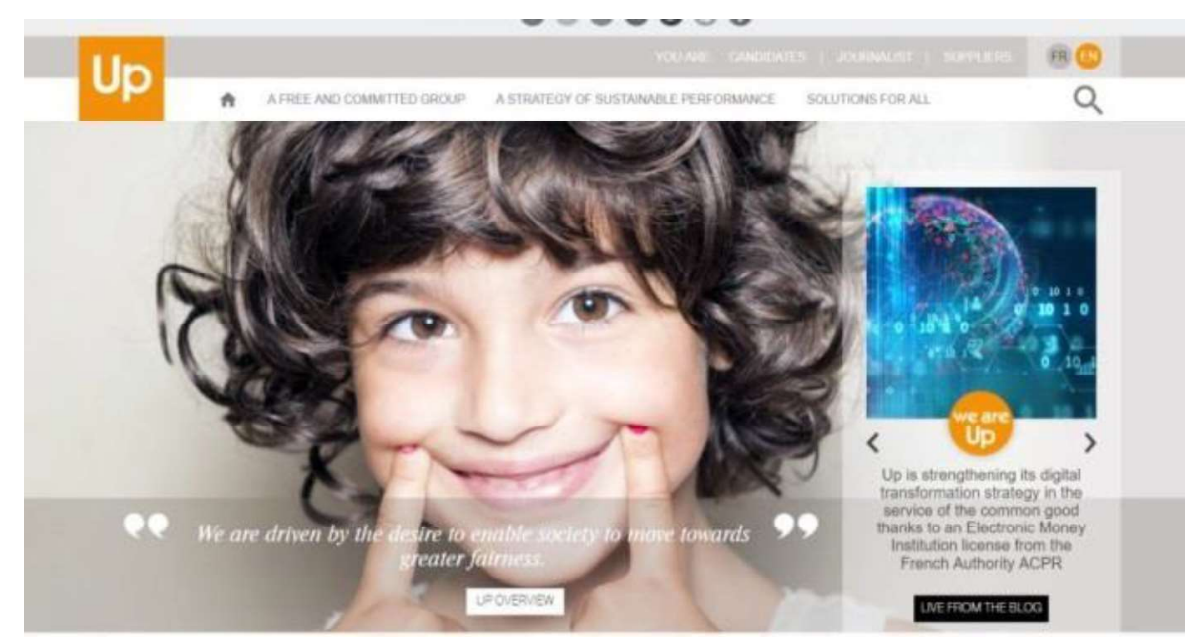

Fuente: https://www.up.coop/en.html, accedido a 09/09/2018

Como cooperativa de trabajo, UP es una empresa autónoma $100 \%$ propiedad de sus empleados, sin contar por tanto con accionistas externos. En concreto, el Grupo UP es propiedad de 664 trabajadores franceses, colectivo que representa el 64\% del total de trabajadores en Francia (el resto se localiza fundamentalmente en las filiales francesas de capital controladas por la matriz). Los socios cooperativistas participan en las decisiones estratégicas del grupo y eligen a la Junta Directiva, que posteriormente nombra a su Presidente. Catherine Coupet es la actual directora general del Grupo. En más de 50 años de existencia, el Grupo UP solo ha tenido tres CEOs.

Grupo UP tiene sus orígenes en 1964, cuando Georges Rino funda la cooperativa de consumo "Chèque Coopératif pour la Restauration" (CCR). En 1972, CCR se transforma en una cooperativa de trabajo con 24 empleados. Desde entonces, la cooperativa ha crecido de manera continuada tanto en Francia como en el extranjero, a través de distintos acuerdos estratégicos y adquisiciones. Por ejemplo, entre 1973 y 1974, la plantilla se duplicó pasando de 37 a 74 trabajadores. En 1984, la empresa, ya denominada Chèque Déjeuner, ya contaba con una plantilla de 130 personas. En 2015, la denominación de la cooperativa pasa a ser Grupo UP. Actualmente, el grupo emplea a un total de 3.396 personas en 17 países. El 54\% son mujeres y el $46 \%$ hombres, y la edad media de la plantilla es de 37,2 años. 
La misión del Grupo UP es "conectar individuos, empresas y territorios mediante el desarrollo de la gestión, plataformas de relaciones y transacciones que contribuyen al bienestar y al rendimiento". Hoy en día, UP es líder en su mercado en Eslovaquia, Turquía, México y co-líder en Francia. El grupo está especializado en soluciones empresariales y beneficios sociales para empleados, llevando a cabo distintas actividades (Figura 1). En concreto, sus distintas actividades pueden clasificarse en 5 grandes mercados:

Beneficios para empleados: Productos y servicios que facilitan la vida cotidiana de los empleados a través del acceso a beneficios en muchas áreas: alimentos, servicios personales, cultura, ocio y bienestar.

Programas públicos y sociales: Soluciones personalizadas para modernizar el sector de acción social, facilitando la vida de los ciudadanos, facilitando la asistencia sanitaria, el ahorro de energía y, en general, para apoyar la implementación de todas las políticas públicas.

Incentivos y recompensas: Soluciones que facilitan la vida cotidiana para los gerentes y mejoran el desempeño de la compañía en base a sistemas de incentivos y lealtad que están completamente integrados y hechos a la medida.

Gestión de gastos comerciales: Soluciones de administración que son fáciles de usar y personalizables para ayudar a los empleadores a implementar una política de gastos comerciales consistente y efectiva.

Servicios mercantiles: Soluciones y servicios que permiten a los socios de UP aumentar su rendimiento, atraer y retener a todos sus clientes.

Figura 2. Principales actividades del Grupo UP

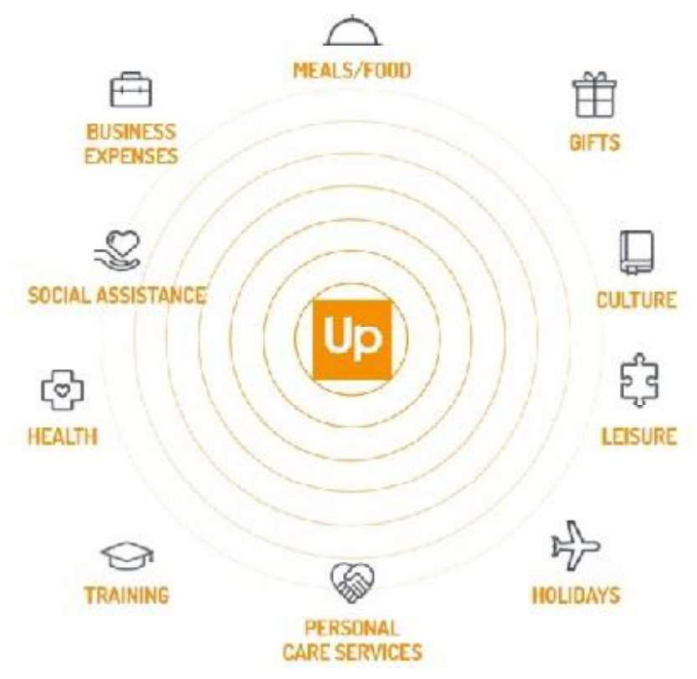

Fuente: https://www.up.coop/en.html, accedido a 09/09/2018 


\subsection{DESARROLLO DEL CASO DEL GRUPO UP}

El Grupo UP es sin duda un grupo empresarial diferente a sus competidores. Su elevado grado de internacionalización y de diversificación en los servicios que ofrece, su naturaleza cooperativa e identificación con el movimiento de la economía social y solidaria, y su fuerte compromiso con la democracia y bienestar laboral, son aspectos únicos que caracterizan a la empresa.

Proceso de expansión global del Grupo UP

El Grupo Up ha desarrollado una intensa estrategia de internacionalización en busca de la apertura de nuevos mercados. Paralelamente, UP no ha dejado de crecer en el mercado doméstico, adquiriendo diversas empresas en Francia. Esta política de expansión multinacional se debe a diversos factores. En primer lugar, destaca la visión global del grupo, donde los socios cooperativistas y el equipo directivo entienden la globalización como una oportunidad de negocio y la internacionalización como una vía para fortalecer el posicionamiento de la marca y obtener una ventaja competitiva respecto a sus competidores. Asimismo, la expansión internacional es esencial para la viabilidad de UP ya que ha permitido diversificar sus negocios y crear una sólida red comercial global.

La andadura internacional del Grupo UP comienza en 1990, cuando se convierte en socio de la cooperativa italiana Camst. Su primera filial propia la abre en España en 1992 a través de Check Lunch. A lo largo de los 90, UP se establece en diversos países. En 1995 crea dos nuevas filiales, en la República Checa y Eslovaquia, en 1996 se implanta en Hungría y en 1997 establece una filial en Polonia.

En la década de los 2000 continúa la expansión internacional de UP, basada fundamentalmente en la adquisición de pequeños negocios en el extranjero. Por ejemplo, la cooperativa entra en diversos países como Rumanía (2002), Bulgaria (2004), Marruecos (2007), Portugal (2009), Alemania (2012) y México (2013). Cabe destacar que hasta el año 2015, la expansión nacional e internacional de UP se fundamentó en la auto-financiación de la cooperativa. No obstante, a partir de dicho año, la cooperativa comienza a utilizar créditos bancarios para poder fortalecer su crecimiento en el exterior. Desde el inicio de esta política, UP ha accedido a distintos mercados como Bélgica, Túnez y Moldavia.

Actualmente, el Grupo UP opera en 19 países (Figura 3). El 70\% de la actividad productiva y el $60 \%$ del empleo total del grupo se concentran fuera de su país de origen, Francia. Su red productiva y comercial de filiales se reparte entre Francia (13 filiales), las Américas (1 filial en México y 3 en Brasil), Europa Mediterránea (4 filiales en España, Italia, Portugal y Marruecos), Europa Occidental (5 filiales en Alemania, Bélgica, Polonia, Eslovaquia y República Checa), y Eurasia (5 filiales en Hungría, Bulgaria, Grecia, Rumanía y Turquía). Además de las representadas en la Figura 3, hay que sumar las 2 filiales incorporadas recientemente en Túnez y Moldavia. 
Figura 3. Presencia global del Grupo UP

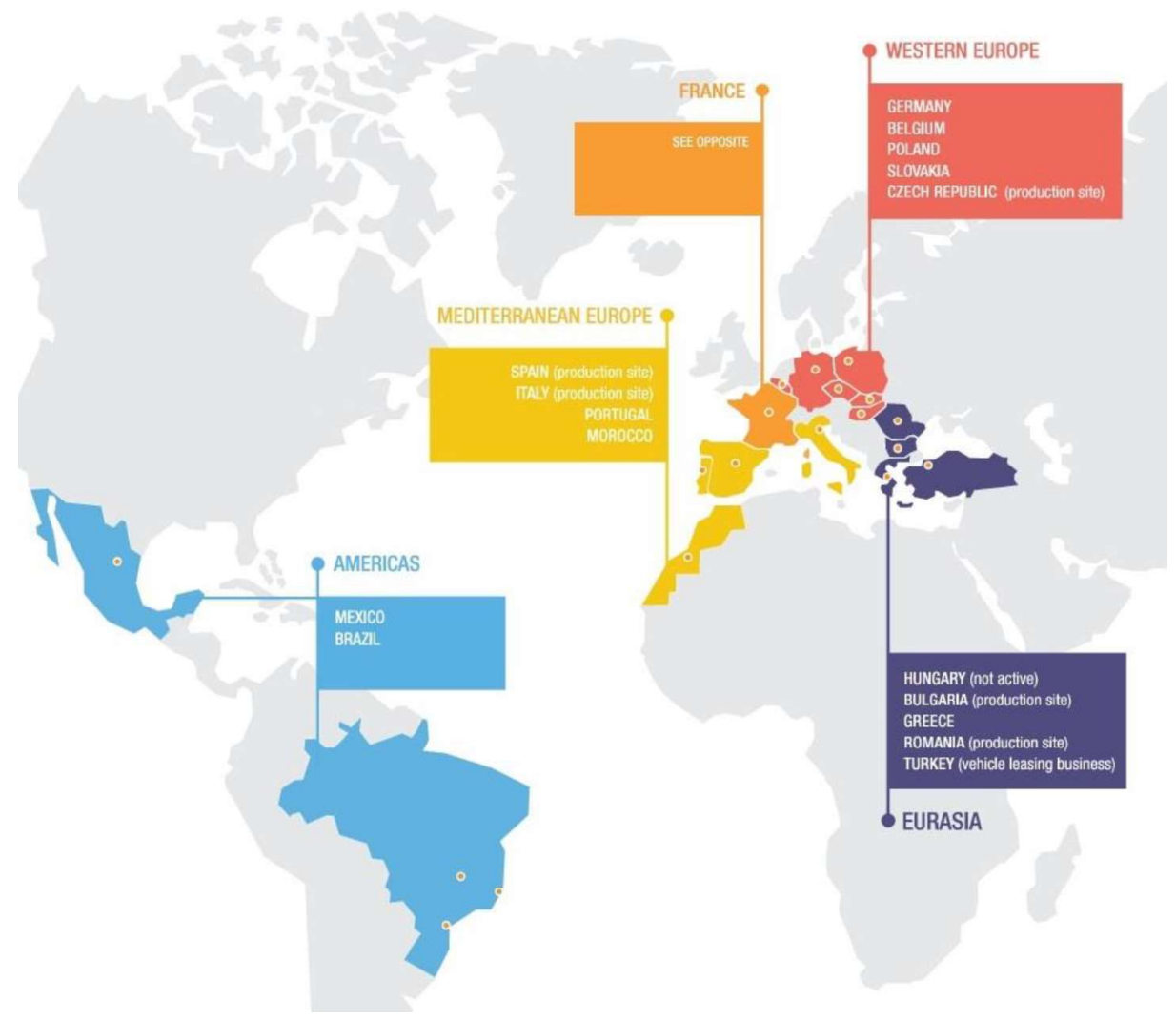

Fuente: Grupo UP (2017), Informe Anual 2016, accedido a 09/09/2018

\section{Plan estratégico 2018: La extensión global del modelo cooperativo}

El Grupo UP está fuertemente identificado con el movimiento de la economía social y solidaria. En este marco, uno de los objetivos clave del Plan Estratégico 2018 de UP consiste en "desarrollar la propiedad de los empleados y fortalecer el modelo cooperativo del Grupo para revitalizar sus principios democráticos fundadores" (Grupo UP, 2017). De esta forma, UP está comprometido en tratar de buscar soluciones para extender el modelo cooperativo a todas sus filiales asociadas durante los próximos años, mediante el despliegue de sus principios democráticos fundacionales que establecen su identidad y su singularidad.

Este proceso de cooperativización ha tenido un fuerte impulso desde 2016. El 1 de enero de este año, tras dos años de trabajo y estudio iniciados por la Junta Directiva y todos los miembros de la cooperativa, el $88 \%$ de los socios cooperativistas de UP votaron a favor de la integración de tres filiales francesas (Cadhoc, Rev \& Sens y Le Chèque Domicile) en la matriz UP, incorporándose de esta forma 249 nuevos socios a la cooperativa. Como destacaba Catherine Coupet, CEO del grupo:

"La fusión de tres subsidiarias en la cooperativa fortalece nuestro modelo cooperativo que, ahora más que nunca, dados los excesos de una economía a veces profundamente 
desigual, está demostrando una relevancia y rendimiento que beneficia a todos. La estructura cooperativa garantiza a largo plazo que las decisiones se toman correctamente y que los empleados participan directamente en el éxito de la empresa". (Grupo UP, 2017).

En el ámbito internacional, el Grupo UP también ha avanzado en los últimos años en la promoción del diálogo social y la participación en las filiales extranjeras. Entre los aspectos clave, cabe destacar los denominados "Values Workshops". Estos son talleres que se realizan en las filiales con el objetivo "es promover la expresión individual y el empoderamiento y contribuir a construir una cultura e identidad grupal más allá de la diversidad de orígenes, que, además, alimentará los sistemas de recursos humanos de las subsidiarias". En estos talleres se trabajan fórmulas para poner en práctica los valores clave de la experiencia cooperativa de UP: innovación, equidad, solidaridad, iniciativa empresarial y compromiso. En 2016, se realizaron talleres en las filiales de 6 países (España, Italia, Rumania, Polonia, Marruecos y Francia) y la idea es extenderlos próximamente a República Checa, en Eslovaquia, Brasil y México, en Bélgica y, después, al resto de países.

Asimismo, uno de los aspectos más relevantes reside en la creación de un Comité de Empresa Europeo (CEE) en 2014, compuesto de 18 representantes repartidos entre Francia (8), España (2), Italia (2), Rumanía (2), República Checa (2) y Eslovaquia (2). Recientemente, el CEE ha introducido el aprendizaje del diálogo social multicultural mediante la confrontación de métodos de trabajo y enfoques muy diversos del diálogo social en diferentes países. Este proceso de integración se reforzó en 2016 específicamente con mejores oportunidades de autoexpresión y mediante la organización de grupos de trabajo para explorar más a fondo una serie de temas como, por ejemplo, las habilidades de gestión. Además, los representantes del CEE recibieron formación sobre cuestiones específicas como el análisis de cuentas o la estrategia de la empresa. También pudieron interactuar con el Gerente de Proyecto a cargo de Diversidad y Calidad de Vida en el Trabajo con respecto a la política de discapacidad implementada en la cooperativa.

Por otra parte, conscientes de las dificultades de distinta índole para transformar en términos formales y legales las filiales extranjeras en cooperativas, el Plan Estratégico 2018 del Grupo UP diseña una serie de principios cooperativos extensibles a dichas filiales y recoge diversos compromisos para aplicarlos. 
Figura 4. Principios del Grupo UP y compromisos en su extensión a las filiales

PRINCIPLES

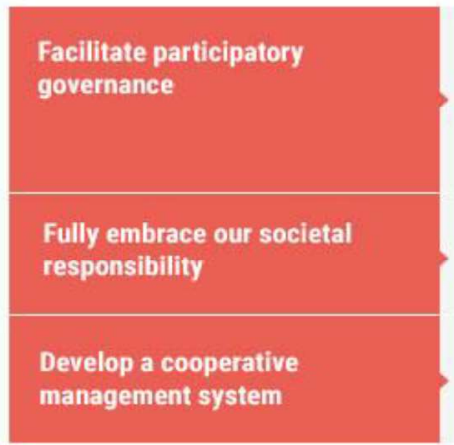

Think of the company

as a source of personal

fulfiliment
COMMITMENTS

Regular information and sharing

with employees on the group's and the subsidiary's strategy, objectives and results

- Encourage representation and engagement

of employees in the company, to foster social dialogue

- Carry out actions for the greater good

Maintain balanced relationships with our partners

Facilitate, mobilize and unite the collective to empower and involve

Think of work as a factor enabling individuals to evolve

- Foster equality and diversity and encourage living together

- Organize the financial and social protection of employees and their families

In keeping with the values of the Group, share the wealth produced collectively (distribute part of the income: profit-sharing and incentives...)

- Ensure the sustainability of the company
Create wealth to ensure

our development and

share it in keeping with

the values of the Group

Fuente: http://rapportannuel2016.up-group.coop/en/, accedido a 09/09/2018

Principio 1. Facilitar la gobernanza participativa

- Difusión regular de información con los empleados sobre la estrategia, objetivos y resultados del grupo y de la filial.

- Fomentar la representación e involucración de los trabajadores en la empresa, con el objetivo último de fomentar el diálogo social.

Principio 2. Aceptar la responsabilidad social

- Llevar a cabo actividades para el "bien común"

- Mantener relaciones equilibradas con los socios

- Principio 3. Desarrollar un sistema de gestión cooperativo

- Movilizar y unir al "colectivo" para empoderar e involucrar

Principio 4. Pensar en la empresa como una fuente de realización personal

- Pensar en el trabajo como un factor que permite evolucionar y crecer a los individuos

- Promover la igualdad y diversidad así como la vida en común

- Organizar la protección social y financiera de los trabajadores y sus familias 
Principio 5. Generar riqueza para asegurar el desarrollo de la empresa y compartirla conforme a los valores del Grupo

- En línea con los valores del Grupo, compartir la riqueza generada colectivamente (distribuir parte de la renta: reparto de beneficios e incentivos, etc.)

- Asegurar la sostenibilidad y viabilidad de la empresa

\subsection{CUESTIONES PARA DISCUSIÓN}

Cuestión 1. ¿Cómo se organiza el Grupo UP?

El Grupo UP conforma una estructura empresarial compleja de carácter multinacional. Su matriz, localizada en Francia, se organiza como una cooperativa de trabajo. Además, la matriz controla diversas filiales de capital en Francia y otros 18 países extranjeros. En total, el grupo está compuesto por cerca de 3.400 trabajadores en todo el mundo. Como cooperativa de trabajo, el 100\% de la empresa es propiedad de 665 socios trabajadores franceses, que son quienes toman las decisiones estratégicas de la compañía, eligen los órganos de gobierno, etc. Éstos representan el 64\% del total de trabajadores del Grupo UP en Francia. En los últimos años, se han producido cambios importantes en el sistema de gobernanza del grupo. Por ejemplo, en 2014, se creó un Comité de Empresa Europeo, que otorga representación y cierta capacidad de participación empresarial a los trabajadores de diversas filiales extranjeras. Asimismo, en 2016, tres filiales capitalistas localizadas en Francia pasaron a formar parte de la matriz cooperativa UP, convirtiéndose así unos 250 trabajadores en nuevos socios cooperativistas.

Cuestión 2. ¿Qué motivos han impulsado la expansión internacional de la cooperativa UP?

En un mundo cada vez más global e integrado, el Grupo UP ha sido capaz de adaptarse a los cambios exigidos por el entorno, llegando a ser líder en su mercado en Eslovaquia, Turquía, México y co-líder en Francia. Tanto los socios cooperativistas como el equipo directivo de la matriz tienen una visión marcadamente global y una fuerte identidad multicultural, lo que ha favorecido la continua búsqueda de nuevos mercados donde ofrecer y diversificar los servicios de UP. Sin lugar a dudas, la competitividad y viabilidad empresarial de UP se ha visto fortalecida por la creación de una red productiva y comercial de carácter multinacional y el posicionamiento internacional de su marca. Además, el sólido compromiso con el movimiento de la economía social y solidaria hace que los socios y directivos de UP entiendan la internacionalización de la empresa como una vía a través de la cual difundir los principios y valores cooperativistas en todo el mundo.

Cuestión 3. ¿Cuáles son las claves que pueden definir el éxito en la extensión del modelo cooperativo de UP a sus filiales extranjeras? 
Uno de los principales objetivos contemplados en el Plan Estratégico de 2018 del Grupo UP consiste en la extensión del modelo cooperativo a todas las filiales es decir, tanto nacionales como extranjeras, del grupo empresarial. Hasta ahora, se han logrado avances significativos en el ámbito doméstico, con la reciente cooperativización de tres filiales capitalistas en Francia. Conscientes de la dificultad de replicar este modelo en el exterior, debido a diversas barreras de carácter legal y cultural que dificultan la transformación directa de las filiales extranjeras en cooperativas, el Grupo UP ha diseñado una serie de principios extensibles a dichas filiales para acercarlas a las prácticas cooperativas que caracterizan a la matriz. Estos principios hacen referencia a la promoción de la gobernanza democrática, la difusión de prácticas de responsabilidad social, el desarrollo de un sistema de gestión cooperativo, el diseño de políticas que favorezcan el desarrollo y realización personal en el puesto de trabajo, y la generación y reparto de riqueza.

\subsection{CONCLUSIONES}

El Grupo UP es una de las cooperativas de mayor envergadura e importancia en Francia. Destaca por el elevado grado de diversificación de los servicios ofrecidos en cinco mercados clave, así como por su amplia presencia global, al controlar multitud de filiales en 19 países. La cooperativa se erige como un caso particularmente relevante en el ámbito del cooperativismo internacional, ya que uno de los principales objetivos recogidos en Plan Estratégico de 2018 consiste en extender el modelo cooperativo en todas las filiales asociadas al grupo, con el objetivo último de fomentar la gobernanza cooperativa, crear una cultura organizacional común y promover el bienestar y desarrollo personal de los trabajadores.

Por el momento, la cooperativa ya ha sido capaz de absorber a cerca de 250 trabajadores franceses que se han convertido en socios cooperativistas de UP mediante la integración de tres filiales capitalistas en la matriz cooperativa. Asimismo, las actuaciones llevadas a cabo hasta ahora en las filiales extranjeras también son muestra del compromiso de UP con el movimiento de la economía social y solidaria, y pueden servir como referencia a otras cooperativas de carácter multinacional. Entre estas actuaciones se puede destacar la creación en 2014 de un Comité de Empresa Europeo con el objetivo de promover la participación empresarial y el diálogo social en las filiales extranjeras, así como la realización de los denominados "Values Workshops", dirigidos a formar a los trabajadores de dichas filiales en la cultura y valores cooperativos que definen a UP.

Por tanto, será interesante estudiar en el futuro cómo el Grupo UP puede hacer frente a las distintas barreras de carácter institucional y cultural que existen en la reproducción del modelo cooperativo del país de origen de la multinacional en sus filiales extranjeras, tal y como sugiere la literatura (véase por ejemplo Bretos y Errasti 2018). 


\section{GRUPO MONDRAGÓN: LA ADAPTACIÓN DEL COOPERATIVISMO A LA GLOBALIZACIÓN}

\section{RESUMEN:}

Mondragón Corporación Cooperativa, más conocido como el Grupo Mondragón, es una de las experiencias cooperativas de mayor éxito e importancia en el mundo. De hecho, destaca como el primer grupo empresarial del País Vasco y el décimo en el ranking de las empresas españolas. El grupo está formado por 266 empresas y cooperativas, muchas de ellas organizadas como empresas multinacionales, que operan en cuatro áreas de negocio: Finanzas, Industria, Distribución y Conocimiento. En total, el Grupo emplea a 80.818 trabajadores en todo el mundo, más del $40 \%$ fuera de España. Mondragón se erige como un caso especialmente significativo para comprender las transformaciones que exige la globalización en las cooperativas, así como para analizar la idiosincrasia cooperativista en aspectos empresariales muy diversos como la estrategia de internacionalización, la innovación social, o la gestión de recursos humanos. 


\subsection{INTRODUCCIÓN}

El Grupo Mondragón es ampliamente reconocido como una de las corporaciones cooperativas propiedad de sus socios trabajadores más exitosas del mundo y como uno de los principales referentes para el movimiento cooperativo. Una de sus principales señas de identidad es la notable diversificación y presencia global de sus cooperativas.

En el año 2017, el conglomerado del grupo Mondragón estaba formado por 266 organizaciones (98 cooperativas, 143 filiales, 7 fundaciones, 1 mutua, 10 entidades de cobertura y 7 empresas de servicios internacionales) que desarrollan su actividad empresarial en cuatro áreas de negocio: industria, finanzas, conocimiento y distribución. El área de Finanzas incluye la actividad de banca, previsión social y seguros. El área de Industria agrupa 12 divisiones industriales dedicadas a la producción de bienes y servicios. El área de Distribución aglutina a las cooperativas y negocios de distribución comercial y la actividad agroalimentaria. El área de Conocimiento incluye la red de centros tecnológicos y unidades de investigación y desarrollo (I+D), Mondragon Unibertsitatea, y varios centros de formación profesional y de enseñanza. Estas organizaciones empleaban en 2017 a un total de 80.818 trabajadores en todo el mundo, principalmente en los sectores de Distribución (un 49,9\% del total) e Industria (un $45,8 \%$ del total), y alcanzaron unos ingresos de 11.936 millones de euros.

Figura 1. Sede de la Corporación Mondragón en Arrasate (Gipuzkoa)

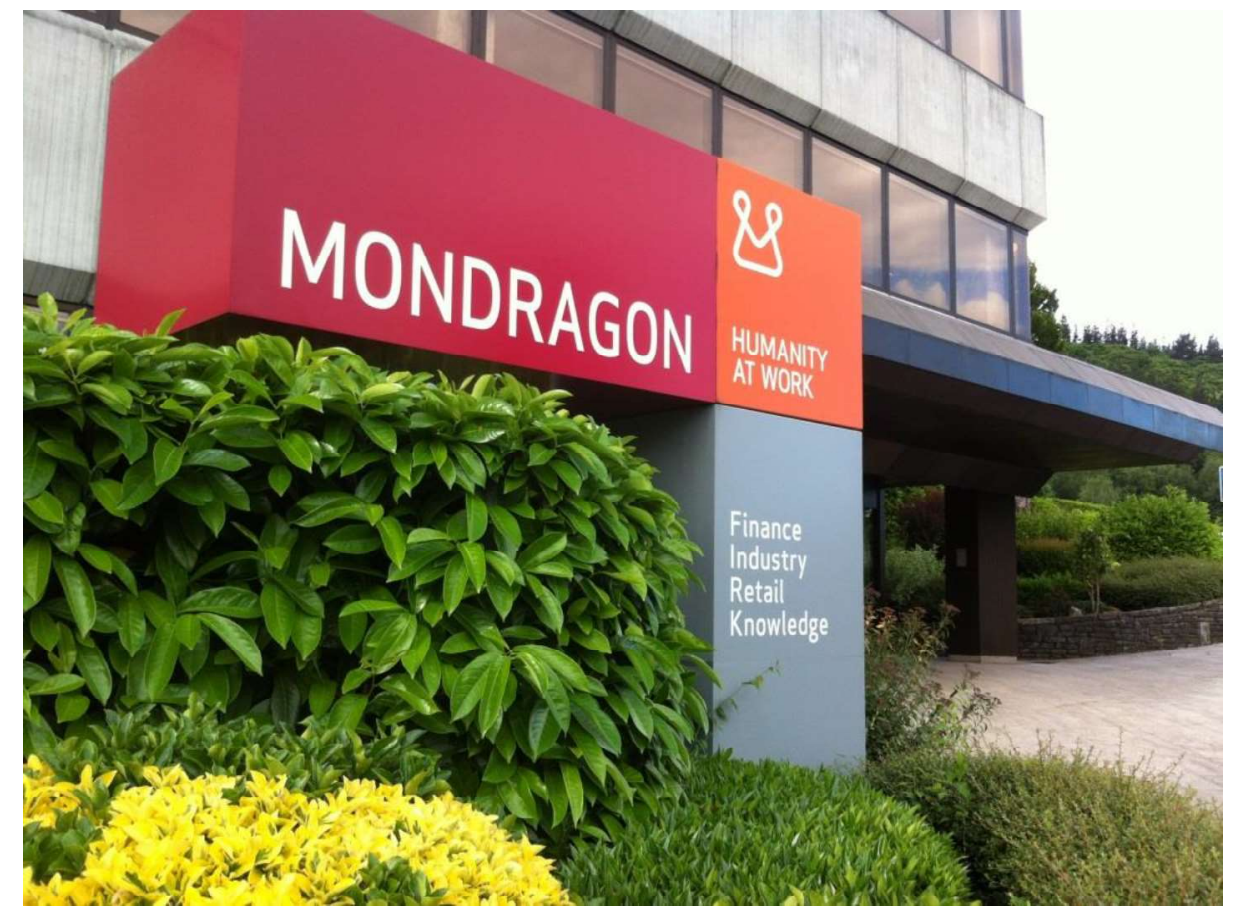

Fuente: Autor

El Grupo Mondragón se originó hace más de medio siglo en Arrasate-Mondragón (Gipuzkoa). Desde sus inicios, fue una experiencia anclada en las necesidades del entorno local, creándose en 1943 la actual Universidad de Mondragón, en 1956 la cooperativa industrial Ulgor (posteriormente Fagor Electrodomésticos), y en 1959 la entidad de crédito cooperativo Laboral Kutxa y el sistema de protección social Lagun 
Aro. Estas cuatro ramas enarbolaron el desarrollo de la comunidad, impulsaron cientos de cooperativas, y consolidaron la hoy denominada Corporación Mondragón (Mondragón, 2015). Inspiradas por la doctrina social católica del padre Arizmendiarrieta, estas cooperativas comenzaron como pequeñas organizaciones democráticas, con profundas raíces en el territorio y un poderoso sentido de comunidad, basado en la noción de que todos los trabajadores eran socios y copropietarios de la empresa (Errasti et al., 2017). Un objetivo primordial, todavía hoy vigente, fue promover el desarrollo humano y crecimiento personal en el trabajo y alentar la creación de nuevas cooperativas y puestos de trabajo en aras de impulsar el desarrollo socioeconómico en la región (Mondragón, 2015). Históricamente, las organizaciones agrupadas en la Corporación Mondragón se han acogido a los siguientes principios básicos:

1. Libre adhesión

2. Organización democrática

3. Soberanía del trabajo

4. Carácter instrumental y subordinado del capital

5. Participación en la gestión

6. Solidaridad retributiva

7. Intercooperación

8. Transformación social

9. Carácter universal

10. Educación

Figura 2. Modelo de gestión corporativa del Grupo Mondragón

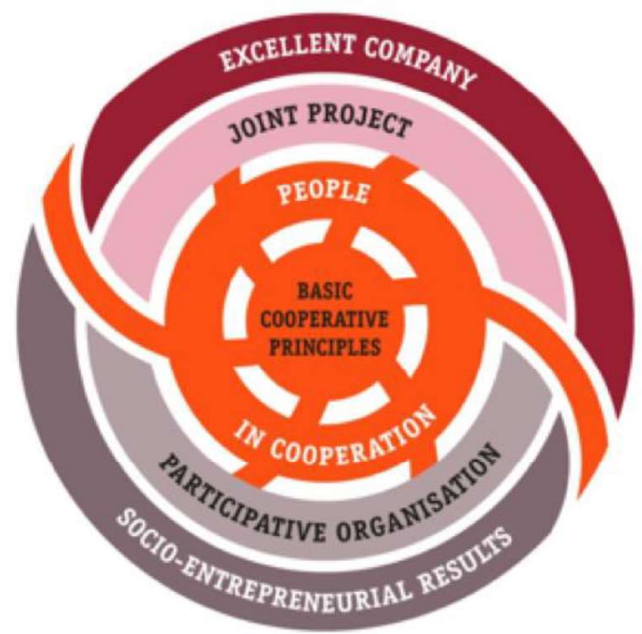

Fuente: Mondragón (2013)

De acuerdo al Modelo de gestión corporativa del Grupo Mondragón, los Principios Cooperativos Básicos "aportan pautas de comportamiento a las Personas en Cooperación (...), quienes construyen un Proyecto Compartido y se dotan de una Organización Participativa para llevarlo a la práctica". Sin embargo, también el modelo también reconoce que el proyecto cooperativo "se lleva a cabo en un contexto de 
producto-mercado, con clientes, proveedores, aliados, etc., en el mismo entorno en el que se desarrollan sus competidores", lo que implica la necesidad de convertirse en una empresa excelente para obtener buenos resultados socio-empresariales (Mondragón, 2013: 13).

\subsection{DESARROLLO DEL CASO DE MONDRAGÓN}

Las cooperativas del grupo Mondragón han destacado a lo largo de su historia por su capacidad de adaptación a la creciente globalización y los distintos ciclos económicos y cambios del entorno. En este sentido, su sistema de gobernanza democrática, la centralidad de los trabajadores en el modelo de gestión y su estrategia de internacionalización han sido elementos esenciales que explican que muchas de estas cooperativas superen el medio siglo de vida.

\section{Sistema de gobernanza y la centralidad del trabajador}

El grupo Mondragón se estructura como una federación con estatus legal de sociedad civil que aglutina a una red de cooperativas. Éstas con organizaciones independientes que funcionan de manera autónoma dentro de una estrategia de conjunto coordinada desde el Centro Corporativo. A pesar de las crecientes presiones económicas y competitivas resultado de la globalización, los valores y prácticas cooperativas siguen guiando el funcionamiento de las cooperativas de Mondragón en el País Vasco. Como propietarios, los socios trabajadores participan en el reparto de beneficios y están involucrados en la toma de decisiones de diversas formas. Por un lado, participan en la Asamblea General bajo la regla "una persona/un voto" y pueden ser elegidos como miembros del Consejo Rector y del Consejo Social (la Figura 3 representa el sistema de gobernanza de una cooperativa de base del grupo Mondragón).

La Asamblea General es el órgano supremo de la cooperativa que expresa la voluntad social expresada por todos los socios. Está compuesto por todos los socios de la cooperativa y se reúne al menos una vez al año. Este órgano aprueba los planes estratégicos de la cooperativa y nombra al Consejo Rector, el Consejo Social y la Comisión de Vigilancia. El Consejo Rector es el órgano de representación y gobierno de la cooperativa, y sus miembros son elegidos en Asamblea General. Este órgano es responsable de gobernar y representar a la compañía, y sus decisiones están subordinadas a las políticas y estrategias fijadas por la Asamblea General. Supervisa la administración, nombra al gerente y supervisa su desempeño. La Comisión de Vigilancia cuyo propósito es dictaminar sobre el correcto cumplimiento de los aspectos contables y de aquellos otros que requieran su consideración. El Consejo Social cumple un papel similar al sindicato. Es un órgano consultivo que representa a los socios ante las instancias internas de la cooperativa. Tiene un papel consultivo y de comunicación social, y actúa como canal entre la gerencia y los trabajadores. Los miembros son elegidos por áreas de trabajo y son ratificados por la Asamblea General. Sus funciones son el asesoramiento laboral, la información, la negociación y el control social. Por último, el Consejo de Dirección es el órgano ejecutivo que gestiona la cooperativa. Está 
constituido por los miembros directivos y el gerente, que es nombrado por el Consejo Rector y puede ser restituido por los socios (Errasti et al. 2016).

Figura 3. Estructura de gobierno de una cooperativa de Mondragón

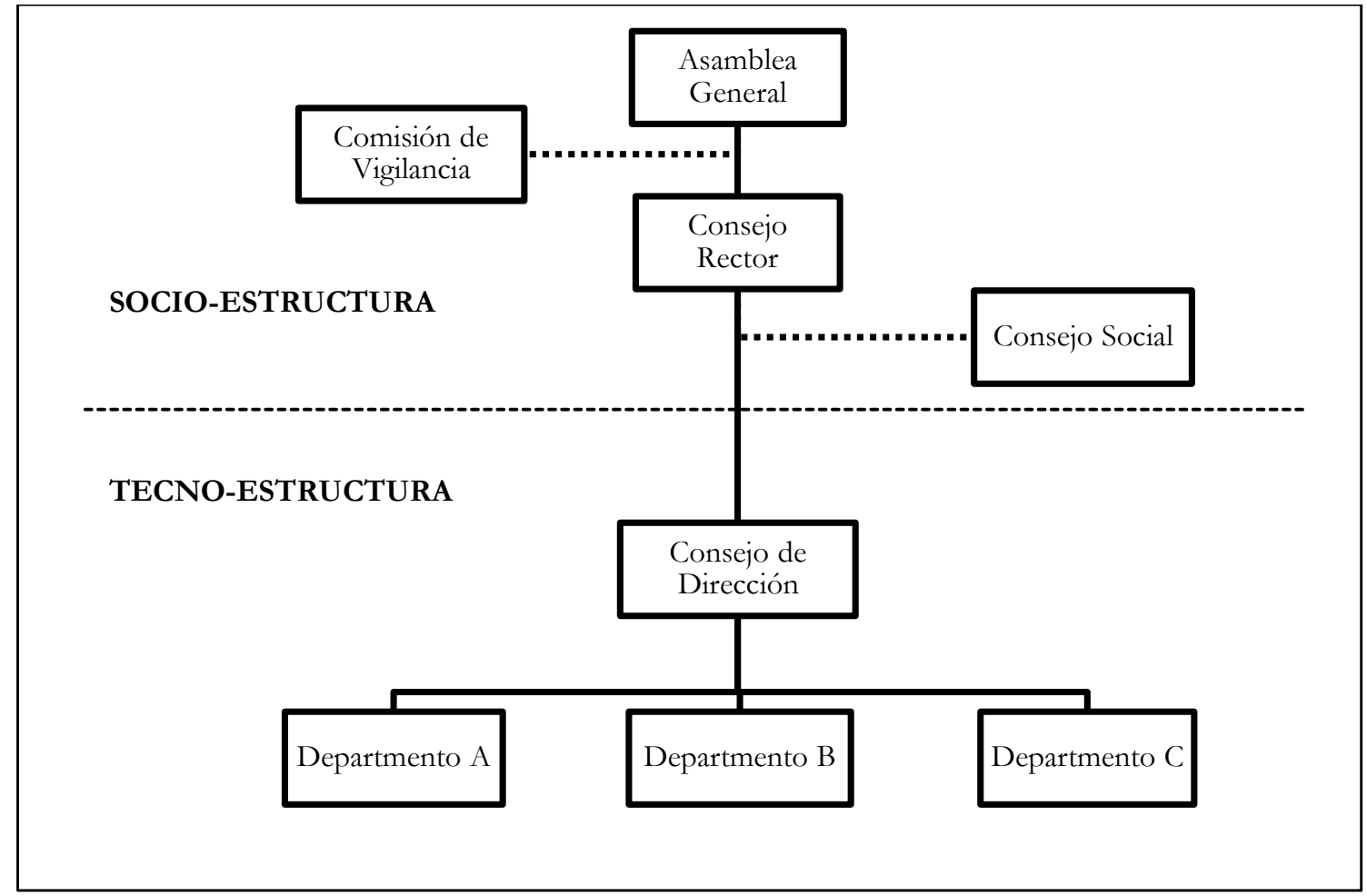

Fuente: elaboración propia

Por otro lado, los trabajadores participan en el área de trabajo por medio de distintos mecanismos, como las reuniones conjuntas entre trabajadores y dirección. Igualmente, la promoción interna y la estabilidad laboral también son primordiales en Mondragón. El despido de socios es extremadamente inusual y, cuando una planta ocasionalmente cierra, los socios son reubicados en otras cooperativas del grupo. Ello se evidenció cuando tras la caída de Fagor Electrodomésticos, única quiebra de una cooperativa dentro del grupo en toda su historia, los cerca de 2.000 socios trabajadores fueron reubicados en otras cooperativas del grupo (Errasti et al. 2017). Asimismo, las diferencias salariales en las cooperativas son notablemente reducidas, aunque han aumentado desde la escala original 1:3 a la actual 1:7 en algunos casos. Por último, cabe señalar que los socios y directivos reciben formación no sólo en aspectos técnicos y de negocio, sino también en la cultura y valores cooperativos tales como el liderazgo colectivo, la cooperación o la comunicación.

\section{La internacionalización como clave de la supervivencia y éxito de Mondragón}

El corazón industrial del grupo Mondragón está formado por diversas cooperativas organizadas como empresas multinacionales que controlan 143 filiales productivas en el exterior. Junto con las delegaciones corporativas, el Grupo Mondragón opera en más de 20 países (véase la Figura 4). Estas filiales emplean a unas 13.000 personas, lo que representa cerca del $40 \%$ del empleo total de la división industrial de Mondragón. 
Además, el $70 \%$ del total de ventas corresponden a ventas internacionales en más 150 países (Mondragón, 2018).

Las cooperativas multinacionales se dedican a actividades económicas muy diversas, que incluyen la automatización industrial, la construcción, los electrodomésticos, los componentes de automoción, la máquina herramienta y los equipos industriales. Algunas de las cooperativas de mayor envergadura y relevancia son Ulma, Fagor Ederlan, Copreci, Fagor Arrasate, Orona, Fagor Electrónica, Danobat, Fagor Automation, Cikautxo, Fagor Industrial, o Maier.

Desde su nacimiento, las cooperativas de Mondragón lograron rápidamente una notable consolidación económica, especialmente porque en aquellos años el mercado interno español absorbía toda la producción que ofrecían las cooperativas. Esto se vio favorecido inicialmente por las políticas autárquicas del régimen franquista, que aislaron el mercado doméstico de la competencia extranjera, y luego por la expansión sin precedentes de la economía española durante los años sesenta y principios de los setenta. Estas circunstancias impulsaron la expansión temprana y constante de las cooperativas. De hecho, entre 1965 y 1975, las cooperativas crecieron en cerca de 1.000 trabajadores de media por año (Bradley y Gelb 1987). Asimismo, en 1980, cooperativas como Fagor Electrodomesticos, Copreci y Ulma ya exportaban alrededor del 70\% de su producción a través de redes comerciales de agentes y distribuidores en Europa y América Latina.

Figura 4. Localizaciones de Mondragón en el mundo

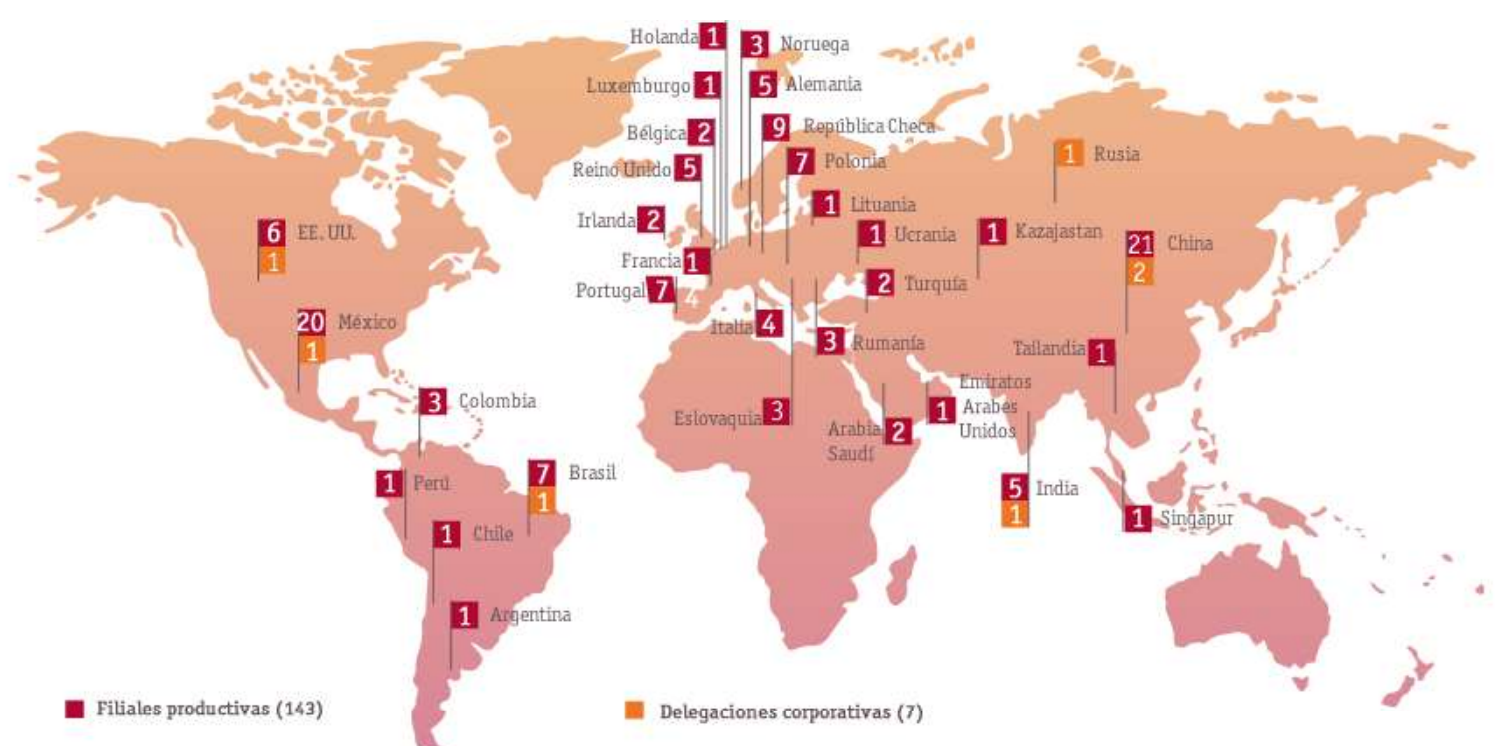

Fuente: Mondragón (2018), Informe Anual 2017, Accedido 08/09/2018

A partir de la década de 1990, la expansión se trasladó a los mercados internacionales a través de adquisiciones y joint ventures. La creciente globalización obligó a muchas cooperativas industriales a desarrollar un intenso proceso de internacionalización para mantener la competitividad en los mercados y salvaguardar los puestos de trabajo de los socios cooperativistas vascos. Por ejemplo, muchas de estas cooperativas son 
proveedoras y han debido seguir a sus clientes allá donde se han establecido, como es el caso de Fagor Ederlan y Maier en el sector de la automoción.

La estrategia de internacionalización se ha basado en la denominada 'multilocalización', esto es, una estrategia expansionista y socialmente responsable ya que la nueva actividad abierta en el exterior no implica el cierre de ninguna actividad preexistente en el mercado doméstico. Ello contrasta con las estrategias agresivas de internacionalización de muchas de sus empresas competidoras, que se han basado en la deslocalización y la consiguiente destrucción de empleo. No obstante, el crecimiento tanto a nivel doméstico como internacional se ha basado en el establecimiento de filiales no cooperativas (sociedades capitalistas) donde sus trabajadores son asalariados y, por tanto, no disfrutan de los mismos derechos que los socios cooperativistas de las matrices, es decir, no participan en la propiedad, reparto de beneficios y gestión de sus empresas (Bretos et al., 2018). De hecho, aunque las matrices han mantenido una elevada proporción de socios cooperativistas sobre empleados asalariados (alrededor del $80 \%$ del empleo está conformado por el colectivo de socios), teniendo en cuenta también el empleo de las filiales, esta proporción baja al 30\%. En este sentido, entre 1991 y 2007, la proporción de empleo cooperativo en el conjunto del Grupo Mondragón disminuyó del 86\% al 29,5\% (Storey et al., 2014).

\section{La extensión del modelo cooperativo en las filiales}

Tras décadas de intenso crecimiento que han alejado a algunas cooperativas de Mondragón de su naturaleza social y cooperativa en favor de las prerrogativas gerenciales y la orientación al mercado, el grupo vive inmerso desde mediados de los años 2000 en un proceso de reflexión y debate orientado a revitalizar aspectos esenciales del modelo cooperativo como la transformación social y comunitaria, la participación de los trabajadores, la gobernanza democrática, la intercooperación, y la formación y educación cooperativa (Bretos y Errasti, 2017). Una de las líneas clave de trabajo reside en la difusión de los principios y valores cooperativos en las empresas y filiales capitalistas del grupo.

En el año 2003, el Congreso Cooperativo de Mondragón aprobó la denominada 'estrategia de expansión social' por parte del. Dicha estrategia se refiere a la difusión de los valores cooperativos en las filiales capitalistas mediante el desarrollo de mecanismos de participación para los trabajadores similares a los existentes en las cooperativas. Este Congreso acordó objetivos cruciales como fomentar una mayor transparencia en la toma de decisiones en las filiales, implementar el mismo modelo de gestión participativa que en las cooperativas, avanzar hasta al menos un $30 \%$ de la propiedad en manos de los trabajadores, y dedicar entre el 1\% y 5\% de los beneficios al desarrollo de los territorios donde están localizadas las filiales (Flecha y Ngai, 2014). Posteriormente, el Modelo de Gestión Corporativo de Mondragón incluyó tres aspectos esenciales a profundizar en las cooperativas y sus filiales: la Autogestión, la Comunicación y el Desarrollo Corporativo (Mondragón, 2013). 
Estas líneas y directrices generales, diseñadas por la tecno-estructura de la Corporación Mondragón, si bien no constituyen normas de obligado cumplimiento, se han traducido en los últimos años en diversas acciones concretas por parte de algunas cooperativas multinacionales dirigidas a promover la 'cooperativización' de las filiales, esto es, la implementación del modelo cooperativo en ellas. Los principales resultados se han alcanzado en el ámbito doméstico, donde varias filiales que anteriormente operaban como empresas de capital han sido transformadas en cooperativas. Algunos de los casos más relevantes son los de Fagor Ederlan Tafalla (Navarra), Maier Ferroplast (Galicia) y Copreci Altsasuko (Navarra) (Bretos y Errasti 2016, 2017).

El ámbito exterior plantea mayores dificultades. Algunas de las principales barreras para implementar el modelo cooperativo en las filiales extranjeras residen, en primer lugar, en que muchos países donde se localizan las cooperativas de Mondragón no existe una legislación que ampare jurídicamente a la fórmula de la cooperativa de trabajo, o la legislación es muy diferente a la existente en el País Vasco. Asimismo, muchos de estos países tampoco cuentan con una tradición cooperativa tan arraigada como la vasca $y$, por tanto, los empleados de están filiales no están acostumbrados a trabajar en una cultura laboral de cooperación. Otras dificultades notables residen, por ejemplo, en las limitaciones económicas de los trabajadores de determinados países, que impedirían realizar el desembolso necesario para convertirse en socios de la cooperativa.

Sin embargo, algunas cooperativas multinacionales de Mondragón han sido capaces de introducir un modelo de gestión similar en sus filiales extranjeras así como ciertas prácticas cooperativas. En términos generales, todas las filiales extranjeras operan bajo el mismo modelo de Gestión de la Calidad Total y técnicas de producción ajustada, con estándares medioambientales, de seguridad y de calidad equivalentes, por lo que la organización del trabajo en estas filiales es bastante similar a la existente en las matrices cooperativas. Además, los trabajadores de las filiales extranjeras también participan en la gestión diaria en el área de trabajo, por ejemplo, a través de sistemas de sugerencias del empleado, y el establecimiento de reuniones de periódicas entre gerencia y trabajadores que fomentan el intercambio de información sobre la producción y otros aspectos técnicos. Adicionalmente, algunas filiales extranjeras caracterizadas por una mayor proximidad cultural con el País Vasco han avanzado en la introducción de ciertas prácticas de recursos humanos asociadas al modelo cooperativo, como la equidad salarial, la estabilidad laboral, la promoción interna, y la formación continua de los trabajadores.

\subsection{CUESTIONES PARA DISCUSIÓN}

Cuestión 1. ¿Cuáles pueden considerarse las claves del éxito de Mondragón?

Un importante cuerpo de literatura académica ha demostrado que las cooperativas son capaces de mantener mejor el empleo que las empresas capitalistas, especialmente en coyunturas económicas negativas (Bretos y Morandeira 2016). Las cooperativas de Mondragón son un claro ejemplo, tal y como demuestra su extraordinaria respuesta ante 
las crisis económicas de los 80 y la más reciente de 2008. Ello se debe en gran medida a su modelo de gobernanza democrática, en el que los trabajadores son los propietarios de la empresa y toman las decisiones estratégicas bajo la regla "una persona, un voto". Asimismo, la adaptación a la globalización mediante la multi-localización es otra de las claves que explican el éxito de Mondragón. Esta estrategia ha sido clave para seguir generando desarrollo y empleo en el País Vasco, a la vez que también se creaba fuera.

Cuestión 2. ¿Qué diferencia a las políticas y prácticas de recursos humanos en las cooperativas de Mondragón?

Algunos autores han sugerido que las empresas propiedad de los trabajadores tienden a adoptar prácticas de recursos humanos "de alto compromiso", es decir, con una visión a largo plazo y centradas en el bienestar y capacidades del trabajador, en lugar de en la reducción de costes laborales (Bretos et al. 2018). Esto es evidente en las cooperativas de Mondragón, donde la dirección de recursos humanos está centrada en la persona y no en los costes. Así, algunas de las principales prácticas diferenciadoras de recursos humanos en Mondragón son la participación de los trabajadores en la toma de decisiones, la retribución variable ligada al reparto de beneficios, la equidad salarial, la formación continuada de los trabajadores en aspectos sociales y de negocio, o la estabilidad laboral.

Cuestión 3. ¿Cuáles son las principales barreras que dificultan la implantación del modelo cooperativo de Mondragón en las filiales exteriores?

La literatura señala que la transferencia de políticas y prácticas organizacionales en las empresas multinacionales entre diferentes países se ve afectada por aspectos de carácter institucional, como las diferencias legales o culturales (Bretos y Errasti, 2017). La difusión del modelo cooperativo de Mondragón y sus prácticas organizacionales a las filiales situadas en países extranjeros se ve limitada por factores similares. Muchos países no tienen una legislación cooperativa o es muy diferente a la del País Vasco, lo que dificultaría la transformación legal de las filiales. Asimismo, hay países en que no existe una cultura cooperativista arraigada y los trabajadores no están dispuestos a asumir las responsabilidades ligadas a convertirse en socio. No obstante, Mondragón ha encontrado fórmulas intermedias al introducir ciertas prácticas cooperativas en las filiales extranjeras, como la participación de los trabajadores en las decisiones que afectan al área de trabajo.

\subsection{CONCLUSIONES}

Mondragón es sin duda uno de los grupos cooperativos de mayor importancia y prestigio en el mundo, debido a que ha sido capaz de construir y mantener un importante ecosistema cooperativo en el País Vasco y desarrollarlo en el exterior. El grupo destaca por un elevado grado de diversificación - sus cooperativas abarcan los sectores de Industria, Distribución, Conocimiento-Educación y Finanzas - así como por su amplia presencia internacional. En este sentido, la División Industrial de 
Mondragón, considerado como el mayor conglomerado cooperativo industrial del mundo, dispone de más de 140 filiales productivas fuera de España que dan empleo a alrededor de 13.000 personas.

Estas cooperativas han sido capaces de adaptarse al proceso de globalización de manera pragmática, siendo capaces de fortalecer su competitividad en los distintos mercados donde opera utilizando a la vez métodos de gestión democrática basados en la participación en el lugar de trabajo y en la comunidad. Asimismo, en los últimos años, las cooperativas vascas se han embarcado en una profunda reflexión acerca del sentido de la Experiencia Cooperativa de Mondragón y la práctica de los principios y valores cooperativistas que han caracterizado históricamente al grupo. Entre algunas cooperativas multinacionales, esta reflexión ha dado como resultado un mayor compromiso en la difusión del modelo cooperativo entre las filiales y empresas capitalistas. De esta forma, diversas cooperativas como Fagor Ederlan o Maier han transformado algunas de sus filiales domésticas en cooperativas, incorporándose sus trabajadores como socios y pasando a disfrutar de los derechos asociados a la membresía cooperativa. En los próximos años, será esencial seguir de cerca los avances realizados en las filiales extranjeras para inculcar los principios y valores cooperativistas en sus modelos de gestión y trabajo diario. 


\section{RABOBANK: UNA EXPERIENCIA DE BANCA COOPERATIVA MULTINACIONAL}

\section{RESUMEN:}

Rabobank es el primer banco holandés y el número 29 del mundo por activos. Está especializado en la financiación al sector agroalimentario. Estructurado como una cooperativa, Rabobank está compuesto por 102 bancos locales propiedad de 1,9 millones de miembros. Además, el grupo controla diversas filiales y empresas asociadas que permiten ofrecer sus servicios financieros en 40 países a través de 835 oficinas (389 en Holanda y 446 en el extranjero). En 2017, Rabobank Group empleaba a un total de 43,810 personas en todo el mundo y alcanzó un beneficio de 2.700 millones de euros. Rabobank se erige como una experiencia cooperativa bancaria única en la consecución de una expansión internacional competitiva y la promoción de un desarrollo sostenible en los distintos países donde opera. 


\subsection{INTRODUCCIÓN}

Rabobank es un proveedor internacional de servicios financieros, especializado en el sector agroalimentario. Su matriz está establecida en Utrecht (Holanda), donde Rabobank se estructura como una cooperativa propiedad de los clientes. Su origen se encuentra en Rabobank Nederland, fundado en 1972 a través de la fusión de bancos cooperativos de crédito agrícola. Entre sus principales actividades se encuentra la banca minorista y mayorista, la banca privada, los servicios de alquiler financiero (leasing) y los negocios de bienes inmuebles. En concreto, la cooperativa está especializada en la financiación agroalimentaria, sector donde hoy en día Rabobank mantiene más de un $80 \%$ de cuota de mercado en Holanda. Actualmente, Rabobank está formado por 102 bancos locales propiedad de 1,9 millones de socios, además de diversas filiales y oficinas internacionales que permiten ofrecer sus servicios financieros en diversos países. En total, dispone de 835 oficinas (389 en Holanda y 446 en el extranjero) y cuenta con una cartera de 8,5 millones de clientes. En 2017, Rabobank Group empleaba a 43,810 personas en todo el mundo y alcanzó un beneficio de 2.700 millones de euros.

Figura 1. Rabobank "at a glance"

\section{More than 8.5 million customers

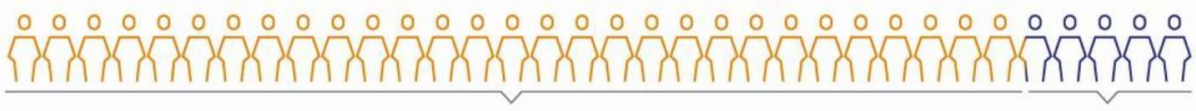 \\ 7.3 million Dutch customers \\ 1.2 million international customers"}

Banking for the Netherlands

102 local Rabobanks

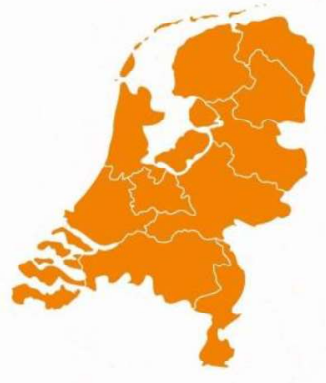

$\begin{array}{cc}\begin{array}{c}446 \\ \text { offices }\end{array} & \begin{array}{c}1.9 \\ \text { million } \\ \text { members }\end{array} \\ \begin{array}{c}13,635 \\ \text { FTEs }\end{array} & \begin{array}{c}1,967 \\ \text { ATMs }\end{array} \\ \begin{array}{c}6.5 \\ \text { million private } \\ \text { customers }\end{array} & \begin{array}{c}0.8 \\ \text { million } \\ \text { commercial } \\ \text { customers }\end{array}\end{array}$

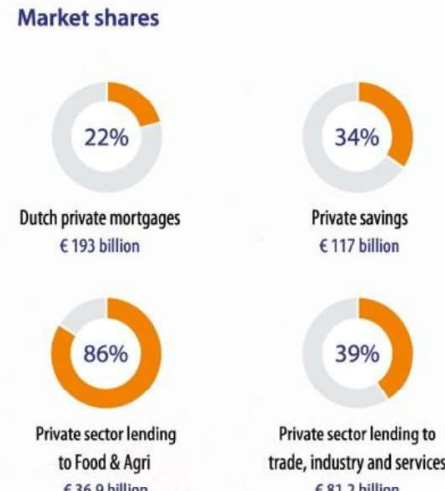

\section{Banking for Food}

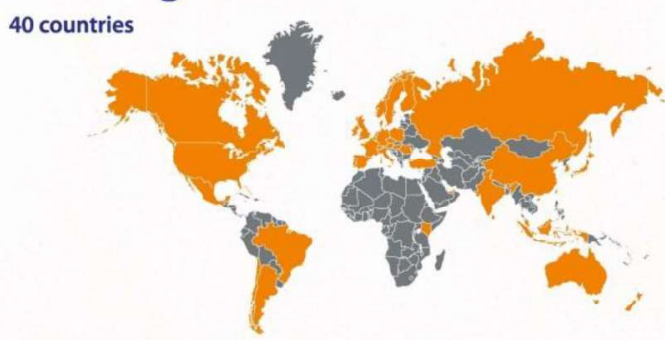

$€ 60.9$

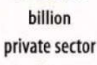

lending to

Food \& Agri"*

389

offices"

\section{$€ 38.4$}

billion

private sector

lending to trade,

industry and services"'

\section{7,909}

Fuente: Rabobank (2018), Informe Anual, accedido a 08/09/2018 
Durante décadas, Rabobank tuvo una estructura cooperativa de dos niveles, que consistía en una serie de bancos miembros locales independientes, que estaban afiliados a la cooperativa central Rabobank Nederland. Bajo esta estructura, Rabobank Nederland actuaba como un centro de servicios para los bancos locales, pero también era responsable de la supervisión delegada de los bancos locales.

En 2014 comenzó el denominado "Diálogo de Gobernanza" con el objetivo de fortalecer la confianza en Rabobank entre clientes, miembros, empleados, reguladores y otros stakeholders. Así, en 2016 se aprueba la creación de una nueva estructura de gobernanza basada en la fusión de los bancos locales y la organización paraguas, Rabobank Nederland, creando así una única estructura cooperativa denominada Rabobank, propiedad de 102 bancos miembros locales, con una única licencia bancaria y balance general. Anteriormente, cada miembro local Rabobank, así como la organización centralizada, tenían su propia licencia bancaria y su propio conjunto de estados financieros. En la nueva estructura, se fortalece el funcionamiento democrático dando un mayor poder de decisión a los miembros. Los consejos de miembros locales se centran más específicamente en los servicios locales del banco y su papel en la sociedad. Su influencia y control también se extiende a la organización de Rabobank en su conjunto, ya que cada miembro local de Rabobank representa directamente a sus miembros en el órgano de gestión supremo de la cooperativa: el Consejo de Miembros Generales. Este consejo aprueba la estrategia y el presupuesto anual, actúa como asesor en grandes fusiones o alianzas estratégicas, y designa a los miembros del Consejo de Supervisión.

Figura 2. Resultados de la revisión del sistema de gobernanza de Rabobank

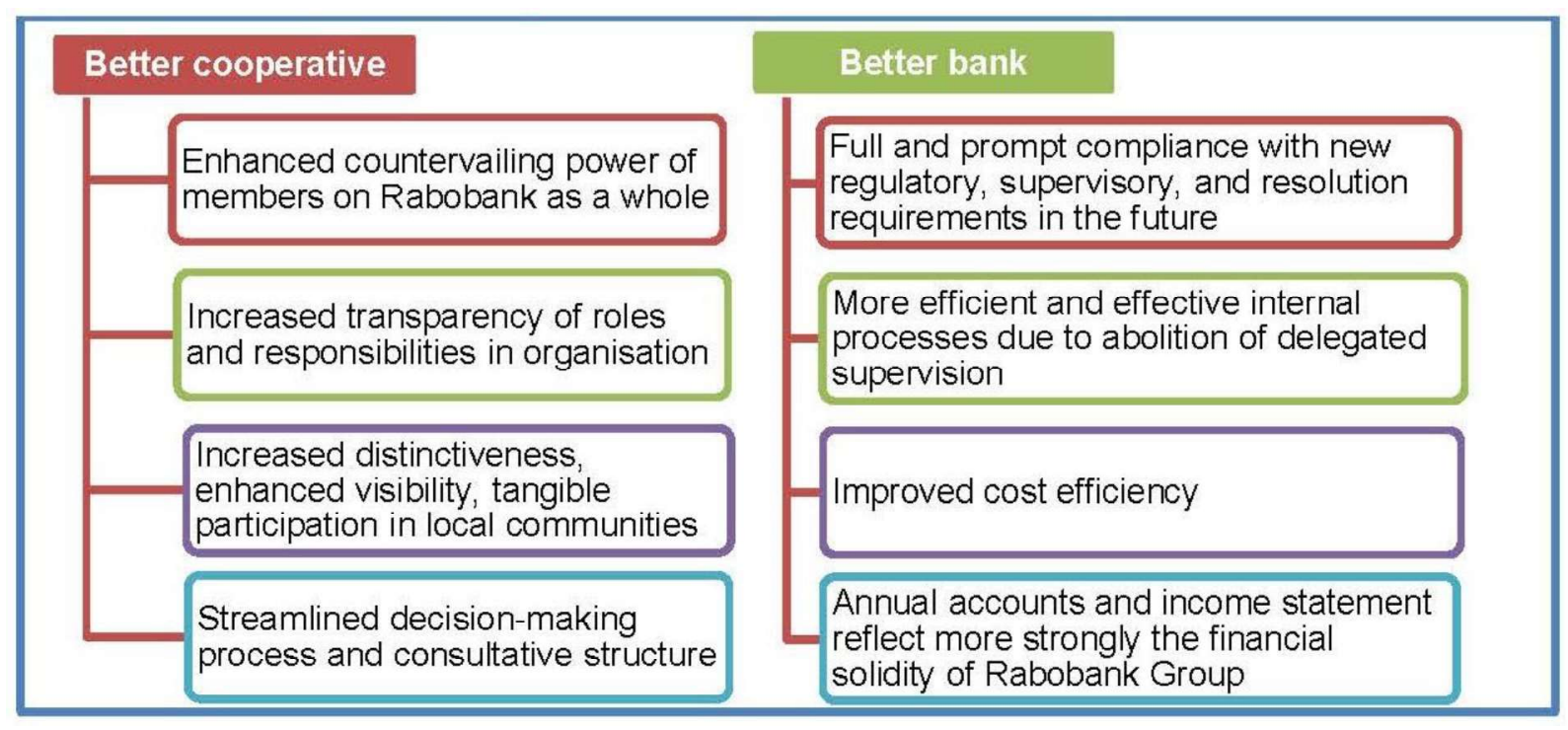

Fuente: Groeneveld (2016), The Road Towards One Cooperative Rabobank

Asimismo, Rabobank ha fortalecido su base societaria y control democrático de manera significativa en los últimos años. Mientras que en 1999 sólo el $6 \%$ de sus clientes entre socios, actualmente son el 24\%. Además, Rabobank ha emitido nuevos tipos de 
acciones sin derecho a voto para sus clientes, por lo que hoy en día cerca del $40 \%$ de los clientes tienen "un interés en el rendimiento financiero del banco y su servicio a los clientes" (Birchall, 2014).

Los principales resultados de la revisión del sistema de gobernanza se recogen en la siguiente figura. La revisión se estructuró en dos líneas clave: construir una cooperativa mejor y construir un banco mejor.

En el ámbito cooperativo, se ha logrado fortalecer el poder de los miembros en las decisiones sobre Rabobank, se ha incrementado la transparencia de roles $y$ responsabilidades en la organización, se mejorado la visibilidad y la participación tangible en las comunidades locales, y se ha fortalecido el proceso de toma de decisiones. Mientras tanto, en el ámbito bancario se ha fomentado el cumplimiento presente y futuro con los requerimientos regulatorios, de supervisión y resolución. Además, gracias a la supresión de la supervisión delegada, los procesos internos de la cooperativa son ahora más efectivos y eficientes. También se ha mejorado la eficiencia en costes y las cuentas anuales actuales reflejan de manera más fidedigna la solidez financiera del grupo Rabobank.

\subsection{DESARROLLO DEL CASO DE RABOBANK}

Rabobank destaca por ser banco cooperativo que opera a nivel multinacional y por su sólido compromiso con la responsabilidad social y el desarrollo sostenible. En los siguientes apartados se explica el proceso de internacionalización de Rabobank, su contribución a la consecución de los objetivos de desarrollo sostenible de Naciones Unidas y su estrategia de futuro "One-Rabobank".

\section{Proceso de expansión internacional de Rabobank}

Varios trabajos señalan que los acuerdos accionariales (principalmente las jointventures y las adquisiciones) son los modos de entrada dominantes en el sector. Petrou (2009) destaca diversas razones como la saturación del sector en los mercados nacionales y la tendencia hacia una mayor concentración de la industria, lo que favorece la proliferación de acuerdos accionariales; la necesidad de establecer joint-ventures debido a la elevada regulación del sector bancario en los países y a la importancia que tienen los recursos locales en dicho sector, como la distribución, imagen local, conocimiento de mercado y base de clientes. Otro aspecto clave es el hecho de que el sector bancario es un sector intensivo en información donde se genera un gran valor añadido cuando la información es compartida de manera adecuada y rápida a lo largo de la red transnacional, lo que lleva a las empresas a preferir acuerdos accionariales, ya que permiten un mayor control sobre sus negocios internacionales. 
Figura 3. Presencia global de Rabobank
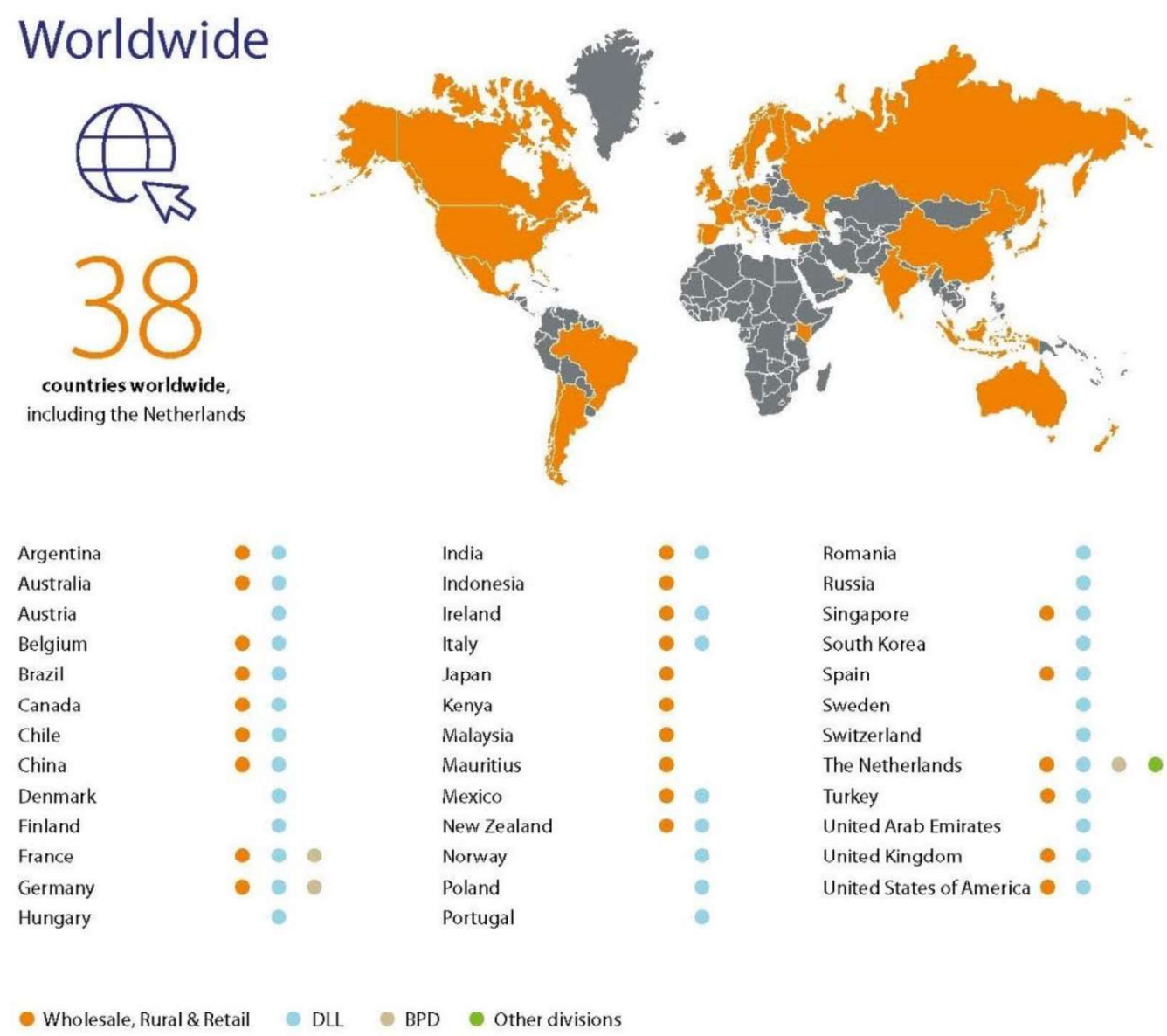

Fuente: Rabobank (2018), Informe Anual, accedido a 08/09/2018

Rabobank ha desarrollado una intensa estrategia de crecimiento desde su creación en 1972, convirtiéndose en un importante actor internacional. En la primera década de 1970 la expansión se basó en el establecimiento de alianzas estratégicas con otros bancos, en parte gracias al apoyo de UNICO, una asociación de 8 entidades bancarias europeas fundada en 1977. En cambio, en la década de 1980, la estrategia de internacionalización pasa a sostenerse en la apertura de oficinas propias en países como Alemania y Estados Unidos. A partir de la década de 1990, Rabobank persiguió una mayor integración vertical, con la adquisición y absorción de pequeños bancos en diferentes países extranjeros. Esta estrategia de diversificación de servicios y países se mantuvo también hasta principios de la crisis económica de 2008. Así, Rabobank accedió a Bélgica e 2002, Irlanda (2005), Nueva Zelanda (2006) o Australia (2007).

En pocas décadas, Rabobank se había convertido en una gran institución internacional que brindaba servicios financieros a clientes nacionales e internacionales. Por ejemplo, en 2006, Rabobank operaba en 42 países y, en sólo 10 años, el número de sucursales internacionales se había triplicado hasta alcanzar las 330. A partir de 2010, debido al fuerte impacto de la crisis económica, se redujo el número de filiales y empresas asociadas tanto en Holanda como en el resto del mundo. Entre otros, se vendieron las 
compañías de gestión de activos Orbay, Robeco y Sarasin. No obstante, entre 2014 y 2016, la política de expansión continuó.

Actualmente, Rabobank opera en 38 países a través de más de 380 filiales en Holanda y el extranjero, que dan empleo a 43,810 personas (Figura 3). Cabe destacar que las filiales exteriores son empresas de capital controladas directamente por la matriz holandesa o por otras filiales.

La contribución de Rabobank a los objetivos de desarrollo sostenible de Naciones Unidas

El Grupo Rabobank contribuye con sus diferentes actividades económicas y sociales a la consecución de 15 de los 17 objetivos de desarrollo sostenible establecidos por Naciones Unidas (Figura 4). A continuación, se especifican las diferentes actuaciones que ha realizado Rabobank y su relación con la promoción de cada uno de los 15 objetivos de desarrollo sostenible en los que participa.

1) Fin de la pobreza

- La Fundación Rabobank ha invertido 28 millones de euros para reducir la pobreza.

- Impacto positivo en 4,9 millones de pequeños propietarios en países en desarrollo países y 619.565 personas vulnerables en los Países Bajos.

2) Hambre Cero

- Rabobank ha invertido 98.000 millones de euros en el suministro mundial de alimentos

- Más de 200 informes de conocimiento sobre Alimentos y Agricultura difundidos a clientes y stakeholders.

3) Salud y bienestar

- Inversiones en el sector de la salud por valor de 5.400 millones de euros.

- Financiación a más de 48.000 clientes en el sector de la salud en Holanda

4) Educación de calidad

- Contribución a la educación de calidad a través de inversiones en el sector por valor de 668 millones de euros.

5) Igualdad de género

- Desarrollo positivo de la igualdad de género en Rabobank: $26 \%$ mujeres en alta gerencia.

- Rabobank fue ganador del premio "Diamante por la Diversidad 2017”. 
7) Energía limpia

- $\quad 3.400$ millones de euros en inversiones para la generación de energía renovable, principalmente a través de la energía eólica y solar.

- 500 millones de euros de Rabobank Green Bond invertidos en 12 proyectos de energía solar y eólica.

- 548 millones de euros en inversiones de Rabo Groen Bank a proyectos de energía renovable

8) Trabajo decente y crecimiento económico

- Fomento del crecimiento económico invirtiendo 213.000 millones en empresas holandesas e internacionales y proporcionando EUR 198.000 millones en préstamos a clientes privados.

- Acceso a servicios bancarios a 7,2 millones de clientes en países en desarrollo a través de 9 bancos asociados.

Figura 4. Rabobank y los objetivos de desarrollo sostenible de Naciones Unidas
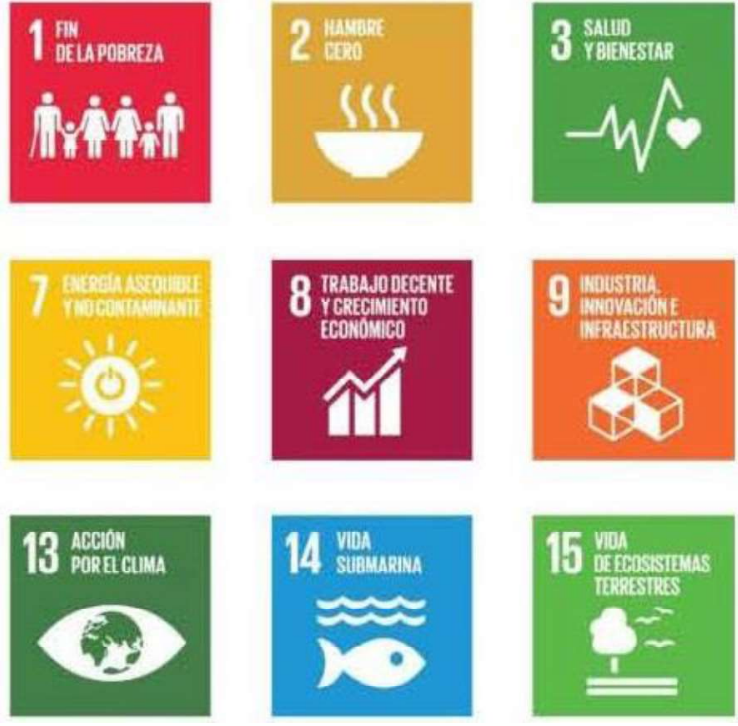
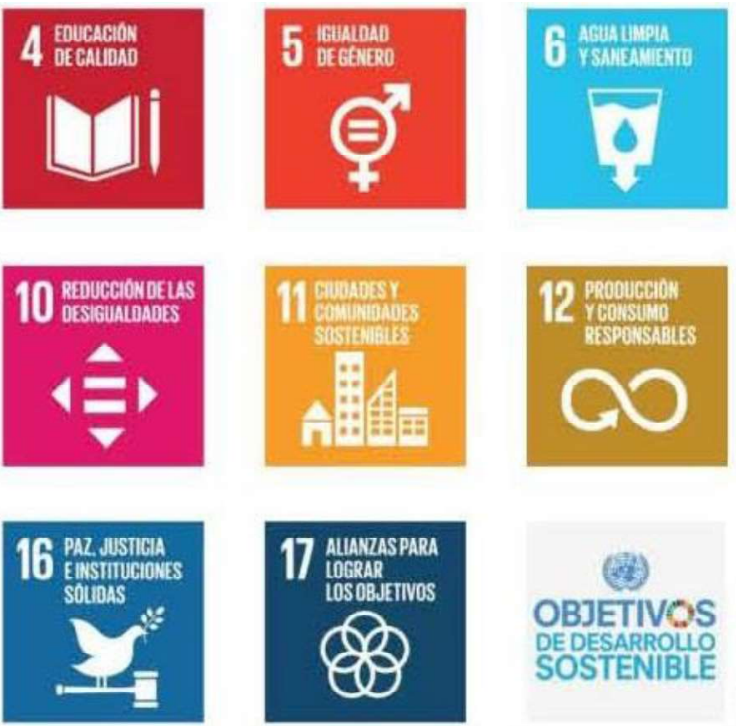

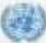

OBJETIVOS DEDESARROLLO

Fuente: https://www.un.org/sustainabledevelopment/es/objetivos-de-desarrollo-sostenible/, accedido a $08 / 09 / 2018$

9) Industria, innovación e infraestructura

- Inversión de 4.600 millones de euros en el sector de la construcción.

11) Ciudades y comunidades sostenibles

- Inversión sin fines de lucro de 65,9 millones de euros en la comunidad

- Mejora de la sostenibilidad de los hogares con el 'Rabobank Hipoteca Verde'.

- Apoyo a 175 nuevas iniciativas locales de cooperación y 260 cooperativas locales, con financiamiento, conocimiento y redes en los Países Bajos. 
- Las nuevas transacciones de finanzas inmobiliarias deben cumplir ambiciosas estándares de etiquetado de energía.

- 14 millones de euros invertidos a través del préstamo de impacto de Rabobank para salud y educación

12) Producción y consumos responsables

- Inversión de 18.900 millones de euros en financiamiento sostenible y 4.000 millones en fondos sostenibles.

- Participación en mesas redondas para 9 cadenas de valor sostenibles.

13) Acción por el clima

- Rabobank "clima neutral" nuevamente en 2017 (operaciones propias)

- Introducción de la estrategia climática Rabobank, participación en UNEP-TCFD y PCAF.

- No se han dado fondos para la producción de gas en el mar de Wadden o para minas de carbón y plantas de energía a carbón.

- Rabobank se convirtió en miembro y copresidente en 2017 del Grupo de trabajo sobre agricultura climáticamente inteligente del WBCSD

14) Vida submarina

- Junto con WWF, se ha apoyado a clientes en Chile con negocios acuícolas y certificación ASC.

- Fomento de acuicultura sostenible ofreciendo un tasa de interés reducida para las granjas acuícolas certificadas.

15) Vida de ecosistemas terrestres

- Asociación con Naciones Unidas Medio Ambiente por valor de 1.000 millones de dólares para el desarrollo de métodos forestales sostenibles.

- Rabobank participa en la Alianza Forestal Tropical 2020 contra la deforestación.

16) Paz, justicia e instituciones sólidas

- Alentar a los fondos de inversión a cumplir con los principios del Pacto Mundial de las UN y los Principios de la ONU para la Inversión Responsable.

- Contribución a acuerdos sobre Conducta Empresarial Responsable Internacional.

17) Alianzas para lograr los objetivos

- Rabobank ha participado en el Foro Económico Mundial.

- El consejero delegado, Wiebe Draijer, fue nombrado miembro de un comité asesor de la Comisión Europea sobre sostenibilidad.

- Participantes en WBCSD para el Desarrollo Sostenible y en FRSSH. 
- Asociación con WWF en producción sostenible.

- Cooperación con las organizaciones de las Naciones Unidas sobre seguridad alimentaria, nutrición y agricultura.

\section{“One-Rabobank": Estrategia futura para un Rabobank más integrado y global}

De cara al 2018 y próximos años, Rabobank ha puesto en marcha la estrategia "OneRabobank", centrada en fomentar su modelo de banca comunitaria local con una visión internacional donde clientes, miembros y stakeholders participen más activamente y todos los trabajadores compartan una cultura organizacional común.

En concreto, la Junta Directiva de Rabobank ha establecido 10 prioridades estratégicas. Éstas se basan en la misión de la cooperativa, es decir, "construir un mundo mejor juntos", y se estructuran en torno a cuatro pilares: i) centralidad del cliente; ii) sentido cooperativo; iii) solidez bancaria; y iv) trabajadores empoderados (Figura 5).

Figura 5. Pilares de la Estrategia "One-Rabobank"

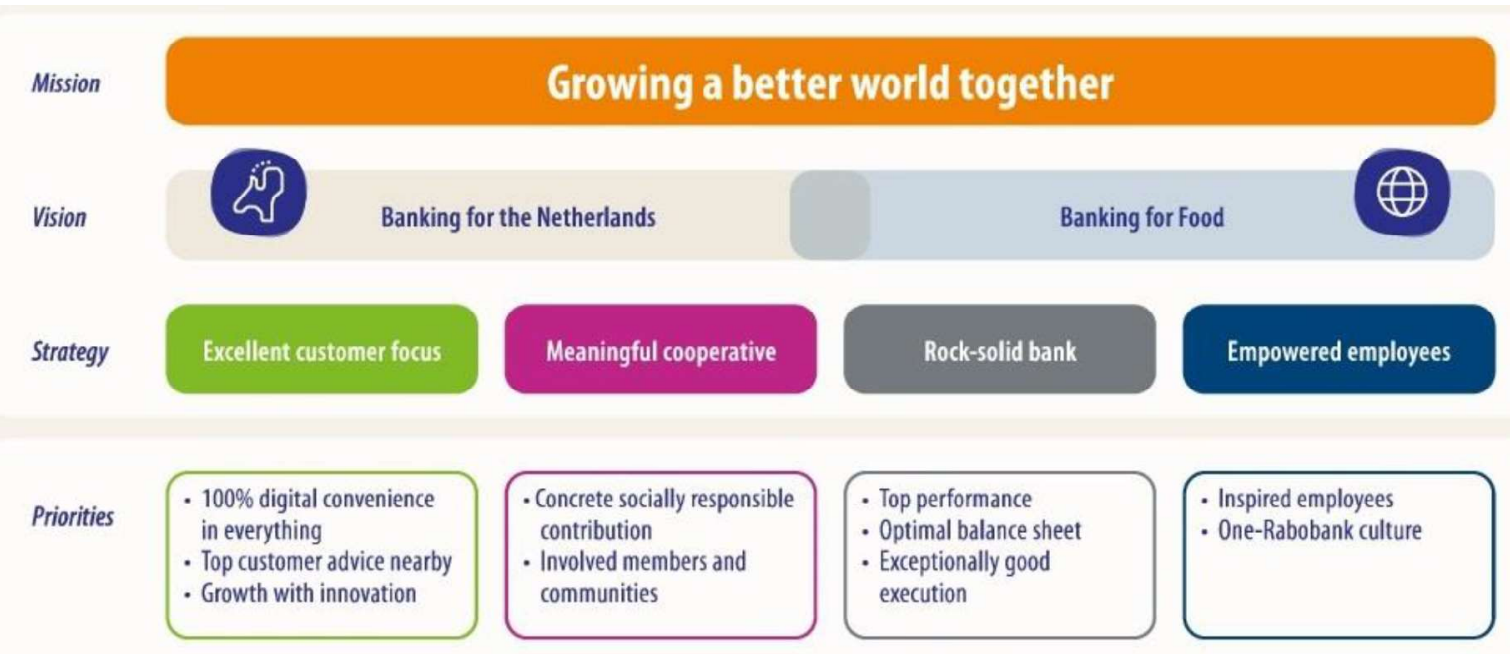

Fuente: Rabobank (2017), Informe Anual, accedido a 08/09/2018

En cuanto a la orientación al cliente, el crecimiento y la adaptación al entorno mediante un aprendizaje organizacional ágil ocupan un lugar destacado en la lista de prioridades, junto con la innovación a gran escala y la digitalización del banco. En lo relativo a la naturaleza cooperativa de Rabobank, se pretende fomentar la involucración de los socios y los principales actores de las comunidades locales, así como seguir promoviendo la responsabilidad social evaluando de manera más concreta su impacto. En términos de solidez bancaria, se busca seguir fomentando el máximo desempeño organizacional y financiero así como la excelencia y eficiencia operativa. A nivel laboral, Rabobank promoverá una cultura empresarial común basada en la cooperación para todos los trabajadores del grupo y asumirá una mayor responsabilidad por el desempeño del grupo en general. 


\subsection{CUESTIONES PARA DISCUSIÓN}

Cuestión 1. ¿Qué transformaciones ha sufrido la estructura de gobernanza corporativa de Rabobank y cuáles han sido sus principales resultados?

Las cooperativas se estructuran como organizaciones democráticas donde la toma de decisiones se basa en la regla "una persona, un voto". No obstante, existe evidencia de que el crecimiento organizacional puede comprometer o dificultar los procesos de gestión democrática (Bretos y Errasti, 2018). Tras décadas de crecimiento, en 2016, Rabobank ha reestructurado su sistema de gobernanza. En 2016, todos los bancos miembros locales (actualmente 102) y la institución central cooperativa Rabobank Nederland se fusionaron formando el grupo cooperativo Rabobank, pasando a tener una única licencia bancaria y un único estado financiero. Ello ha promovido el control democrático al fortalecer la involucración de los socios en la toma de decisiones y la participación de diferentes stakeholders, a la vez que ha favorecido la eficiencia económica y la eficacia en los procesos internos de la organización. No obstante, cabe destacar que la mayoría de filiales y empresas asociadas del grupo Rabobank están estructuradas como empresas de capital y, por tanto, no están integradas en la toma de decisiones estratégicas sobre, por ejemplo, expansión, venta de activos, cierre, aprobación de planes estratégicos y elección de los órganos de gobierno.

Cuestión 2. ¿Qué motivos han impulsado la expansión internacional de Rabobank y cómo ha evolucionado en estos últimos años dicho proceso?

En los últimos años, el sector bancario ha experimentado una extraordinaria transformación, gracias especialmente al surgimiento de nuevas tecnologías de información y comunicación y a la liberalización económica generalizada. Así mismo, este sector ha, con multitud de fusiones y absorciones en el ámbito internacional. Rabobank no ha sido una excepción y ha seguido una estrategia de internacionalización claramente progresiva adaptada a los cambios exigidos en cada momento en el sector, a la vez que ha mantenido su estructura de funcionamiento cooperativo y su esencia social. Rabobank comenzó su andadura internacional estableciendo acuerdos estratégicos con bancos extranjeros durante los $70 \mathrm{y}$, posteriormente, mediante la apertura de oficinas en el exterior en los 80. No obstante, a partir de la década de 1990, su estrategia de expansión internacional se ha basado en la diversificación de servicios y la adquisición o absorción de pequeños bancos locales en distintos países extranjeros. Asimismo, Rabobank ha mantenido importantes cuotas de mercado en Holanda gracias a su continua expansión doméstica.

Cuestión 3. ¿Cómo contribuye Rabobank al desarrollo sostenible de los territorios donde está implantado?

Las cooperativas han sido ampliamente consideradas como herramientas clave para promover un desarrollo sostenible, inteligente e integrador en el contexto de la globalización (Bretos y Marcuello 2017). Rabobank opera como una organización multinacional en multitud de países y lo hace con un negocio sólido y viable a largo 
plazo, lo que favorece un crecimiento económico enraizado en los territorios locales donde la cooperativa está establecida. Además, Rabobank lleva a cabo multitud de proyectos de carácter económico y social que contribuyen a la consecución de diversos objetivos de desarrollo sostenible de las Naciones Unidas. Entre otras actuaciones, destacan las inversiones de la cooperativa en proyectos que favorecen la sostenibilidad medioambiental o la reducción de la pobreza, así como la firma de acuerdos de colaboración con organizaciones sin ánimo de lucro.

\subsection{CONCLUSIONES}

Rabobank es un banco multinacional de referencia para el movimiento cooperativista mundial. El grupo ha desarrollado una intensa estrategia de crecimiento nacional y global, desarrollando su actividad actualmente en 38 países, controlando más de 380 filiales y dando empleo a cerca de 44.000 personas.

De hecho, Rabobank se erige como una experiencia cooperativa bancaria única en la consecución de una expansión internacional competitiva y la promoción de un desarrollo sostenible en los distintos países donde opera. En este sentido, la actividad económica y social de la cooperativa de los distintos países donde opera contribuye de manera clara a la consecución de diversos objetivos de desarrollo sostenible de las Naciones Unidos relativos, por ejemplo, a la reducción de la pobreza y el hambre, la salud y el bienestar, la educación de calidad, la igualdad de género, y distintos aspectos de carácter medioambiental.

También sobresale que, en los últimos años, Rabobank ha implementado importantes cambios en su estructura de gobernanza al fusionar su organización central, Rabobank Nederland, con los distintos bancos locales que forman la base social y comunitaria de la cooperativa. Esta reestructuración ha proporcionado mejoras importantes en los aspectos de negocio, a la vez que ha fortalecido el sistema democrático de la organización y la participación de base de los socios. 


\section{GRUPO ARCOÍRIS: LA FUERZA DEL COOPERATIVISMO AGROALIMENTARIO}

\section{RESUMEN:}

El Grupo Arcoíris, una sociedad de carácter humanista, con capital social igualitario, nace con el objetivo de ofrecer la mejor calidad en todos los productos generados por la ganadería. Actualmente, el Grupo Arcoíris es uno de los mayores grupos ganaderos de la Comunidad Autónoma de Aragón y se ha convertido en un referente de cooperativa y trabajo en equipo. Todo ello lo ha conseguido gracias a su apuesta por la calidad, asegurándose la trazabilidad alimentaria al 100\%, ya que todos los procesos productivos son propios, así como implicándose socialmente con el territorio en el que surgió, Matarraña (Teruel). Se trata de una corporación socialmente responsable, contribuyen activa y voluntariamente a la mejora del territorio en el que se encuentra, otorgándole un valor añadido. Todas las prácticas, estrategias y sistemas de gestión se cohesionan para conseguir un equilibrio entre las dimensiones empresarial, social, cultural y medioambiental basada en la consecución de un "crecimiento global socialmente responsable, cooperativo, saludable y natural". 


\subsection{INTRODUCCIÓN}

La historia de Grupo Arcoíris se remonta al año 1978 cuando se constituye, en la Comarca del Matarraña (Teruel) ${ }^{1}$, la Sociedad Ganadería Unida Comarcal (GUCO) para la fabricación de piensos que abasteciera al ganado porcino. Así, GUCO sería el germen para el nacimiento de otras sociedades relacionadas con la ganadería o con la prestación de otros productos y servicios que pudieran satisfacer a las primeras. Paulatinamente, tanto el sector cunícola como ovino se incorporan a la sociedad, con la consiguiente adaptación de la maquinaria y ampliación de las instalaciones, por lo que la sociedad plantea crear una nueva organización y reestructurar el sistema de representación. Se crea el Consejo de Delegados Locales con el objetivo de lograr una mayor participación y comunicación con los socios, que estaban distribuidos en 50 localidades.

Gracias a la implantación de la Denominación de Origen del Jamón de Teruel en 1984, se impulsa el sector de la ganadería porcina y se apuesta por la calidad tanto en la genética como en la alimentación de este tipo de animales. Así, se desarrolla el Programa de Producción de Cerdas Reproductoras (cruce de dos selectas razas: Largue White y Landrace), consiguiendo un aumento de la calidad y la productividad.

A partir de 1986, los socios de GUCO son conscientes de la necesidad de fijarse en parámetros exteriores para continuar creciendo, por lo que se comienzan a promover una serie de viajes para obtener nuevos puntos de vista y referencias para la constitución de nuevas sociedades. Fundamentalmente serán dos viajes los que traigan nuevas ideas, el primero a Guijuelo (Salamanca) para estudiar la construcción de los secaderos de jamones, sentando las bases para el nacimiento en 1986, de la Sociedad para la Industrialización de la Carne (SOINCAR), dedicada a la comercialización del cerdo vivo, canales refrigeradas y curados. El segundo viaje será en 1987 para visitar una serie de instalaciones en Dinamarca, con el objetivo de desarrollar el proyecto de un Centro de Inseminación Artificial Porcina (CIAR), que nace al año siguiente.

Finalmente, en 1990 surge el Grupo Arcoíris, formado por nueve entidades asociativas: GUCO, SOINCAR, CIAR, INCO, AVIBA, ADS, FSI, Cooperativa del Campo-Sección Servicios y PROGA. Posteriormente, dejará de ser un consorcio y se constituirá como agrupación de Sociedades Agrarias de Transformación (SSAATT de segundo grado) y la formarán las cinco primeras sociedades.

El año 2005 es altamente productivo: Se constituye Granjas GUCO para el desarrollo de la genética. Una de las primeras medidas consiste en incorporar la granja de J. Miguel Cerdá para selección genética de cerdas Landrace, con lo que se mejora el servicio al socio de GUCO y la genética pasa a ser controlada por la propia estructura. Actualmente la cooperativa se encuentra consolidada, aglutinando a 21 empresas que trabajan en la explotación del sector ganadero, fundamentalmente porcino y cunícola. Trabajan 630 profesionales del ramo y se han generado 302 puestos de trabajo en los

\footnotetext{
${ }^{1}$ La Comarca del Matarraña se sitúa al noreste de la Provincia de Teruel (España) limitando con las provincias de Castellón y Tarragona. Está formada por 18 municipios, siendo Valderrobres la capital administrativa.
} 
últimos años. Todo ello, a partir de la unión de cinco sociedades: la fábrica de piensos y servicios GUCO, Ganadería Unida Comarcal; SOINCAR, dedicada a la industrialización del cerdo; CIAR, Centro de Inseminación del Porcino; INCO, especializada en la industrialización del conejo; y AVIBA, cuya actividad se centra en la producción y comercialización de pollos de engorde. En la Tabla 1 se muestran las fechas más relevantes del grupo.

Tabla 1. Fechas destacadas del Grupo Arcoiris

\begin{tabular}{|c|c|}
\hline \multicolumn{2}{|c|}{ Fechas destacadas GRUPO ARCOÍRIS } \\
\hline 1978 & Creación de la Sociedad Ganadería Unida Comarcal (GUCO). \\
\hline 1980 & Inauguración de la fábrica de piensos GUCO. \\
\hline 1981 & Incorporación de los sectores cunícula y ovino a GUCO. \\
\hline 1986 & Nacimiento de la Sociedad para la Industrialización de la Carne (SOINCAR). \\
\hline 1988 & Constitución de CIAR, Centro de Inseminación Porcino. \\
\hline 1989 & Constitución de la industria para la Comercialización de la Carne de Conejo (INCO). \\
\hline 1990 & $\begin{array}{l}\text { Constitución de la sociedad Avicultores del Bajo Aragón (AVIBA), para la } \\
\text { comercialización del pollo de engorde en vivo. } \\
\text { Se crea el Consorcio GRUPO ARCOÍRIS. }\end{array}$ \\
\hline 1992 & $\begin{array}{l}\text { GRUPO ARCOÍRIS se constituye como Agrupación de SAT con seis sociedades: CIAR, } \\
\text { SOINCAR, GUCO, INCO, AVIBA y APROGA. }\end{array}$ \\
\hline $\begin{array}{l}\text { Hasta la } \\
\text { actualidad... }\end{array}$ & $\begin{array}{l}\text { Accionista de: Segan, Bigmat Brica, Montajes Generales Matarraña, Centro de } \\
\text { Jardinería, Foccon, Esypu, Cotécnica, Matadero Comarcal de Valderrobres, Tres Reyes. } \\
\text { Participa en: Sersuco, Lavados y Limpiezas Generales, Gestoría Arcoíris Gesrural, } \\
\text { Gestoría Arcoíris del Bajo Aragón, Geinval, Correduría de Seguros Arcoíris, } \\
\text { Transarcoíris, Central de Compras Tienda Tres Reyes, Insinec, Jamones Calamocha, } \\
\text { Carns de Morella, Fenie Energía. }\end{array}$ \\
\hline
\end{tabular}

Fuente: Elaboración propia a partir de la información de www.grupoarcoiris.com

\subsection{DESARROLLO DEL CASO GRUPO ARCOIRIS}

\section{Los comienzos y la filosofía de la compañía}

De la mano de Enrique Bayona, director y fundador del Grupo Arcoíris, todas las personas que conforman el sector agropecuario de la Comarca del Matarraña comenzaron a unirse por necesidad, para crear unas redes sólidas y duraderas de producción y comercialización de los distintos productos agropecuarios. Observamos que la filosofía cooperativa del Grupo Arcoíris es el de una economía social que tiene 
por objetivo generar empleo vinculado a los habitantes del territorio, estabilizar el tejido industrial de la Comarca, así como ayudar a la vertebración del territorio

La finalidad de la cooperativa es la de generar estabilidad en el empleo tanto para los trabajadores locales como para los empleados inmigrantes, que actualmente rondan los 95 trabajadores, colaborando en la dinamización de la sociedad. El entorno en el que se desarrolla la actividad económica del Grupo Arcoíris es en el sector agropecuario, destacando el de la ganadería. Las principales características de dicho sector son:

- Predominio del sector ganadero, más del $67 \%$ de su producción final agraria.

- Agricultura de secano (olivar, almendro y a distancia el cereal y la vid.)

- Regadío de carácter residual, con un 4\% de su superficie agrícola útil.

- Una producción agropecuaria que representa el $2 \%$ de la producción final agraria aragonesa, ocupando el vigésimo lugar de entre las 33 comarcas de Aragón.

- Dos tercios de su superficie se reparte entre masa forestal y tierras de cultivo.

- Comarca de Aragón que menos subvención recibe de la P.A.C ya que no existe una organización común para el mercado de porcino y de conejo, por lo que está liberalizado y no cuenta con subsidios y ayudas. Se regula por el propio mercado.

- La industrialización de sus productos agrícolas y ganaderos, que se han convertido en una alternativa de futuro, con la generación de valores añadidos y empleos.

- Los procesos de industrialización, que se desarrollan básicamente a través de estructuras asociativas de filosofía cooperativa.

\section{Trazabilidad}

El Grupo Arcoíris controla al 100\% todos los procesos de producción, ya que utiliza los propios, con el objetivo de obtener la máxima calidad a un precio asequible. De este modo, realiza el seguimiento completo del animal, a partir de la selección genética, y siguiendo la alimentación, crecimiento, cría y cuidados veterinarios que se le aplican (www.grupoarcoiris.com). Poseen matadero, sala de despiece y secadero propio, utilizando los métodos tradicionales, pero aplicando los últimos avances tecnológicos para obtener una carne de excelente calidad.

El proceso productivo cuenta con múltiples etapas de las que se ocupa el grupo. El proceso se inicia en la selección genética de los animales, la alimentación del ganado y la central de compras, además del transporte de materias primas. A continuación, se controla la sanidad animal y asesoramiento para la producción de ganado de calidad, así como el proceso de sacrificio. A partir de ahí se procede al despiece y envasado según proceda y se pasa a la fase de comercialización y transporte, ambas etapas son llevadas a cabo por medios propios o con otros distribuidores y colaboradores. El proceso finaliza con la etapa de reciclaje de residuos que son objeto de tratamiento por parte del grupo. En la Figura 1 se muestran las diferentes etapas del proceso productivo. 
Figura 1. Trazabilidad del Grupo Arcoíris

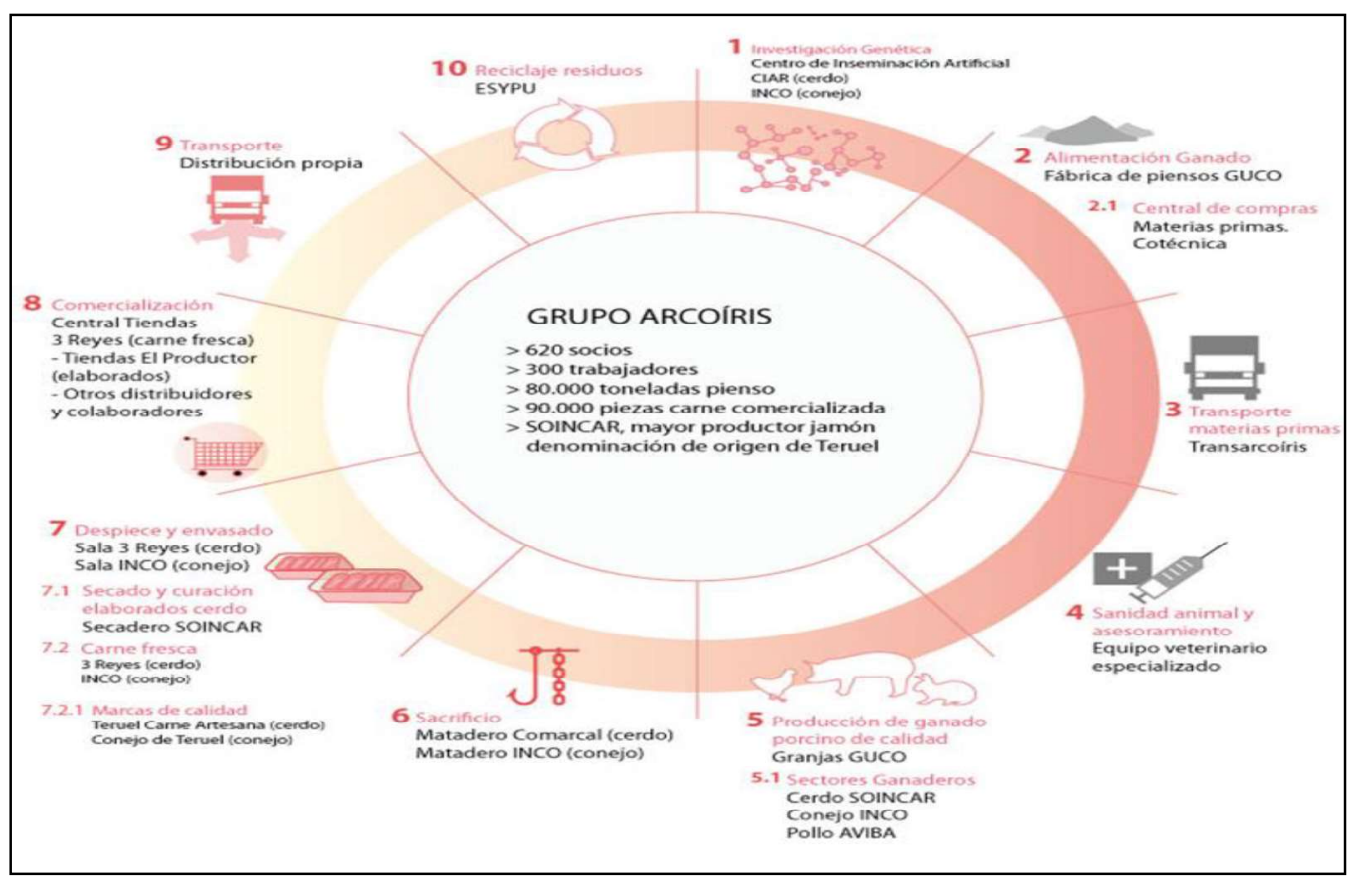

Fuente: www.grupoarcoiris.com

\section{Otros servicios del Grupo Arcoíris.}

A medida que el Grupo se iba consolidando, se comenzó a plantear la necesidad de ampliar los sectores de actividad y servicios de la cooperativa. En este sentido surgen diferentes iniciativas en torno al Grupo Arcoíris, siguiendo siempre la filosofía de empresa, generar empleo duradero en el territorio. A continuación, se detallan los diferentes servicios que se ofrecen:

- Correduría de Seguros (Correduría Arcoíris).

- Gestoría laboral, contable, fiscal, etc. (Gestoría Arcoíris).

- Asesoría Informática (Insinec).

- Supermercado (Sersuco).

- Taller mecánico (Sersuco).

- Poste de gasóleo (Sersuco).

- Distribución de gasóleo a domicilio (Sersuco).

- Agencia inmobiliaria (Geinval).

- Agencia de viajes (Geinval).

- Empresa de mantenimiento (Pinturas, Lavados y Limpiezas).

- Departamento de gestión y análisis.

- Departamento de gestión de costes.

- Departamento comercial.

- Departamento de formación, prevención de riesgos laborales y ayudas.

- Departamento de asesoría jurídica. 
- Departamento de comunicación y marketing.

- Departamento de calidad.

- Materiales de construcción y decoración (Bricas).

- Construcción de naves y granjas (Montajes Generales Matarraña).

- Decoración y jardinería (Centro de Jardinería).

\section{Los tres pilares del Grupo: Investigación, desarrollo e innovación tecnológica}

La innovación estratégica se ha convertido en una de las cuestiones de mayor interés para el Grupo, se proponen nuevas actuaciones en el conjunto de alternativas estratégicas y ese propósito impulsa la mejora continua. Según Hamel (2006), la innovación estratégica es la capacidad de reconcebir el modelo actual de negocio de forma que cree un nuevo valor para los clientes, pueda dejar fuera a los competidores y produzca nueva riqueza para todos los participantes en la empresa. Así la innovación estratégica se sustenta en alguna de las dimensiones siguientes: grupos de nuevos clientes que están apareciendo; nuevos productos o servicios que permitan atender de manera más eficiente las nuevas necesidades; y nuevas formas de atender a los clientes y de relacionarse con ellos. En este sentido, el Grupo Arcoíris ha ido redefiniendo el negocio, el quién, el qué y el cómo para modificar la estrategia del Grupo a través de los tres pilares siguientes:

Investigación. En los centros de inseminación de porcino (CIAR) y de conejo (INCO), se desarrollan proyectos para obtener el mejor ADN. Se investiga para conseguir la mayor calidad en todos sus productos a través de la mejora genética de los animales y la selección de los piensos para su alimentación.

Desarrollo. El Grupo Arcoíris aplica todos los resultados obtenidos en sus investigaciones, así como las conclusiones de los estudios científicos para la fabricación de materiales y productos, como también para la mejora de los procesos y sistemas de trabajo. Por otra parte, se sigue un decálogo de diez prácticas positivas en ganadería, para que las explotaciones ganaderas sean más eficientes, estás prácticas son las siguientes:

- contar con materias primas y animales con genética de calidad garantizada;

- asegurarse la continuidad de la explotación;

- llevar un control documental de las variaciones en las granjas;

- evitar la acumulación de animales por explotación;

- seguir trabajando en la prevención sanitaria con mayores controles de higiene y seguridad;

- aplicar los tratamientos médicos obligatorios;

- establecer un sistema de trabajo en bandas, dividiendo el trabajo por semanas y la población de la granja por lotes;

- instaurar definitivamente la inseminación artificial como procedimiento habitual de reproducción; 
- aplicar técnicas innovadoras que se adapten a las necesidades del ganadero y a las normativas;

- actualizar los procesos para rentabilizar las explotaciones.

Innovación tecnológica: Desde los inicios del Grupo, se ha apostado por la modernización de los procesos en todas las instalaciones. Como resultado de estas mejoras, se han conseguido nuevos productos y renovado los que ya poseían, gracias a la actualización en los procesos de producción o por la aplicación de nuevos sistemas.

\section{Carácter socialmente responsable del Grupo Arcoíris.}

Nos encontramos ante una corporación socialmente responsable, ya que contribuye activa y voluntariamente para un desarrollo económicamente sostenible del territorio en el que se localizan. Siguiendo el principio de empresa social, todas las prácticas se cohesionan para ofrecer un equilibrio entre las dimensiones empresarial, social, cultural y medioambiental. Entre las acciones llevadas a cabo se encuentran (Saz Gil, 2012):

Responsabilidad empresarial: El Grupo Arcoíris contribuye a mantener la población y a vertebrar el territorio, evitando la emigración, ya que ofrece trabajo directo a más de 300 familias. Por otra parte, realiza una importante labor de apoyo empresarial para otros emprendedores de la Comarca del Matarraña, en donde más del 56\% de la población es trabajadora autónoma, así como respalda nuevas iniciativas de jóvenes empresarios.

Responsabilidad social: Más del 34\% de la plantilla son mujeres, de las cuales, el 29\% son emigrantes. Se destaca el papel de la mujer en el entorno rural, ofreciendo un plan de carrera a largo plazo y remunerado en función de sus conocimientos y aptitudes. De este modo, el sector femenino ocupa tanto cargos administrativos y de dirección como técnicos y artesanales. Asimismo, el 29\% de los trabajadores son emigrantes de países como Rumanía, Marruecos, Bulgaria, Senegal, Ucrania, Colombia y Perú (tabla 2). El Grupo colabora en su integración, fomentando el compañerismo y la convivencia con otros trabajadores.

Tabla 2. Trabajadores del grupo

TRABAJADORES DE GRUPO ARCOIRIS*

\begin{tabular}{lllll}
\hline & HOMBRES & MUJERES & TOTAL & \\
Españoles & 135 & 85 & 220 & $71 \%$ \\
Extranjeros & 70 & 20 & 90 & $29 \%$ \\
TOTAL & 205 & 105 & 310 & \\
& $66 \%$ & $34 \%$ & & \\
& & & &
\end{tabular}

*Datos actualizados en septiembre de 2010

Fuente:www.grupoarcoiris.com 
Responsabilidad cultural: La agrupación apoya a la cultura y la tradición de la Comarca del Matarraña a través de diferentes iniciativas ofreciendo gastronomía de calidad, siguiendo procesos de producción tradicionales y participando en los eventos relacionados con la cultura de la comarca.

Responsabilidad medioambiental: Ya que la cooperativa se encuentra junto al Parque Natural de los Puertos de Beceite, ésta tiene siempre presente el equilibrio medioambiental. Por ello, se recicla e investiga para dar nueva utilidad a los residuos generados en las distintas actividades para no deteriorar el medio ambiente. Las acciones giran en torno al reciclaje sostenible de purines como abono natural, al mantenimiento de reservas naturales de buitres, reutilización en la industria textil y al reciclaje de material de oficina.

\subsection{CUESTIONES PARA DISCUSIÓN}

Cuestión 1. ¿Considera que el modelo Arcoiris es exportable a otros territorios?

Como ya es sabido, al sector agro-ganadero se le exige que cumpla un papel multifuncional, y que además de la producción tradicional de alimentos, cumpla objetivos sociales, medioambientales y de desarrollo rural. El cooperativismo se erige como fórmula idónea para lograr la reactivación de las áreas rurales mediante la puesta en marcha de actividades económicas basadas en el aprovechamiento y la reorganización de los recursos endógenos del territorio, permite diversificar el riesgo y plantear la diversificación no sólo como una cuestión económica donde confluyen intereses privados tratados por soluciones exclusivamente de mercado, sino más bien considerar las facetas de bienes sociales que proporciona el medio rural (Ramón Fernández y Saz Gil, 2005). El sector agro-ganadero necesita desarrollar partenariados que tengan por objeto coordinar y equilibrar, por un lado, los desafíos que se le plantean al sector agrario y, por otro, las demandas que espera la sociedad. En este sentido, es conveniente fomentar cooperativismo en territorios con falta de iniciativas industriales y cuya única salida es la explotación de los recursos endógenos existentes en su territorio fundamentalmente de tipo agrícola y ganadero. A través de las cooperativas se puede rentabilizar de manera más productiva la explotación y comercialización de los productos generados. Estas iniciativas son fundamentales para desarrollar actividad y crear nuevos puestos de trabajo y al mismo tiempo se contribuye a la sostenibilidad del territorio, contribuyendo al mantenimiento de los pequeños pueblos. El caso Arcoíris ha sido capaz de revitalizar una comarca y su modelo de crecimiento puede ser replicado en otros ámbitos territoriales.

Cuestión 2. ¿Cree que es importante la trazabilidad de la cadena alimentaria?

Las empresas de distribución han desarrollado un conjunto de normas que tiene como objetivo imponer niveles propios de calidad, de seguridad alimentaria y de trazabilidad (Ramón Fernández y Saz Gil, 2005). Estas normas, confieren un poder creciente para 
controlar la producción agraria. Las exigencias en trazabilidad, calidad y la seguridad alimentaria obligan a primar a aquellas cooperativas que actúen de forma acorde con los requerimientos crecientes del mercado en estos ámbitos. En este sentido, el Grupo Arcoíris controla al 100\% todos los procesos de producción con el objetivo de obtener la máxima calidad. Realiza el seguimiento completo del animal, a partir de la selección genética, y siguiendo la alimentación, crecimiento, cría y cuidados veterinarios que se le aplican. La trazabilidad se mantiene en el proceso de sacrificio, despiece y secadero propio. Todo ello utilizando métodos tradicionales e incorporando los avances tecnológicos para garantiza la calidad de los productos.

Cuestión 3. ¿Deberían tener los Consejos Rectores de las sociedades cooperativas dirigentes altamente cualificados y los socios cooperativistas mentalidad empresarial?

Sí que deberían contar los consejos rectores con este tipo de dirigentes, debido a que la gestión de la mayoría de estas cooperativas debe estar en manos cualificadas, por lo que es necesario profundizar en la profesionalización en los puestos directivos, sumada al incremento de la mentalidad empresarial de los socios. La cualificación permite alcanzar objetivos que redundan en un mejor funcionamiento interno y aumentan la competitividad de la organización.

Por otra parte, es necesaria la participación de los socios en la gestión de la organización y la adopción de una actitud activa, por lo que deben cobrar un renovado protagonismo en la elección y control de dirigentes cualificados y con mentalidad empresarial para un mejor funcionamiento y competitividad de la sociedad. En este sentido, se puede poner como ejemplo en Aragón, la Escuela Aragonesa de Directores de Economía Social que viene realizando su labor formativa desde 1963. Actualmente, el Estudio Propio en Experto Universitario en Dirección de Empresas de Economía Social (EUDEES) (http://eues.unizar.es/), se trata de un Estudio Propio de Postgrado de la Universidad de Zaragoza, que pretende ser una herramienta de formación para la creación, dirección y fomento de empresas de Economía Social en Aragón.

\subsection{CONCLUSIONES}

ARCOIRIS ha demostrado que la industrialización de los productos agrícolas y ganaderos del Matarraña es una alternativa de futuro, que se está consiguiendo a través de una herramienta de estructuras asociativas de filosofía cooperativa. Tanto es así que en 2008, este grupo de empresas presume de negocios propios paralelos a la producción agropecuaria, como una agencia de transportes, dos gestorías con sede en Valderrobres y Alcañiz, una correduría de seguros y una agencia de viajes, entre otros.

Este grupo es un modelo que debería ser exportable a otras comarcas de Aragón y en particular a la provincia de Teruel, como una cooperativa capaz de aglutinar a toda una comarca en torno a un proyecto fundamentalmente agropecuario que explote los recursos endógenos de la zona, que son fundamentalmente la agricultura y ganadería, extendiendo su actividad a todo el proceso productivo con la producción de piensos, engordes, mataderos y comercialización del jamón denominación de origen de Teruel, 
actividades cunícolas y avícolas, complementadas con la producción de aceite del bajo Aragón, almendras y producción de quesos artesanales. Podríamos decir que es el modelo ideal exportable a otras zonas azotadas por la despoblación y la crisis de la agricultura y ganadería, fundamentalmente en la provincia de Teruel. Al mismo tiempo, da trabajo a más de 300 personas y contribuye a mantener la población en los pequeños pueblos limítrofes a Valderrobres, que es el núcleo donde se desarrollan todas las principales actividades agroindustriales de la comarca.

El principal logro de esta iniciativa empresarial creada por un grupo de emprendedores de la zona, que ha conseguido relanzar una comarca despoblada y siendo los jóvenes los más perjudicados teniendo que emigrar durante años a otras regiones en busca de trabajo, es que se ha logrado el asentamiento de la población, que unido a la promoción del turismo de calidad, y el establecimiento de negocios hosteleros, muchos de ellos con capital extranjero, atraídos por la belleza de su paisaje natural han desarrollado otra actividad importante como es la compra de antiguas masías abandonadas y su completa restauración para transformarlas en negocios hosteleros que han atraído turismo nacional y extranjero. 


\section{ATADI: AGRUPACIÓN TUROLENSE DE ASOCIACIONES DE PERSONAS CON DISCAPACIDAD INTELECTUAL}

\section{RESUMEN:}

La problemática de la Discapacidad Intelectual hace que las organizaciones que la abordan tengan especial interés. Estas organizaciones se integran en el Tercer Sector de Acción Social, dando cobertura y asesorando a todas las asociaciones que se ocupan de ello. La Agrupación Turolense de Asociaciones de Personas con Discapacidad Intelectual (ATADI) es una entidad no lucrativa cuyos valores éticos se definen en su actividad, que es la de ofrecer ayuda a las personas con discapacidad, cuyo ámbito de actuación es la provincia de Teruel y el pilar básico para su funcionamiento es el voluntariado. 


\subsection{INTRODUCCIÓN}

La Agrupación Turolense de Asociaciones de personas con Discapacidad Intelectual ATADI es una entidad sin ánimo de lucro, se crea en el año 2005 y es el resultado de la unión de asociaciones y entidades integradas en ella, cuya representación ostenta en el ámbito provincial (figura 1). Tiene personalidad jurídica propia y, en consecuencia, goza de plena capacidad para ser sujeto de derechos y obligaciones en los términos previstos por sus Estatutos y las Leyes. Es una entidad sin ánimo de lucro y los beneficios económicos que eventualmente se pudieran obtener se aplicarán íntegramente para el cumplimiento de sus objetivos. En 2018 atiende aproximadamente a 280 personas con discapacidad, por medio de "centros de día", "centros ocupacionales", residencias, un piso tutelado y un centro especial de empleo. Trabajan 155 personas y, de ellas, el $91 \%$ son mujeres y 5 son personas con discapacidad intelectual. El ámbito de actuación se extiende a todo el territorio que comprende la provincia de Teruel y basa su actuación en la democracia interna, la transparencia en su actuación y la solidaridad entre sus miembros. Además, colabora habitualmente con centros educativos, contando actualmente con 4 trabajadoras de Formación Profesional Dual. Además, en "ATADI Empleo, S.L.U.", trabajan otras 30 personas (23 hombres y 7 mujeres). En total, el empleo directo que genera la organización, en estos momentos, es de 189 personas.

Figura 1: Asociaciones Fundadoras que componen la Asociación

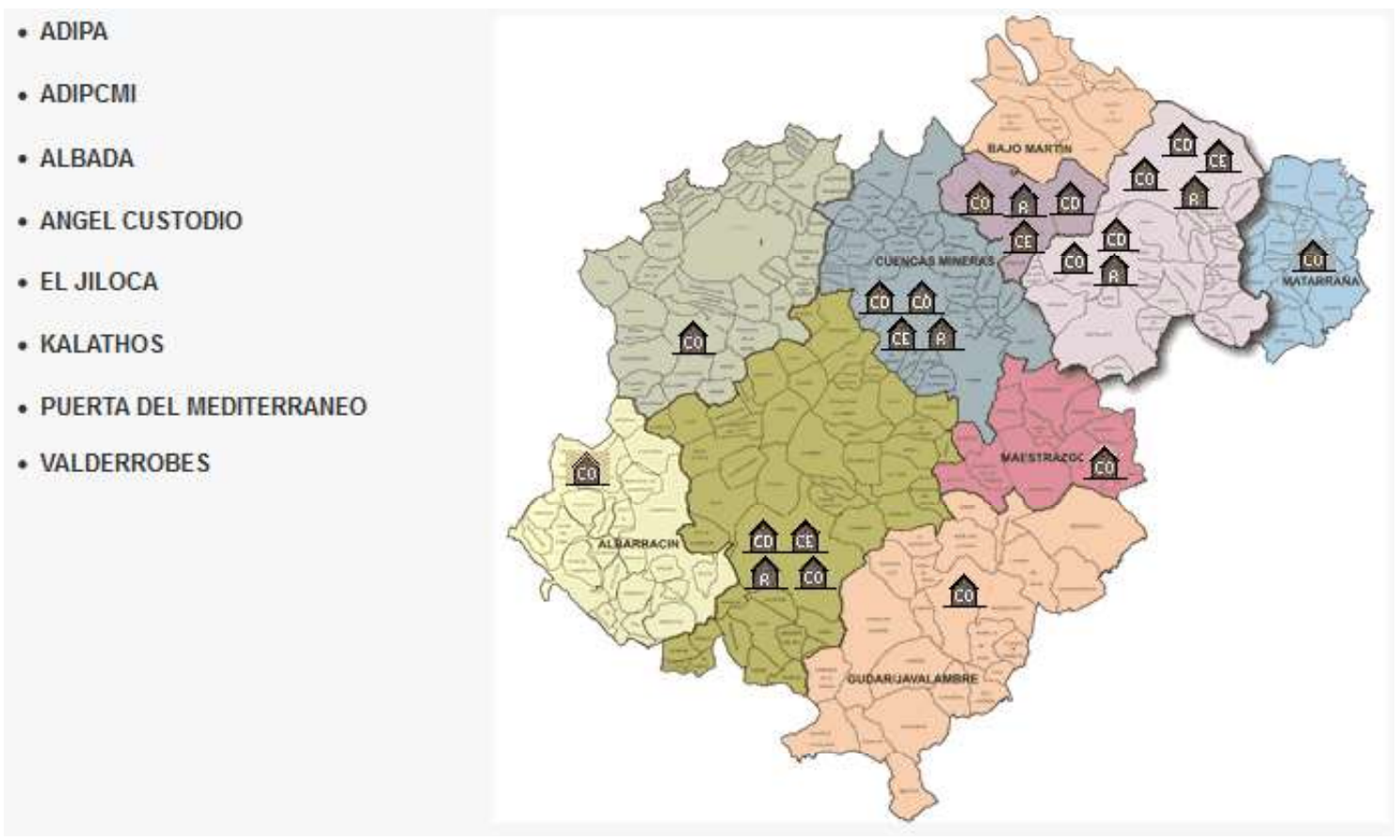

Fuente: Atadi.es

La definición de la discapacidad, como la de cualquier otro fenómeno social, es algo que se va construyendo socialmente. Las soluciones ante los retos que plantea la discapacidad han de abarcar muchos aspectos que van más allá de las definiciones 
(Jiménez Lara, 2007). La discapacidad adquiere sentido en el contexto de una cultura y, en ella, depende del sentido asignado a otros conceptos culturalmente próximos.

FEAPS es un conjunto de organizaciones familiares que defienden los derechos, imparten servicios y son agentes de cambio social. Grupos de padres informados, preocupados y muy involucrados se fueron dando cuenta de la necesidad de crear asociaciones que dieran respuesta a sus necesidades y que respaldasen sus demandas ante la Administración. Dichas asociaciones nacieron con una vocación apolítica, en las que se daba cabida a todos los afectados, sin tener en cuenta clases sociales. En la comunidad autónoma de Aragón existen numerosas entidades con este fin. En la provincia de Teruel ATADI es una organización con presencia en toda la provincia dedicada a la atención y cuidado de personas con discapacidad intelectual y al apoyo de sus familiares. En figura 2 se presenta su página web.

Figura 2. Web de Atadi

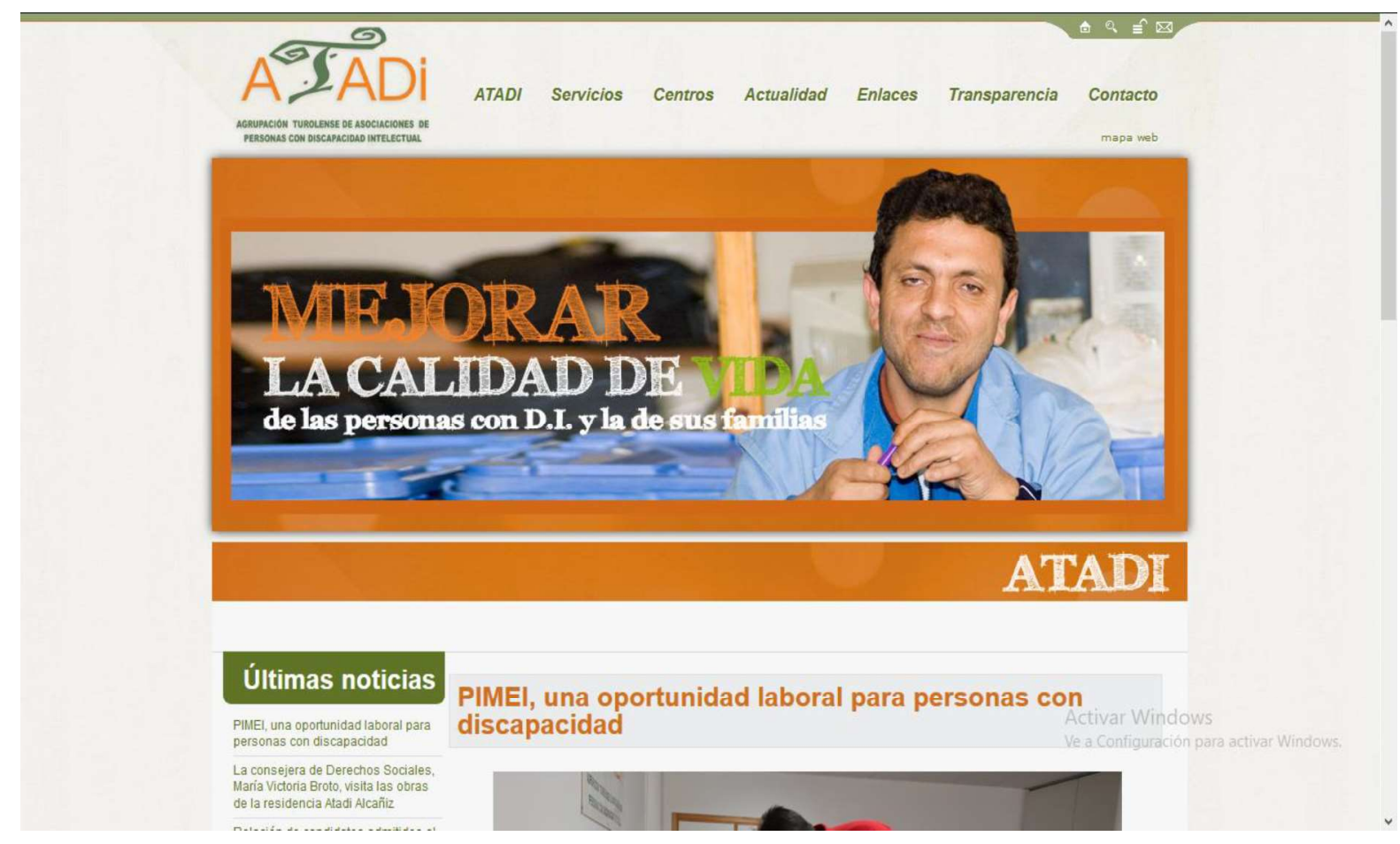

Fuente: http://www.atadi.es/

\subsection{DESARROLLO DEL CASO ATADI}

Las entidades sin ánimo de lucro necesitan convertirse en organizaciones de aprendizaje constante, adaptándose y cambiando para promover sus puntos fuertes y reducir sus debilidades. La misión, valores e ideología de la entidad tienen una importancia estratégica fundamental. Estos son los que en definitiva van a permitir diferenciarla de otras iniciativas. Lo realmente importante es la prestación de servicios adecuados y alineados con los valores que identifican a la organización. Una fortaleza debe ser la 
flexibilidad y la innovación constante para mejorar el servicio y las expectativas de los diferentes grupos de interés (Saz Gil, 2008).

\section{Valores y Misión}

Los Valores que defiende son, la consideración de la persona con discapacidad como sujeto con igualdad de derechos y deberes, la calidad como norma principal en la actuación de las organizaciones, la importancia de las familias y el interés de la globalidad del colectivo de personas con discapacidad.

La Misión de ATADI es contribuir, desde su compromiso ético, con apoyos y oportunidades, a que cada persona con discapacidad intelectual o del desarrollo y su familia puedan desarrollar su proyecto de calidad de vida, así como a promover su inclusión como ciudadana de pleno derecho en una sociedad justa y solidaria.

\section{Personas}

ATADI atiende a las personas con Discapacidad Intelectual, principalmente, y aquellas otras personas con discapacidad, dependencia, riesgo de exclusión o socialmente desfavorecidos que puedan compartir sus proyectos y servicios.

\section{Servicios}

La gama de servicios con la que cuenta ATADI es muy amplia y van dirigidos directamente a los usuarios de la asociación y a los familiares, sin descuidar a sus propios trabajadores.

Asistenciales: proporcionan una atención integral a la persona y son el soporte para el desarrollo de programas individualizados, potenciando su integración social y laboral y apoyando con servicios de vivienda exclusivos, de forma temporal o permanente, si así lo requieren (Centro de día Ocupacional, Asistencial, Vivienda).

De ajuste personal y social: potencian las habilidades de comunicación, auto-cuidado, vida en el hogar, habilidades sociales, salud y seguridad, ocio y tiempo libre, etc.

Multiprofesionales: psicología, trabajo social, fisioterapia, terapia ocupacional y formación.

Complementarios personalizados: transporte, comedor y acompañamiento sanitario.

A familias: información, formación y apoyo a familias. Realizan actividades que contribuyen al descanso familiar y ayudan a sobrellevar las situaciones de dificultad por internamiento hospitalario o enfermedad de uno de los familiares.

De formación: de trabajadores tanto interna y con medios propios o ajenos como la externa, grupos de educación de adultos en el departamento de educación del Gobierno de Aragón, para trabajadores y desempleados en el INAEM, atención socio-sanitaria a personas dependientes en instituciones sociales y en su domicilio, cuidador de enfermos de Alzheimer. 


\section{Programas}

Dispone de diversos programas para favorecer la integración de las personas con discapacidad en la sociedad, como, por ejemplo, el de desventaja social, intercambio ocupacional, atención temprana, reeducativos de trabajos en beneficio de la comunidad, etc. Sin embargo, el programa más importante de ATADI es el Programa de Voluntariado, en el que participan personas comprometidas con edades comprendidas entre los 14 y 65 años. La asociación realiza actividades de sensibilización, difusión, captación y fidelización de voluntariado, acompañan en actividades formativas, deportivas, programas de vacaciones, de ocio y tiempo libre. También coorganizan eventos y actividades (Catalán, 2018).

\section{Estudio con metodología SROI del Centro Atadi - Kalathos de Alcorisa}

El Retorno Social de la Inversión (SROI) es un método que añade principios de medición del valor extra-financiero en relación a los recursos invertidos, es decir, el valor social que actualmente no se refleja en las cuentas financieras convencionales, que está desarrollado a partir de un análisis tradicional de costo-beneficio y la contabilidad social, siendo un enfoque participativo que permite capturar en forma monetaria el valor de una amplia gama de resultados, tengan éstos un valor de mercado o no.

A continuación, se presenta los resultados más relevantes del estudio desarrollado a través de la metodología SROI para conocer y visibilizar los beneficios sociales, laborales y económicos que la actividad que el Centro Atadi - Kalathos de Alcorisa aporta, determinando el retorno económico y social que produce cada euro invertido por la administración en su actividad, para los distintos grupos de interés (ISASS, 2014).

El Centro Atadi - Kalathos de Alcorisa es uno de los 10 centros gestionados por la Agrupación Turolense de Asociaciones de personas con Discapacidad Intelectual (ATADI).En este centro se desarrollan servicios básicos de residencia, Centro de Día y Centro Ocupacional así como servicios complementarios de comedor, transporte, fisioterapeuta, psicomotricidad, respiro, formación, enfermería, actividades físicodeportivas, actividades de ocio y tiempo libre y escuela de familias, psicología, trabajo social, terapia ocupacional, etc. Actualmente, presta apoyos y servicios a 38 personas con Discapacidad Intelectual (el 64\% mujeres y el 37\% hombres). La mayoría (el 92\%) tiene un grado de discapacidad reconocido del 65\% o más, presentando necesidades de apoyo extenso o generalizado.

- Por cada euro invertido en el funcionamiento del Centro Atadi - Kalathos en 2013 (tanto público como privado) procedente tanto de las administraciones públicas $0,71 €$, del copago de las personas con discapacidad usuarias $0,28 €$, como de otras fuentes de financiación privada $0,01 €$, el Centro ha conseguido retornar a la sociedad con su actividad 1,48 $€$ (en retornos sociales y económicos), y supone ahorros en sobrecostes para los Sistemas de Protección Social, para las personas y las familias, de $1,97 €$. 
- El retorno económico y social de la actividad del Centro Kalathos sobre la inversión total realizada (pública y privada) para su funcionamiento durante 2013 asciende a 1.340.335,07 € (un 148\%) en retornos económicos directos, retornos indirectos para las familias, valor social de voluntariado y resultados en calidad de vida.

- Además, la existencia de este Centro supone un ahorro para los Sistemas de Protección Social, para las personas usuarias y para las familias, de 1,97 euros (un 197\%) por cada euro de inversión total. En concreto, un ahorro de $1.786 .793,35$ euros.

- Aporta soluciones adecuadas a la diversidad de su población, arraigo y asentamiento de población en el territorio rural, oportunidades de desarrollo económico y laboral (en particular, como yacimiento de empleo femenino).

\section{Gestión del Voluntariado}

La gestión del voluntariado debe seguir un ciclo de gestión en el que se identifican varias etapas claramente diferenciadas con el objetivo de satisfacer las expectativas de los voluntarios y de retener los (Saz y Zardoya, 2014). ATADI tiene un modelo de gestión del voluntariado profesionalizado que sigue diferentes etapas, desde actividades de captación hasta la desvinculación y posterior relación con ex-voluntarios (figura, 2). Las etapas establecidas por ATADI son las siguientes (Catalán, 2018):

Acciones de sensibilización, captación y promoción de voluntariado

Tiene el objetivo de dar a conocer la posibilidad de realizar voluntariado, y especialmente con el colectivo de personas con discapacidad intelectual con el cual trabajan, realizando acciones en Teruel y sus localidades, como, por ejemplo, en el IES Santa Emerenciana de Teruel, el IES Bajo Aragón de Alcañiz, en el Campus Universitario de Teruel o en el Colegio Justicia de Aragón de Alcorisa.

Las acciones de sensibilización y promoción de voluntariado dan como resultado nuevas solicitudes de personas que quieren hacerse voluntarias de ATADI, en mayor medida ocurre con los alumnos de los IES debido a que su edad les permite participar como voluntarios y anualmente se incorporan nuevos voluntarios coincidiendo con inicio del curso escolar. Cuando surgen necesidades concretas de voluntariado, se programan actuaciones más breves y específicas utilizando medios a su alcance, como redes sociales (Facebook), aparición en el Boletín de la Coord. Aragonesa de Voluntariado, el boca a boca o cartelería, prensa y sesión informativa. 
Figura 2. Ciclo de Gestión del Voluntariado

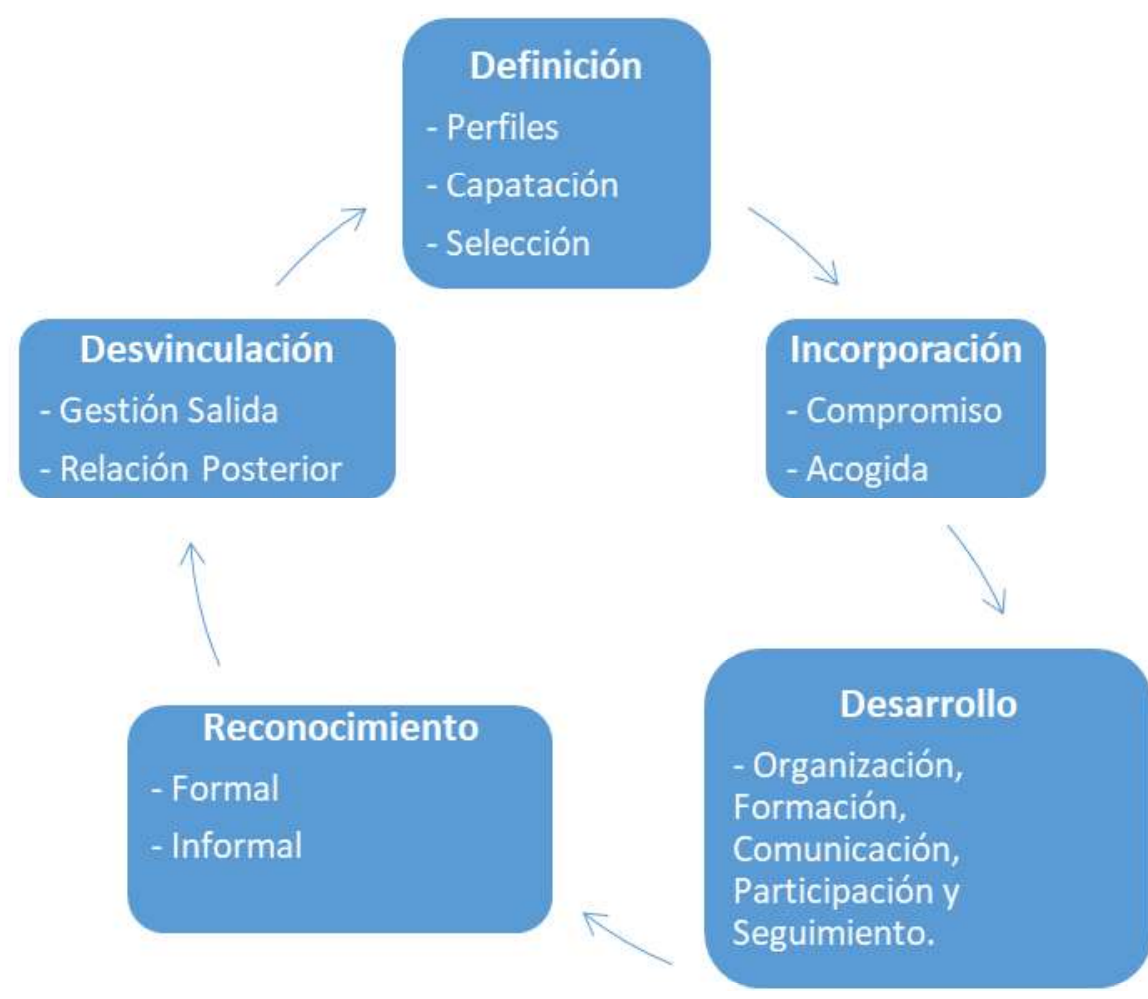

Fuente: Elaboración propia

Acogida, orientación y acompañamiento a la persona voluntaria

Se realiza a lo largo de todo el año cuando un voluntario se incorpora a la entidad y el procedimiento que siguen es el siguiente:

- Entrevista inicial, agradeciéndole el acercamiento y precisándole información de proceder de ATADI. A la vez se recoge información sobre el voluntario sobre motivaciones, disponibilidad horaria experiencia, etc.

- Posteriormente se valora la posible incorporación o no de la persona, y se acuerda la colaboración, firma autorización en caso de ser menor de edad, compromiso de confidencialidad, contratación del seguro de voluntariado y entrega del carnet de voluntariado.

- Al comienzo del voluntariado se le da una orientación sobre tareas a realizar, información sobre usuarios, características del grupo, conductas significativas, funciones a desempeñar, persona de referencia en caso de cualquier problema, etc.

- El acompañamiento a la persona voluntaria se realiza desde el primer momento que decide colaborar con la entidad, se le intenta acercar de forma progresiva al objetivo de la entidad y a los objetivos y actuación en el programa, actividad o servicio en el que va a colaborar sin perder de vista la necesidad de hacerle sentir partícipe, integrada y bienvenida. 


\section{Formación del voluntario}

Es un derecho para el voluntario y es necesaria para la correcta implicación de la persona voluntaria en la entidad, en concreto se realizan actividades como, por ejemplo, el curso básico "Qué es ser voluntario", un curso específico de "Voluntariado con personas con discapacidad intelectual", una sesión "acercándonos a la discapacidad" y formación para profesionales de ATADI relacionados con el voluntariado. Por último, siempre se les informa a los voluntariados de información interesante para el desarrollo de sus funciones.

\section{Reconocimiento}

El reconocimiento que reciben los voluntarios por parte de ATADI es de dos tipos. Uno formal, en el que se reconoce la labor de los voluntarios y tiene lugar en la conmemoración del "Día Internacional del Voluntariado" (5 diciembre) en Alcañiz, Alcorisa, Andorra y Teruel. Otro informal, en el que se cuida el reconocimiento a su labor en la entidad a través de felicitaciones de navidad, comidas, etc. También hay un agradecimiento público en medios de comunicación, como, por ejemplo, artículos en la sección "Avanzamos" del Diario de Teruel.

\section{Despedida de la persona voluntaria}

Siempre se realiza una entrevista de forma cálida con la persona voluntaria que decide dejar la entidad, con el fin de conocer el motivo por el cual no seguirá colaborando, valorar qué tal se ha sentido en la entidad, si se han cubierto sus expectativas, etc. y dejando siempre la posibilidad de que pueda volver en un futuro si lo desea. Realizan una encuesta de fin de actividad y otra de desvinculación. Además, se envía por correo una carta de despedida y un certificado de participación y se procura seguir manteniendo el contacto con los voluntarios de forma periódica felicitándolos por navidad y enviándoles el boletín de ATADI por e-mail.

\subsection{CUESTIONES PARA DISCUSIÓN}

Cuestión 1. ¿Qué implicaciones tiene la utilización de la metodología SROI para el éxito de ATADI?

La gestión de las Organizaciones No Lucrativas (ONL) ha de orientarse tanto hacia la consecución de legitimidad social, como a la obtención de capacidades competitivas para hacer frente a los retos que tienen que afrontar (Saz Gil, 2008). La participación en la adopción de decisiones por parte de los diversos stakeholders o grupos de interés son muy relevantes en el éxito. Además, el éxito de las ONL depende de la coherencia entre el planteamiento ideológico -los valores sociales que comparten los promotores, generan estrechos vínculos en su interior y facilitan el enlace con el entorno más próximo-, el modelo organizativo -que permite la coexistencia de trabajadores remunerados y de voluntarios- y el funcionamiento real de la organización. (Rodríguez Fernández y Saz Gil, 2011). En este sentido, una de las características del proceso de 
análisis de la metodología SROI es que es altamente participativo. Mediante el estudio realizado se pretende conocer y visibilizar los beneficios sociales, laborales y económicos que la actividad de este Centro aporta, determinando el retorno económico y social que produce cada euro invertido por la administración en su actividad, para los distintos grupos de interés: las propias personas con discapacidad usuarias, sus familias, los/as profesionales que trabajan en el Centro, las personas voluntarias que colaboran con las actividades del Centro, otras entidades y organizaciones del territorio, las administraciones públicas, el municipio de Alcorisa, la comarca de Bajo Aragón y otras colindantes.

Cuestión 2. ¿Cuáles son las principales estrategias de ATADI?

Como señalan diversos estudios las organizaciones no lucrativas (ONL) son entidades orientadas hacia una pluralidad de objetivos, que no reparten beneficios y en cuya base se encuentra la confianza, la adhesión voluntaria, la colaboración mutua y la participación en la adopción de decisiones. Estos rasgos distintivos facilitan las relaciones con el entorno y permiten ampliar su compromiso a través de redes de cooperación (Rodríguez Fernández y Saz Gil, 2011). Los teóricos del capital social están de acuerdo en que los actores mejor conectados en su red poseen una ventaja competitiva sobre los pobremente conectados. La perspectiva de redes nace como contraste a una visión atomística, cuando se habla de una red, se entiende como un grupo de individuos que, en forma agrupada o individual, se relacionan con otros con un fin específico (Saz-Gil et al., 2016). La estrategia de ATADI se basa en dos aspectos: la penetración en el territorio, a través de alianzas con otras entidades y asociaciones de la provincia; y en la diversificación de actividades buscando la colaboración con otras entidades ya existentes.

Cuestión 3. ¿Cuáles pueden considerarse las claves del éxito de la gestión del voluntariado de ATADI?

La participación en las Organizaciones No Lucrativas a través del voluntariado permite un triple beneficio, tanto para las personas beneficiarias de la ayuda solidaria, como para los voluntarios que aumentan su formación integral como persona, $\mathrm{y}$, en tercer lugar, para la sociedad en su conjunto mejorando el bienestar en el entorno. La gestión del voluntariado debe seguir unas fases y es relevante que exista un responsable de voluntariado que permita un adecuado seguimiento de la acción voluntaria (Saz y Zardoya, 2014). ATADI tiene un modelo de gestión del voluntariado profesionalizado que sigue diferentes etapas, desde actividades de captación hasta la desvinculación y posterior relación con ex-voluntarios. El programa más importante de ATADI es el Programa de Voluntariado, en el que participan personas comprometidas con edades comprendidas entre los 14 y 65 años. 


\subsection{CONCLUSIONES}

La Agrupación Turolense de Asociaciones de Personas con Discapacidad Intelectual (ATADI), una entidad integrada en el Tercer Sector de Acción Social turolense. Ya que organizaciones que trabajan en el ámbito de la discapacidad se integran en el Tercer Sector de Acción Social (TSAS), regulado por la Ley 43/2015. Este sector lo conforman aquellas organizaciones de carácter privado, surgidas de la iniciativa ciudadana o social, bajo diferentes modalidades, que responden a criterios de solidaridad y de participación social, con fines de interés general y ausencia de ánimo de lucro, que impulsan el reconocimiento y el ejercicio de los derechos civiles, así como los de los derechos económicos, sociales o culturales de las personas y grupos que sufren condiciones de vulnerabilidad o que se encuentran en riesgo de exclusión social. El TSAS trabaja con voluntariado, por ello es importante la Ley 45/2015, que identifica los distintos tipos de voluntariado

La estrategia de ATADI se basa en dos aspectos: la penetración en el territorio, a través de alianzas con otras entidades y asociaciones de la provincia; y en la diversificación de actividades. Una de las fortalezas de la organización es haber logrado incrementar la concienciación ciudadana con la discapacidad y con las entidades sociales que trabajan en ese ámbito. El voluntariado constituye un motor de la organización por lo que su gestión está profesionalizada y se identifican diferentes tipologías.

La influencia de ATADI en la provincia de Teruel es muy alta, ya que es una entidad que tiene presencia en toda la provincia y es reconocida tanto por los ciudadanos como por las diferentes instituciones locales que actúan en la provincia. Un ejemplo de la relevancia que tiene en la provincia de Teruel es el reconocimiento conseguido a través del Premio Empresa 2017.

ATADI cuenta con una mayoría de voluntarios ocasionales (89\%), es decir, participan en los eventos que organizan a lo largo del año en la provincia de Teruel y a los que acuden voluntarios de otras entidades, el 11\% restante son fijos, y en este caso coinciden que son personas jubiladas, con familiares usuarios de ATADI. En cuanto al género del voluntariado hay un $60 \%$ de mujeres por un $40 \%$ de hombres. Todos coinciden en la importancia de ayudar a los demás (Catalán, 2018).

ATADI sigue paso por paso todo el proceso del ciclo de gestión del voluntariado. La relación se inicia con una ficha de registro y la firma de un acuerdo de confidencialidad. El proceso cuenta un programa de seguimiento de la acción voluntaria en el que se tiene en cuenta la opinión del voluntario y sus propuestas de mejora para la organización, además la organización puede conocer la satisfacción del voluntario a través de encuestas, al fin de la actividad y al término de la relación de colaboración se cumplimenta una encuesta de desvinculación. 


\section{CEREALES TERUEL: SOCIEDAD COOPERATIVA DEL ALTO TERUEL}

\section{RESUMEN:}

Cereales Teruel Sociedad Cooperativa es una sociedad de economía social, primando lo colectivo frente a lo individual. Actualmente, la empresa está compuesta por más de 2500 socios agrupados en diez secciones que se ubican en distintos puntos de la provincia de Teruel (España). Esta cooperativa apuesta por el mantenimiento de la población en el medio rural y la vertebración del territorio ofreciendo un medio de subsistencia para el desarrollo de la región. El modelo cooperativo da seguridad y fortaleza a sus socios, permitiendo a Cereales Teruel seguir creciendo y diversificando su actividad. La cooperativa ha creado puestos de trabajo por todas las comarcas del Alto Teruel y sus actividades, incluso han permitido que en algunos pueblos se mantenga abierta la escuela. 


\subsection{INTRODUCCIÓN}

La Cooperativa Cereales Teruel fue fruto de un largo proceso que comenzó con la constitución de la cooperativa comarcal La Albónica. Paulatinamente se hizo evidente la necesidad de contar con una estructura cooperativa fuerte, que permitiera a los agricultores ser competitivos. En el año 1989 ocho cooperativas de primer grado del alto Teruel, Fuente de Cella, Campo de Visiedo, Bañón, La Val, Valondo, Albónica, Tosi y San Isidro de Villarquemado, unieron sus fuerzas para crear Cereales Teruel bajo la figura de cooperativa de segundo grado, permitiéndoles realizar una gestión más eficaz en la comercialización de sus productos y obtener una serie de servicios, indispensables para todas ellas, que por separado no podrían conseguir.

En 2003, se convirtió en una cooperativa de primer grado a través de la fusión por absorción de la mayor parte de las cooperativas asociadas para optimizar sus recursos y simplificar la gestión. En la actualidad Cereales Teruel Sociedad Cooperativa cuenta con más de 2500 socios repartidos en nueve secciones: Sierras del Jiloca, Sierras del Pobo, Alto Jiloca, Cereales del Huerva, Campo de Bello, Campo de Visiedo, Albónica, La Val, Bañón.

Figura 1. El camino de Cereales Teruel

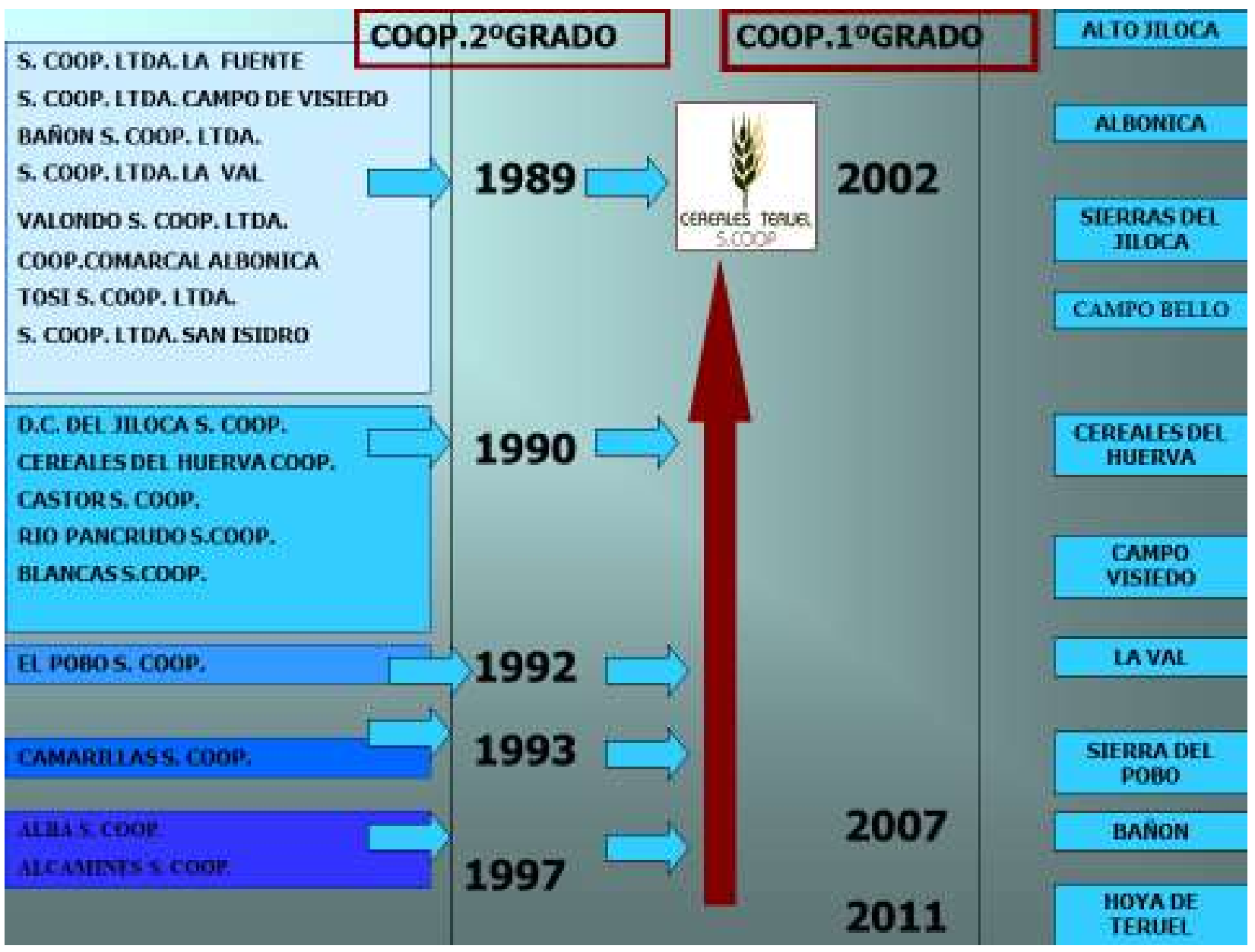

Fuente: I Taller de Economía Social Campus de Teruel, 2012 
Entre las razones aducidas para la fusión por absorción se encuentran las siguientes: limitación fiscal a participación en S.A./S.L. Al 50\% de Fondos Propios, consolidación balances, optimización recursos financieros, unificar estrategias, optimización recursos humanos, disminución trabajo administrativo, optimización fiscal, problemas relevo cargos en cooperativas pequeñas, capitalización deficiente en cooperativas pequeñas, jubilación socios y devolución capital social.

El esquema de funcionamiento es de una cooperativa de primer grado con una organización por secciones (comarcas), nombramiento de una junta en cada sección, consejo cooperativo con un representante de cada sección; convergencia ritmos capitalización de secciones; criterios uniformes para decisión nuevas inversiones; posibilidad constitución nuevas secciones para otras actividades.

La sede central se sitúa en el centro histórico de la ciudad de Teruel y coordina los diferentes centros de gestión que representan a todos los socios. Estos centros cuentan con todos los recursos materiales y humanos para ofrecer el mejor servicio a los socios y usuarios de la cooperativa. Se diferencia de otras empresas en el modelo empresarial ya que es una sociedad de economía social, por lo que prima lo colectivo frente a lo individual.

Figura 1. Página web oficial de Cereales Teruel

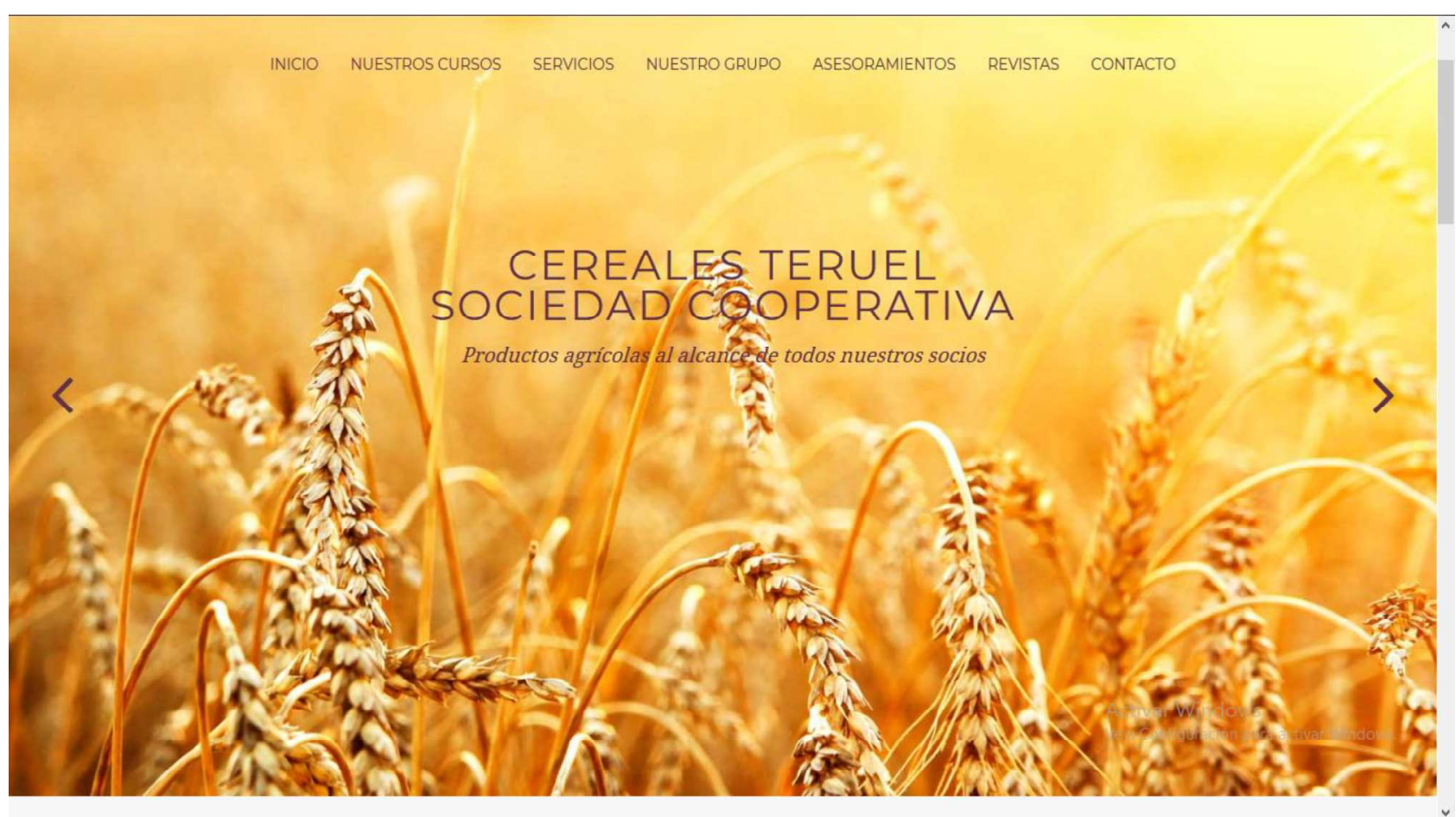

Fuente: $\underline{w w w . c e r e a l e s t e r u e l . c o m ~}$ 


\subsection{DESARROLLO DEL CASO CEREALES TERUEL}

\section{La cooperativa como motor de desarrollo de las comarcas turolenses}

Con un capital social de 6.500.000 euros, 30 trabajadores fijos, Cereales Teruel es uno de los motores de la economía de la provincia ya que se extiende por todas las comarcas del Alto Teruel. Aproximadamente comercializa el 60\% de la superficie que ocupan los cultivos de cereales en la provincia de Teruel, además de cebada, trigo, maíz, centeno, fertilizantes y gasoil. Está comprometida con cada uno de sus socios, se involucra en diferentes proyectos y actividades directamente relacionadas con las principales líneas de actuación de la cooperativa. En concreto, uno de los objetivos ha sido unificar e impulsar el desarrollo del territorio.

La cooperativa siempre ha apostado por crear o participar en empresas ya consolidadas que garantizaran sus suministros y facilitaran la comercialización de sus productos. Un ejemplo de estas empresas son Gasóleos Teruel S.A., Grupo Agrimartín, Mercacoop (Agrimail. Agricultura y Alimentación S.L.), Cereales Teruel S.L. y Porcino Teruel S.A., con esta última perseguía que sus cereales se quedasen en su territorio, cerrando el ciclo productivo desde la obtención del cereal hasta la comercialización de la carne de porcino. En el año 2010, se constituye Turoleólica, una empresa constituida por Gasóleos Teruel S.A. (50\%) y el grupo Térvalis (50\%), para el desarrollo de parques eólicos en el ámbito del Alto Teruel. Otra alianza estratégica es la conseguida con Caja Rural de Teruel, para garantizar el apoyo en las inversiones. En la figura 1 muestra el organigrama de Cereales Teruel sociedad cooperativa y se observa la diversificación relacionada que ha ido desarrollando en su estrategia de crecimiento.

Figura 1. Organigrama empresarial Cereales Teruel

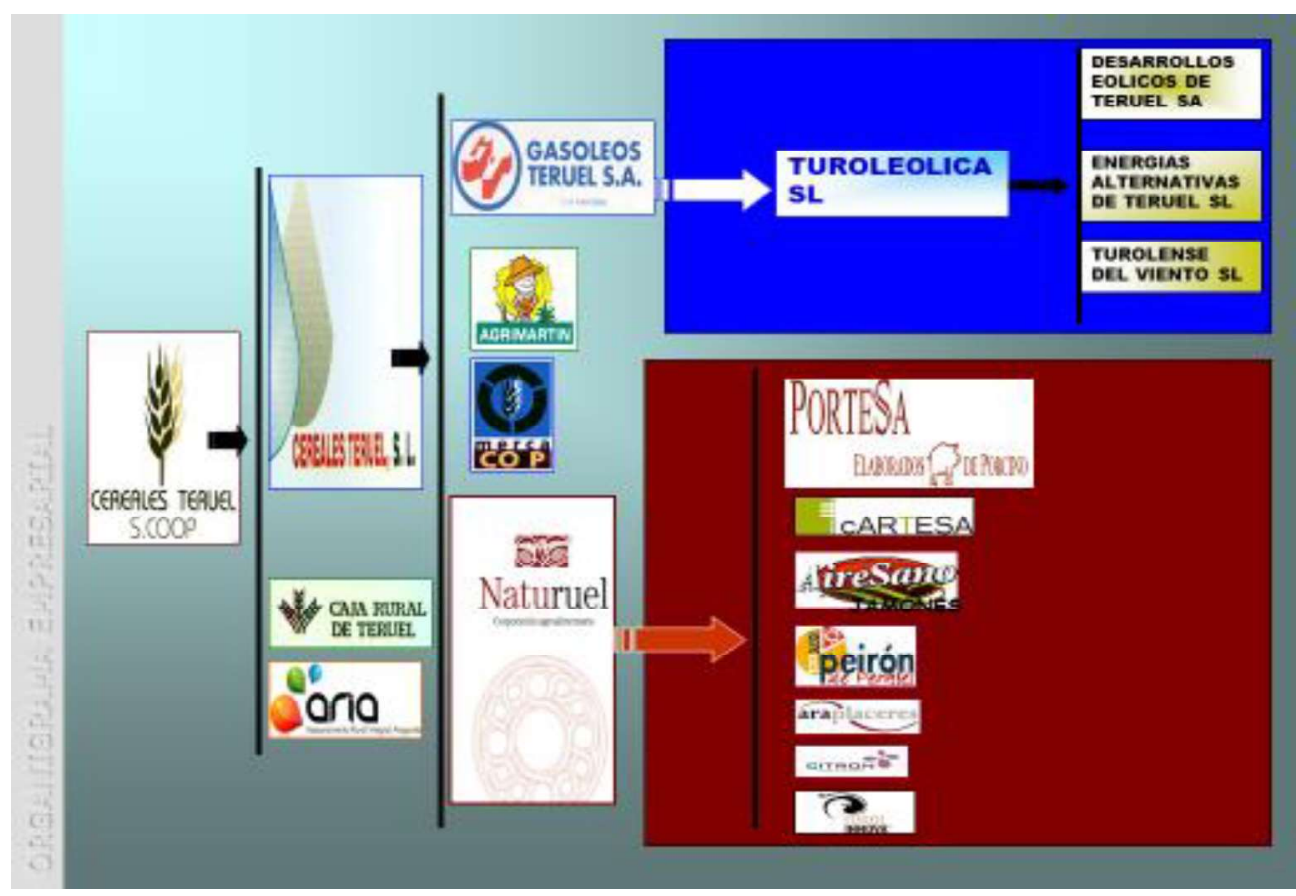

Fuente: I Taller de Economía Social Campus de Teruel, 2012. 
Cereales Teruel se dedica a la comercialización de productos agrícolas. Cuenta con más de 2.500 socios agrupados en 10 secciones ubicadas en municipios de Alto Teruel:

Albónica, Alto Jiloca, Bañón, Campo de Bello, Campo de Visiedo, Cereales del Huerva, La Val, Sierras del Jiloca, Sierras del Pobo y La Hoya de Teruel. En la Figura 2 se presenta el ámbito de actuación en la provincia de Teruel

Figura 2. Localización actividades en la provincia de Teruel

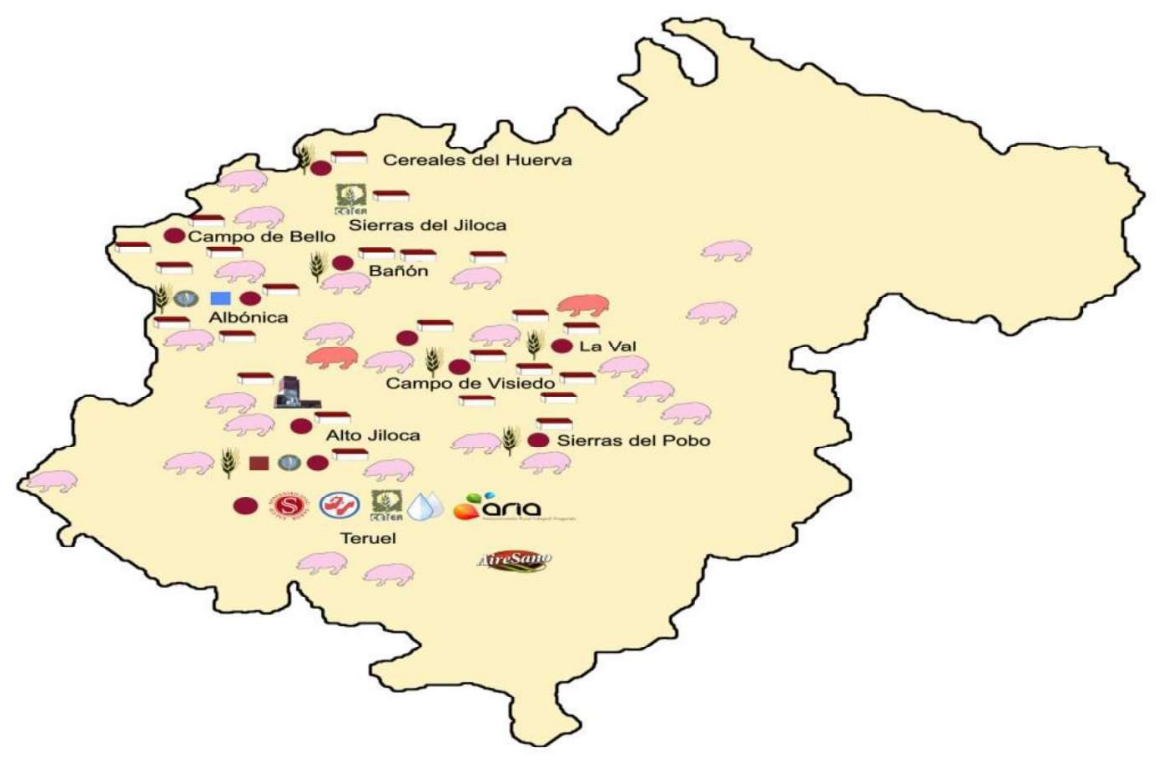

Fuente: I Taller de Economía Social Campus de Teruel, 2012.

\section{Servicios}

Cereales Teruel Sociedad Cooperativa es productor multiplicador de semillas de cereal y forrajeras, llevando a cabo alrededor de $2.000 \mathrm{Tm} /$ año de certificación y cumpliendo exquisitamente, no sólo el marco legal sino también el comercial. CETER S. Coop. cuenta con el certificado de inscripción en el registro oficial de productores multiplicadores de semilla de cereales y forrajeras $\mathrm{N}^{0}$ ES / 02 / 44-0126 desde el año 1994. Del volumen certificado un $60 \%$ es de semilla de cebada y un $40 \%$ de trigo. A su vez, nuestros centros de selección están inscritos para habilitar grano, cumpliendo escrupulosamente con la normativa que los regula y son inspeccionados habitualmente por el organismo responsable (Centro de Semillas y Plantas de Vivero). Uno de nuestros centros, situado en Bañon, se encuentra reconocido para llevar a cabo la certificación de semilla de producción ecológica.

Para llevar a cabo las producciones de los socios, la cooperativa comercializa los inputs básicos: 1) Fertilizantes: desde los almacenes se distribuyen más de $20.000 \mathrm{tm}$ de fertilizantes de fondo y de cobertera. 2) Gasóleo: cuenta con 30 surtidores de gasóleo agrícola que distribuyen más de 6 millones de litros.

Los agricultores son productores de alimentos, llevando a cabo un tipo de agricultura familiar, sostenible y respetuosa con el medioambiente. El objetivo es proporcionar alimentos de calidad y la actividad genera empleo y vida en los pueblos, lo que les 
convierte en mantenedores del territorio. Con estas premisas la cooperativa lleva a cabo la producción de 70.000 ha de cultivo, estando reconocida como Agrupación de Productores Agrarios desde el año 1991. También, Dispone de la marca de garantía de Producción Integrada de Aragón, otorgada por el Gobierno de Aragón, siendo pionera a nivel nacional en la producción de cereal obtenidos bajo la certificación de este sello. La cooperativa se encuentra inscrita como Operador de Producción Ecológica de Aragón, siendo el producto estrella la esparceta o pipirigallo.

La preocupación por el entorno y por la conservación de su biodiversidad les ha llevado implicarnos en el proyecto Harmony, en el cual, cada uno de los agricultores dedica el $3 \%$ de sus campos al cultivo de flores melíferas, con el objetivo de favorecer la supervivencia de las poblaciones de abejas y mariposas, y asegurar la polinización. La cooperativa se encuentra reconocida como Agrupación de Tratamiento Integrado en Agricultura por el Ministerio de Agricultura y el Gobierno de Aragón para los cultivos de cereal, patata y leguminosas. El departamento técnico, integrado por personal cualificado, es el responsable de llevar a cabo el asesoramiento, control y seguimiento de nuestras explotaciones, en materia de aplicaciones fitosanitarias y de fertilización. Por otra parte, dispone de asesoramiento en materia de condicionalidad y requisitos legales de gestión, llevándose a cabo a través de los profesionales de la Asociación para el Desarrollo Rural Integral Aragonés, entidad promovida por la cooperativa.

La cooperativa Cereales Teruel, cuyo negocio se ha centrado en la producción agroalimentaria ha iniciado gestiones para diversificar su actividad a través de un proyecto que pretende desarrollar parques eólicos en la provincia. La razón de optar por diversificar su actividad hacia el sector de la energía se considera una forma de obtener dividendos que permitan a los socios paliar el incremento de las tarifas eléctricas. La energía eólica está considerada como una posibilidad más, dentro de la estrategia expansiva de la cooperativa. Además, la cooperativa ha desarrollado proyectos innovadores para desarrollar nuevos productos como por ejemplo la que persigue sustituir con guisantes las proteínas de sus piensos, hasta ahora basadas en soja. Esta innovación constituye una fórmula adecuada para la alimentación del ganado porcino (Franco, 2011).

Cereales Teruel busca alternativas a la producción convencional debido a su limitada rentabilidad por las características agroclimáticas de la provincia se lleva a cabo en dos fincas ubicadas en Monreal del Campo y Concud. Encabeza el proyecto Ceteralimenta cuyo objetivo es conseguir la diferenciación y la valorización de las producciones cerealistas de secano del Alto Teruel. Aunque aún no se tienen resultados. La gestión de los cultivos de este proyecto es distinta a los convencionales, sobre todo en lo referido al uso de abonos y herbicidas. Los costes de la producción ecológica pueden llegar a ser entre un $30 \%$ y un $35 \%$ inferiores debido sobre todo a que no son necesarios los fertilizantes minerales ni los herbicidas (Royo, 2018). 


\section{Actuaciones socialmente responsables}

Desde Cereales Teruel se pretende definir proyectos viables y reconciliar los aspectos económicos, sociales y ambientales de las actividades humanas. De ahí que desarrollen distintos planes de mejora del territorio. De acuerdo con Saz-Gil (2012), entre las acciones socialmente responsables se destacan las siguientes:

\section{- Plan de desarrollo rural}

Los presidentes de la Comarca de Teruel y de Cereales Teruel, firmaron un convenio de colaboración para difundir el Plan de Desarrollo Rural Sostenible de la Comarca a través de un espacio en la sección de actualidad de la revista "Al Grano" que edita la cooperativa. Mediante el convenio suscrito, la Comarca Comunidad de Teruel ha ido aportando recursos económicos dos años a la publicación con el objetivo de que se informe a los habitantes de la comarca de las diversas convocatorias de ayudas y subvenciones. El Plan de Desarrollo Rural Sostenible de la Comarca realizado en diferentes años. Se trata de actuaciones en el sector agrario, en acción social, en medioambiente, en iniciativas industriales, en infraestructuras dirigidas al fomento de la actividad turística y en facilitar una serie de servicios a los municipios del territorio.

\section{- Atención a los jóvenes}

Desde la cooperativa se considera que el futuro del desarrollo rural está en manos de los jóvenes. De ellos depende que continúe la actividad agraria y con ella la vertebración del territorio y el mantenimiento del hábitat. Además, la nueva política agraria que llega desde Europa apunta a que muchas de las ayudas van a ir dirigidas a jóvenes y mujeres, claves en la fijación de la población en el medio rural. Por estos motivos, el Consejo de Cereales Teruel se interesó en constituir una asociación que uniera a los socios menores de 40 años. Este colectivo se caracteriza por ser numeroso, pero dadas las particularidades territoriales, demográficas y económicas de la Comunidad Autónoma de Aragón en general y de la provincia de Teruel, en particular, estaban un poco dispersos.

Así, en la sede principal de Cereales Teruel, se constituyó la Asociación de Jóvenes Sembrando Futuro. Entre los principales objetivos que recogen sus estatutos, encontramos la formación continuada para la obtención de una cualificación profesional adecuada que permita conseguir una agricultura diferenciada, productiva y competitiva. Además, la asociación pretende defender las exportaciones agrarias y su desarrollo como actividad viable facilitando el acceso de los más jóvenes a la agricultura.

- Asesoramiento rural

La formación y el asesoramiento son prioritarios para Cereales Teruel por lo que el año pasado se constituyó la Asociación para el Asesoramiento Rural Integral Aragonés (ARIA), destinada a la prestación de asistencia y asesoramiento a agricultores, ganaderos y pobladores del medio rural. Esta entidad sin ánimo de lucro ofrece servicios de asesoramiento y condicionalidad para todo aquel socio que lo necesite. 
La condicionalidad, se refiere a una serie de condiciones o requisitos que el agricultor ha de cumplir para recibir íntegramente las ayudas que correspondan. Estos requisitos están relacionados con el medio ambiente, la salud pública, las buenas prácticas en el campo, tanto laborales como medioambientales, etc. Al principio de la creación de ARIA se expuso a los socios la posibilidad de solicitar unas ayudas al asesoramiento, subvencionadas por el Fondo Europeo Agrícola de Desarrollo Rural (FEADER), el Ministerio de Agricultura, Alimentación y Medio Ambiente (MARM) y la Comunidad Autónoma. De todos los solicitantes se eligieron a determinados agricultores, por las características de sus explotaciones, y estos recibieron una subvención que cubría el $80 \%$ del total de los costes del servicio de asesoramiento.

En el caso de agricultores jóvenes, realiza acciones de formación, como cursos de capacitación en técnicas agrarias, manipulación de fitosanitarios, fiscalidad, etc. El consejo establece unas tarifas muy ajustadas para cada uno de los servicios. Estos incluyen el seguimiento de las explotaciones y el asesoramiento ante cualquier eventualidad, también ayudan a cumplimentar y presentar todos los documentos obligatorios. Las tarifas se implantan en función del tipo de explotación, pero pensando que con o sin subvención resulten lo más económicas posibles para los socios. Muchas de las explotaciones socias de la Cooperativa ya han sido beneficiarias de las ayudas de asesoramiento de forma gratuita.

\section{- Responsabilidad social empresarial}

La revista publicada por la cooperativa, llamada Al Grano ha sido reconocida por Cointegra y el Ministerio de Trabajo e Inmigración como una buena práctica en Responsabilidad Social Empresarial de las Cooperativas Agroalimentarias Españolas. A principios del 2010, se publicó el primer Catálogo de Buenas Prácticas en Responsabilidad Social Empresarial de las Cooperativas Agroalimentarias Españolas, proyecto pionero de gran alcance y difusión, con lo que se pretendía sensibilizar al sector cooperativo sobre el concepto de Responsabilidad Social Cooperativa y poner en valor la aportación social y las características de la economía social. El catálogo recoge buenas prácticas de algunas de las cooperativas agroalimentarias españolas de mayor reputación e impacto en el sector.

Cereales Teruel ha sido seleccionada por haber puesto en marcha una publicación trimestral destinada principalmente a los socios de la cooperativa, concebida como medio de comunicación interno y vehículo para la participación de los socios. La revista Al Grano se ha considerado una buena práctica en el ámbito de las relaciones con terceros y de la comunicación.

Otras categorías del catálogo son Ambiente natural, Acción social, Creatividad y Gestión de Empresas, Gestión de Recursos Humanos e Innovación.

\section{- Los niños turolenses "se plantaron" contra el cambio climático.}

La cooperativa está volcada en la difusión para un mayor conocimiento del medio ambiente y así poder protegerlo. Un ejemplo de esta labor es la colaboración en la 
iniciativa ;Plántate!, del programa de las Naciones Unidas para el Medio Ambiente. Decenas de escolares turolenses participaron en una gran plantada de árboles que está recorriendo España para luchar contra el cambio climático. En la ciudad de Teruel, la actividad contó con la colaboración de Cereales Teruel, entre otras asociaciones turolenses. El proyecto pretende inculcar buenas prácticas medioambientales a la sociedad actual, sobre todo entre los más jóvenes. Los niños no solo plantaron árboles, sino que visionaron un documental donde se explicaban los procesos de reforestación de un bosque, las especies autóctonas de España, el proceso de vida de un árbol, etc.

\subsection{CUESTIONES PARA DISCUSIÓN}

Cuestión 1. Identifique las distintas formas de crecimiento que sigue Cereales Teruel

El crecimiento en las organizaciones es un proceso de adaptación a los cambios exigidos por el entorno y los responsables de la toma de decisiones puede establecer los cambios organizacionales necesarios con tal de que la oriente hacia una dinámica de crecimiento. Los responsables de las organizaciones tratan de establecer condiciones para orientar sus empresas de tal manera que logren crecer. Uno de los autores relevantes en la dirección estratégica Igor Ansoff señala que cuando se entiende el ambiente y se reconoce que el ambiente está en constante cambio, entonces se pueden tomar las decisiones correctas liderando las organizaciones hacia el futuro. Ansoff (1965) describe cuatro componentes de la estrategia: el ámbito de actuación, el vector de crecimiento, la ventaja competitiva y la sinergia. A través del segundo de los componentes, el vector de crecimiento, realiza la aportación de lo que hoy son conocidas como estrategias de crecimiento: penetración en el mercado, desarrollo del producto o del mercado, y diversificación estratégica. En el Caso de Cereales Teruel una de las primeras acciones llevadas a cabo fue la fusión por absorción lo que le proporciona una gran penetración en el territorio.La cooperativa siempre ha apostado por crear o participar en empresas ya consolidadas que garantizaran sus suministros y facilitaran la comercialización de sus productos, en lo que se aprecia una diversificación relacional. Un ejemplo de estas empresas son Gasóleos Teruel S.A., Grupo Agrimartín, Mercacoop (Agrimail. Agricultura y Alimentación S.L.), Cereales Teruel S.L. y Porcino Teruel S.A. Otra alianza estratégica es la conseguida con Caja Rural de Teruel, para garantizar el apoyo en las inversiones.

Cuestión 2. Desde la Asociación para el Asesoramiento Rural Integral Aragonés (ARIA), ¿Qué tipo de asesoramiento se lleva a cabo?

Para cada cliente, se confecciona un diagnóstico personalizado de su explotación, se elabora un informe de recomendaciones y se prepara toda la documentación complementaria para el seguimiento del cumplimiento de las obligaciones de la condicionalidad en su explotación. Además, se asesora al agricultor sobre tratamientos ante enfermedades y plagas, vigencia de los productos fitosanitarios, etc. En caso de inspección, el técnico de ARIA se encarga de preparar la documentación y los libros que deben presentar además de acompañar al agricultor el día en que se la realizan. 
Cuestión 3. ¿Cómo afectan los principios cooperativos a la innovación en Cereales Teruel?

En la actualidad, considerando los grandes desafíos y retos que origina una economía mundial globalizada, las organizaciones deben propiciar escenarios con horizontes en los cuales se posibilite asegurar su supervivencia en el tiempo. La innovación estratégica es la clave de la creación de riqueza (Hamel, 1998).

Para la supervivencia de las organizaciones es fundamental el valor agregado que se deriva de la unión sinérgica entre conocimiento e innovación como fuente de ventajas competitivas. Las cooperativas pueden poseer ciertas ventajas, en virtud del cumplimiento y profundización en sus valores y principios cooperativos, ya que éstos posibilitan la generación de capital social en la sociedad cooperativa el cual influye en la innovación (Marcuello y Saz, 2008). En este sentido, tanto en los servicios que desarrolla para los cooperativistas como las actuaciones socialmente responsables que realiza Cereales Teruel se pone de relieve la implementación de los principios y valores cooperativos que conducen a la creación de capital social y al desarrollo de innovaciones que permiten la creación de riqueza en el territorio.

\subsection{CONCLUSIONES}

Las cooperativas están impulsadas por los beneficios y los valores sociales. Son empresas en las que todos sus socios, que pueden ser trabajadores o clientes, participan tanto en las decisiones como en los beneficios y que se apoyan en los valores de la cooperación, autoayuda, auto responsabilidad, democracia, igualdad, equidad y solidaridad. Además, su correcto funcionamiento se basa en la honestidad, transparencia, responsabilidad social y la preocupación por los demás. El éxito de las cooperativas ayuda a crear empresas sostenibles que generen empleo y prosperidad. Éstas impulsan la economía, responden al cambio social, son resistentes a la crisis económica mundial y son empresas serias, con éxito, que fomentan la creación de puestos de trabajo en todos los sectores.

Cereales Teruel ha conseguido colaborar en el desarrollo y en la vertebración de una región deprimida, con escasa población y que necesita de la unión para conseguir sus metas. A la hora de organizarse de forma empresarial, Cereales Teruel siempre ha apostado por la innovación para conseguir todos sus objetivos de manera eficiente, y sin contradecir los principios fundamentales que la identifican como cooperativa.

Definitivamente, nos encontramos ante una de las pocas salidas, si no la única, para muchas pequeñas cooperativas turolenses que por sí mismas no tendrían ni tantos medios, ni la protección que asegura Cereales Teruel, una entidad fuerte y perdurable en el tiempo y en el territorio que facilita a las primeras el desempeño de su labor. 


\section{KOOPERA: INNOVACIÓN SOCIAL Y MEDIOAMBIENTAL}

\section{RESUMEN:}

La red Koopera se integra en la economía social y solidaria y es un ejemplo de economía circular. Los residuos que se generan con el consumo provocan una degradación medioambiental que puede ser detenida o, al menos, frenada por nuevas formas de producción y consumo. La economía circular permite la recuperación de los productos ya usados y proporcionales una nueva vida. Además, la economía circular requiere de consumidores responsables que inicien el proceso llevando los productos a puntos de recogida adecuados. Todas las actuaciones tienen el fin de lograr un desarrollo sostenible, el cual debe ser promovido tanto por los consumidores, por las empresas, y por los diferentes ámbitos institucionales. 


\subsection{INTRODUCCIÓN}

La Red Koopera nace en Bilbao en el año 2008 impulsada por Cáritas. Es una cooperativa de segundo grado sin ánimo de lucro integrada por cooperativas de iniciativa social y empresas de inserción, todas ellas tienen el objetivo común de insertar en la sociedad y en un ambiente laboral a personas en situación de exclusión o con riesgo de sufrirla. Conseguir el objetivo de inserción de las personas que lo necesitan supone llevar a cabo una labor social y Koopera lo consigue mediante la realización de actividades saludables para el medioambiente. Intentan alargar la vida útil de los productos a partir de la reutilización, el reciclaje y el consumo sostenible y llegar a un vertido cero. Vemos que la labor social se lleva a cabo mediante una actuación medioambiental. La finalidad del Grupo Koopera es alcanzar una economía social y solidaria, respetando los principios de la Red de Economía Alternativa y Solidaria ${ }^{2}$ (REAS), como la igualdad, el empleo, el respeto medioambiental, la cooperación, el compromiso con el entorno y el carácter no lucrativo de la actividad

La organización se mueve en torno a cinco ejes principales: servicios ambientales, cuidado de personas, reutilización y reciclaje, inclusión social y laboral y consumo responsable. En relación a los servicios ambientales hay que destacar que Koopera abarca temas de recogida de residuos, realiza actividades de mantenimiento y limpieza de municipios, promueve la movilidad urbana mediante un servicio público de alquiler de bicicletas eléctricas, dispone de ekohuertas solidarias, trabaja para cuidar los montes y promueve la educación ambiental.

Entre sus proyectos más destacables la entidad ha patentado un modelo de contenedores (2011), o ha puesto en funcionamiento en 2012 el Koopera Reusing Center, la primera planta a nivel estatal de clasificación de objetos mediante el reconocimiento de voz. Al margen del papel innovador en la gestión de los recursos textiles de Cáritas, Koopera sobresale por su filosofía ligada al cooperativismo, la economía solidaria y la inclusión sociolaboral. La incorporación de personas insertadas como socios cooperativistas copropietarias de las empresas de inserción en cuestión es uno de los aspectos más socialmente innovadores de la iniciativa. En 2016 se reportan en la web de la entidad 243 empleos de inserción, 433 personas trabajando, 61,643 miembros del club Koopera y 6819 atenciones a personas necesitadas.

La organización está formada por diferentes cooperativas de iniciativa social y empresas de inserción, en la Figura 1 se puede observar su distribución en España. En la zona norte ${ }^{3}$ Koopera cuenta con 11 centros; cuenta con dos en la zona este ${ }^{4}$, en la centro ${ }^{5}$ y en la sur ${ }^{6}$. Además de trabajar en territorio español, Koopera impulsa proyectos de cooperación al desarrollo en otros países.

\footnotetext{
${ }^{2} \mathrm{http}$ ///www.economiasolidaria.org/carta.php

${ }^{3}$ País Vasco, Asturias y Cantabria

${ }^{4}$ Comunidad Valenciana y Teruel.

${ }^{5}$ Albacete

${ }^{6}$ Almería
} 
Tiene dos proyectos de ámbito internacional ${ }^{7}$ : Koopera Chile y Ekorropa Romania. Koopera trabaja en Chile desde 2004 y cuenta con un almacén y una tienda "Koopera Moda Española", mientras que en Rumanía la organización comienza su labor en el año 2007 y tiene dos tiendas de segunda mano. Con esta expansión hacia el exterior Koopera quiere satisfacer las necesidades de sus clientes con un servicio similar al de España, además continúa con el objetivo de la inclusión social de las personas que lo necesitan por medio de actividades que protegen el medioambiente.

Figura 1. Distribución de las plantas y centros sociales de Koopera

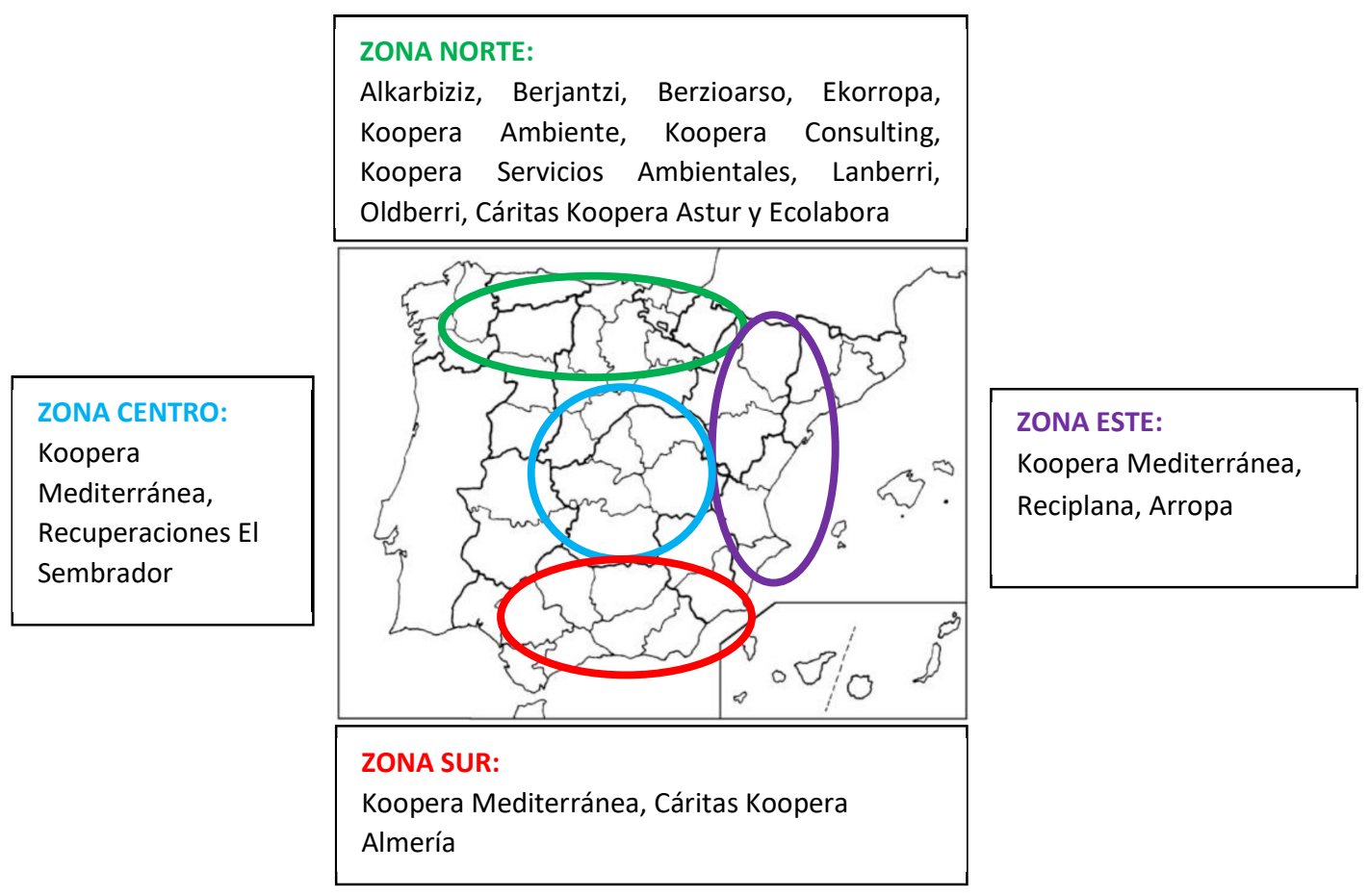

Fuente: Extraído de Báguena (2016)

\subsection{DESARROLLO DEL CASO RED KOOPERA}

\section{Misión y Valores de Koopera}

La visión, misión y valores de las organizaciones deben proporcionar respuestas a las preguntas: ¿qué queremos crear?, ¿cuál es nuestra razón de ser?, ¿cuáles son los valores hacen referencia a los principios morales y éticos que van a guiar la acción? Se trata de reflejar las aspiraciones de los fundadores de la organización y de determinar cuál es la función básica que va a desempeñar en un entorno determinado (Saz y Marcuello 2007).

\section{Misión}

En la Red Social Koopera trabaja por cambiar la situación de las personas que necesitan otra oportunidad. Son estas personas las auténticas protagonistas de la Red. La misión

\footnotetext{
${ }^{7}$ http://koopera.org/reutilizacion-y-reciclaje/implantacion-exterior/
} 
es la creación de empleo para personas en situación de exclusión social. Por ello, los servicios de inserción socio-laboral son transversales a todas las áreas donde trabaja. Estos servicios aúnan el capacitar a las personas a nivel profesional, con un acompañamiento educativo inclusivo, realizados siempre desde itinerarios individualizados. Los educadores/as sociales acompañan a las personas que realizan en Koopera un proceso de mejora de su empleabilidad, impulsando su cualificación técnica y su inclusión social. Contamos con una Bolsa de empleo dirigida a todas las empresas que quieran incorporan en su plantilla a trabajadores resolutivos e innovadores.

\section{Actividad de la entidad}

Red Social Koopera realiza servicios medioambientales principalmente de Gestión de residuos. Además, comercializa producto solidarios, justos y ecológicos que promueven un consumo responsable, el desarrollo sostenible del planeta y unas relaciones comerciales justas. En Red Social Koopera también colabora con el desarrollo de un mundo más equitativo a través de la promoción de la economía social y solidaria en países en vías de desarrollo. Se trabaja en la reutilización y el reciclaje a través de la innovación y desarrollo y de la preparación para la reutilización. Las Plantas de Reutilización Koopera procesan el textil, calzado y otros artículos. Los artículos reutilizados en buen estado, están disponibles a precios reducidos en las tiendas de segunda mano Koopera Store, desde donde se realizan donaciones para quienes más lo necesitan (Figura 2 y Figura 3).

Figura 2. Proyecto Koopera Store

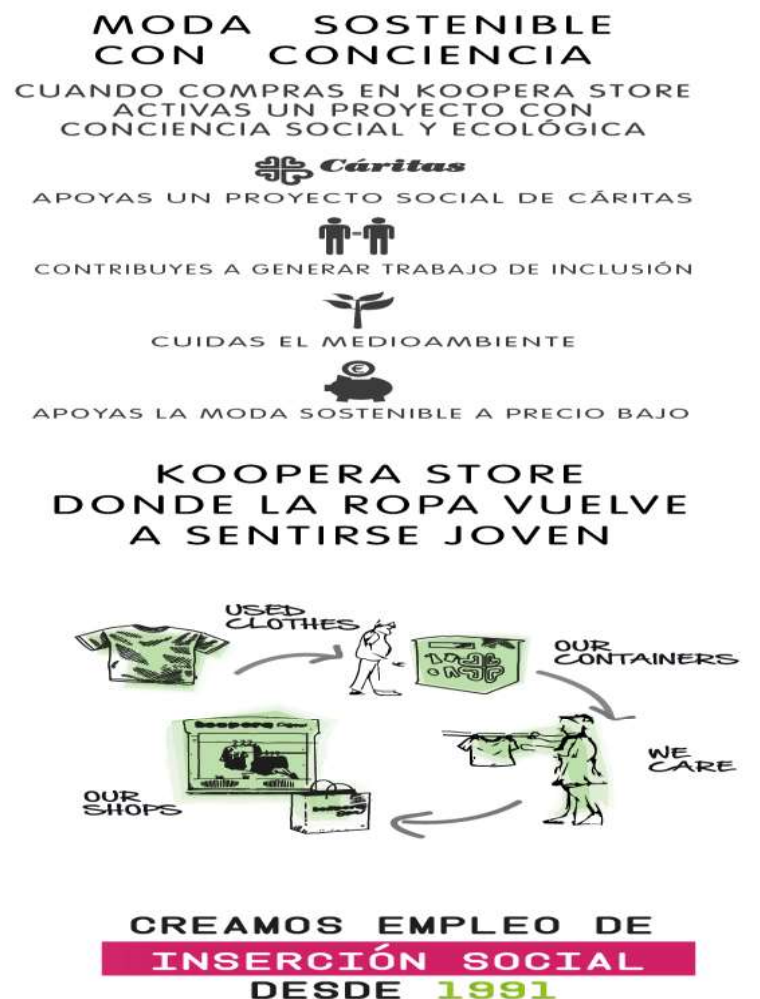

Figura 3. Proceso de reciclado y reutilización

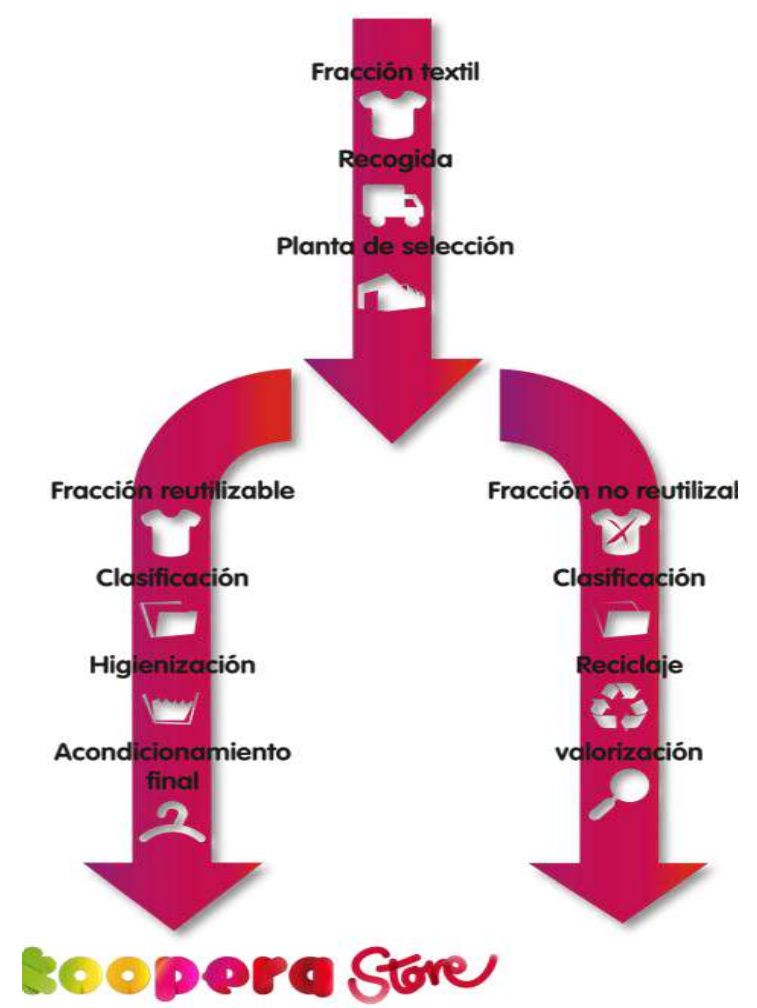

Fuente: http://koopera.org 
La Comisión Europea (2014) indica que la economía circular trata de mantener el mayor tiempo posible el valor añadido de los productos y excluir los residuos. Esto se da cuando un recurso que llega al final de su vida se mantiene dentro de la economía por más tiempo y así puede ser reutilizado varias veces creando más valor (figura 3). Con la introducción de la economía circular se intentan obtener los mínimos recursos de la naturaleza y, como pieza principal, se diseñan nuevos procesos de producción, productos y servicios. El diseño en los procesos de producción consiste en introducir innovaciones basadas en la reutilización de los materiales, de esta forma se reducen las cantidades de materiales nuevos y energía que se necesitan para producir

Figura 3. Fases de la economía circular

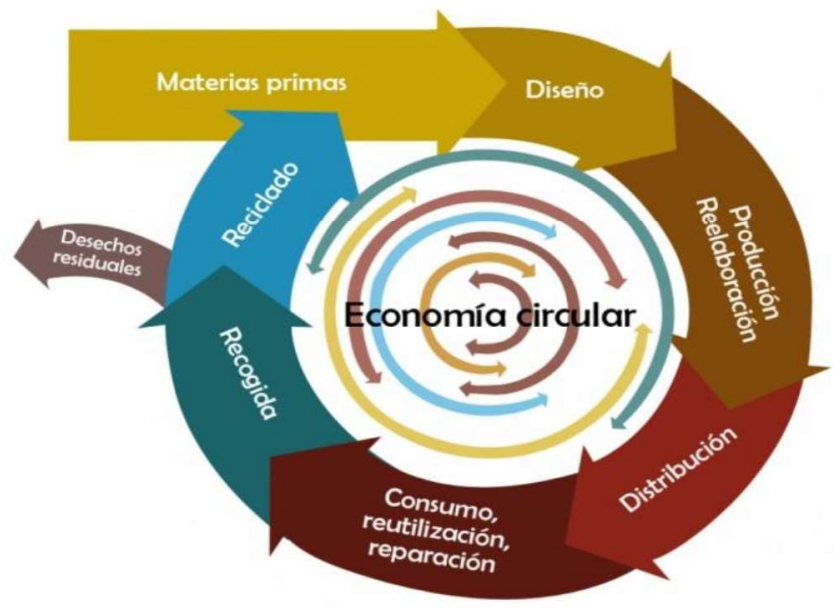

Fuente: Comisión Europea, COM (2014)

Valores y buenas prácticas

Los valores emanan de la voluntad de disponer la economía al servicio de las personas y aceptan y complementan los de la Economía Solidaria y los Principios Cooperativos. Son los siguientes: trabajo en red, austeridad, innovación, transformación, sostenibilidad, profesionalidad; participación; corresponsabilidad, respeto.

\section{Sostenibilidad social, económica y medioambiental de Koopera}

Las organizaciones se consideran sostenibles cuando además de sostenerse económicamente llevan a cabo su actividad sin degradar el medioambiente y sin crear problemas en la sociedad. La sostenibilidad en las organizaciones comprende tres ámbitos: medioambiente, sociedad y economía (Ramírez, 2006). La sostenibilidad de Koopera la podemos ver a través de su triple ámbito (Báguena, 2016).

En el ámbito social hay que destacar que Koopera es generadora de empleo además de realizar funciones de inserción y comercio justo. En el Gráfico 1 se pueden observar los 
datos referentes a los empleados de Koopera en el año 2014: Koopera cuenta con 433 empleados contratados, de los cuales 365 son a jornada completa. El 55\% de esos empleados contratados son personas en riesgo de exclusión.

Gráfico 1. Número de empleados de Koopera a jornada completa por provincia (2014)

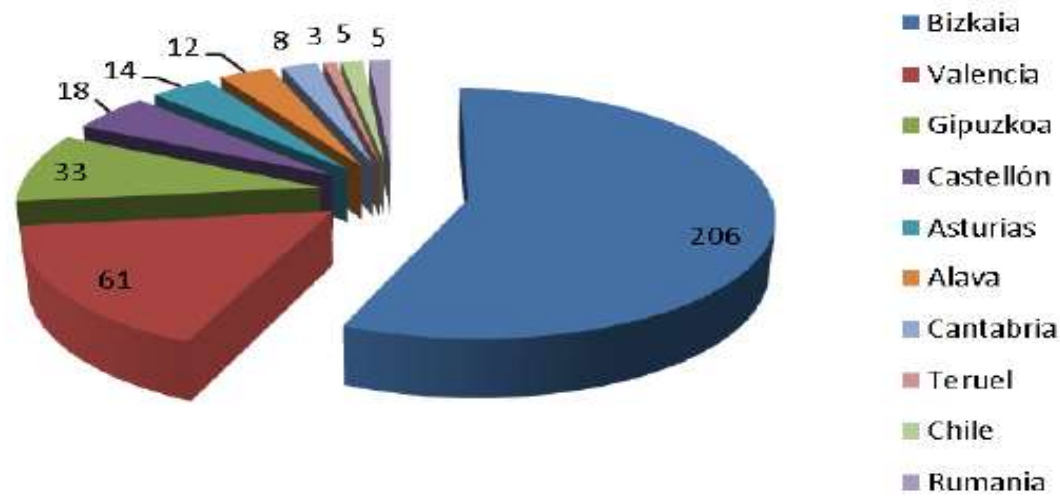

Fuente: Jornadas de Economía Social y Solidaria, Teruel el 05/05/2016

En el ámbito ambiental se trata de una organización que garantiza un fin ético del $100 \%$ de los residuos que llegan hasta ellos, ya que el destino de la ropa recogida es (datos del año 2014): reutilización: 10,2\%; exportación: 50,3\%, las prendas que están bien, pero por cuestión de moda no se consumiría en España, se envía a Rumanía; reciclaje: $30,2 \%$; creación de energía: $8.8 \%$, puede generarse la energía mediante la incineración de las prendas que no se puedan reutilizar ni reciclar; eliminación: $0 \%$.

Entre otras cifras en 2014 en relación al reciclaje y la reutilización de la ropa se encuentran: se recogieron 10.166 toneladas de ropa donada; se disminuyeron las emisiones de $\mathrm{CO}_{2}$ en 28.668 toneladas; se ha logrado disminuir $609.951 \mathrm{~m}^{3}$ de agua consumida; se ha reducido el consumo de electricidad en $47.000 \mathrm{kw}$.

Estas reducciones de emisiones y consumos se deben, en parte, a la tecnología que utilizan en el proceso de higienización con ozono. El ozono es un gas desinfectante en tiempos cortos, además de que no resulta dañino para el medioambiente, por eso se utiliza para desinfectar y limpiar la ropa donada que se venderá en las tiendas Koopera Store. El uso de la higienización con ozono en lugar del tradicional lavado con lavadoras ofrece las reducciones de agua y electricidad antes mencionadas, pero con su uso también se reducen los vertidos y la necesidad de utilizar detergentes nocivos para el medioambiente.

En el Gráfico 2 se muestra que el 33,2\% de los empleados de Koopera trabajan en el área de reutilización y reciclaje. Además, los mayores porcentajes de empleo también se dan en sus áreas medioambientales, el área de servicios ambientales ocupa al 33,4\% de sus empleados y el consumo sostenible ocupa al 18,1\%. 
Gráfico 2. Porcentaje de empleados de Koopera por área (2014)
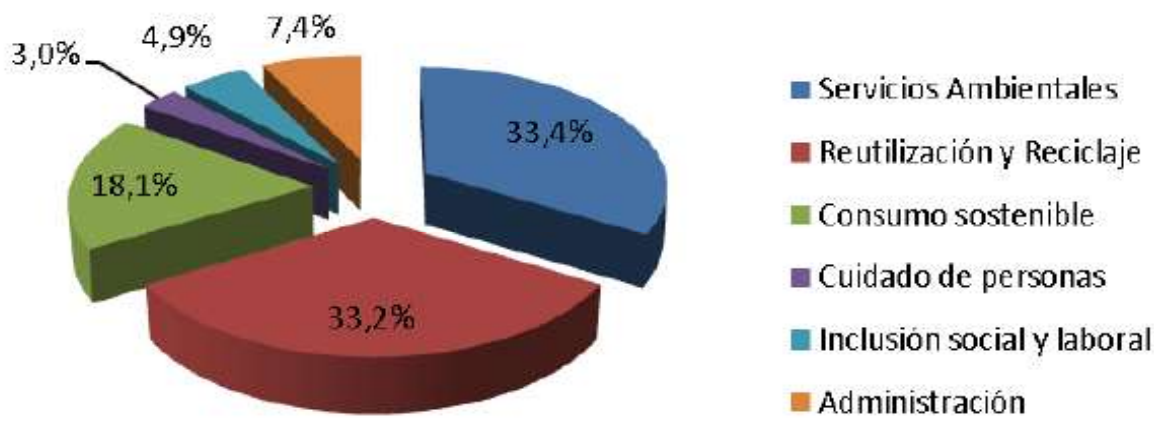

Fuente: Jornadas de Economía Social y Solidaria, Teruel 05/05/2016

En relación a los aspectos económicos, Koopera tiene en la actualidad 31 tiendas en 11 provincias diferentes con las que se obtiene la sostenibilidad económica del proyecto. Por lo que respecta a la localización de las tiendas Koopera Store se encuentran en diferentes comunidades autónomas: en País Vasco hay quince tiendas, en Cantabria una, en Asturias una, en Aragón hay una, en la Comunidad Valenciana hay ocho, en Castilla-La Mancha hay cuatro y en Andalucía hay una. En la Tabla.1 se detalla la distribución de las tiendas Koopera Store por provincia y municipio.

Tabla 1. Número de tiendas Koopera Store por provincia y municipio

\begin{tabular}{|c|c|c|c|c|c|}
\hline PROVINCIA & MUNICIPIO & $\mathrm{N}^{0}$ TIENDAS & PROVINCIA & MUNICIPIO & $\mathrm{N}^{0}$ TIENDAS \\
\hline \multirow{7}{*}{ Vizcaya } & Bilbao & 3 & \multirow{2}{*}{ Valencia } & Valencia & 3 \\
\hline & Galdakao & 1 & & Gandía & 1 \\
\hline & Durango & 1 & \multirow{2}{*}{ Castellón } & Castellón & 2 \\
\hline & Ermua & 1 & & Burriana & 1 \\
\hline & Barakaldo & 1 & Alicante & Alcoy & 1 \\
\hline & Portugalete & 1 & Teruel & Teruel & 1 \\
\hline & Getxo & 2 & \multirow{4}{*}{ Albacete } & Albacete & 1 \\
\hline Álava & Vitoria & 2 & & Almansa & 1 \\
\hline \multirow{3}{*}{ Guipúzcoa } & Donostia & 1 & & La Roda & 1 \\
\hline & Errenteria & 1 & & Hellín & 1 \\
\hline & Irún & 1 & Almería & Almería & 1 \\
\hline Cantabria & Santander & 1 & & & \\
\hline Asturias & Oviedo & 1 & & & \\
\hline
\end{tabular}

Fuente: Elaboración propia a partir de información de la página web de Koopera, http://koopera.org 
Así mismo, de forma creciente se implantan las nuevas tecnologías en la organización y esto ayuda a Koopera a ser más eficiente y tener una mayor eficacia en la realización del trabajo. El uso de tecnología les proporciona una ventaja competitiva y por tanto mayores ventas, como ejemplo se puede destacar en cada actividad de Koopera alguna tecnología aplicada: en la recogida de los residuos se utilizan tablets para llevar un seguimiento, en las plantas de clasificación las prendas se separara por voz, en los almacenes existe la tecnología de higienización y un nuevo etiquetado actual y en las tiendas hay disponibilidad de terminales en el punto de venta (TPV) para mejorar la gestión de stocks.

\subsection{CUESTIONES PARA DISCUSIÓN}

Cuestión 1. ¿Koopera forma parte de la denominada economía circular?

Según expresa la Comisión Europea (2014), y coincidiendo con Calleja (2015), el actual sistema de crecimiento lineal se basa en la abundancia, disponibilidad, facilidad de obtención y una eliminación barata de recursos, la economía circular pretende acabar con este patrón alargando la vida útil de los productos y materiales. Con la introducción de la economía circular se intentan obtener los mínimos recursos de la naturaleza y, como pieza principal, se diseñan nuevos procesos de producción, productos y servicios. La economía circular supone nuevas oportunidades de negocio.

Red Social Koopera realiza servicios medioambientales principalmente de Gestión de residuos. Además, comercializa producto solidarios, justos y ecológicos que promueven un consumo responsable, el desarrollo sostenible del planeta y unas relaciones comerciales justas. Koopera Store se aprovisiona a través de las donaciones de ropa que realizan las personas en los contenedores de Cáritas ubicados por las ciudades, por lo que es un ejemplo de economía circular al darle una nueva vida a prendas que han sido desechadas. Además, reduce residuos, reutiliza, recicla, crea energía, no genera ningún residuo, reduce emisiones de $\mathrm{CO}_{2}$ y ahorra agua y electricidad en el proceso de higienización de las prendas

Cuestión 2. ¿Qué cambios del comportamiento del consumidor han afectado a la evolución de Koopera?

La industria textil es muy contaminante ya que emplea un alto consumo de energía además de usar grandes cantidades de sustancias químicas (Muthu, 2014). El incremento del consumo de ropa provoca que año a año aumente el volumen de ropa desechada, y con éste, la conciencia sobre la necesidad de reutilizar dicho recurso. Los consumidores responsables son aquellos que se preocupan por diversos elementos, entre los cuales se encuentran la procedencia del producto, su producción, su manufactura, los regímenes opresivos, los derechos humanos, las relaciones laborales, etc. (Newholm y Shaw, 2007). Así pues, hay un crecimiento de consumidores responsables que están cada vez más concienciados de la necesidad de un desarrollo sostenible para disminuir los efectos negativos que tiene el consumo y tienen presente, de forma creciente, 
aspectos sociales y medioambientales vinculados con su decisión de compra. En este sentido, los cambios observados en el comportamiento del consumidor afectan positivamente a la actividad de Koopera.

Cuestión 3. ¿Cómo contribuye Koopera al desarrollo sostenible?

El desarrollo sostenible es un desarrollo que permite satisfacer las necesidades actuales sin interferir en la capacidad para satisfacer las necesidades en un futuro (Brundtland, 1987), lo que implica sostenibilidad económica, social y medioambiental. Koopera contribuye al desarrollo sostenible de los territorios tanto desde el punto de vista, económico, social y medioambiental. Por lo que respecta al ámbito económico dispone de tiendas con el fin de obtener beneficios para seguir invirtiendo en su proyecto y establece sistemas de gestión que permita incrementar la eficiencia de las organizaciones integradas en la red. En cuanto al ámbito social crea empleo e inserta a personas en riesgo o exclusión social. Hay que señalar, que el Tercer Sector de Acción Social (TSAS) es uno de los pilares del sistema de bienestar particularmente estratégico en zonas rurales. Además, se evidencia que las redes sociales existentes y las relaciones entre las organizaciones e instituciones relevantes para el sistema de bienestar (Saz-Gil et al., 2016). En este sentido, la red Koopera establece vínculos con múltiples agentes, tanto a nivel interno como externo. Por último, en el ámbito medioambiental reduce residuos, reutiliza, recicla, crea energía, no genera ningún residuo, reduce emisiones de $\mathrm{CO}_{2}$ y ahorra agua y electricidad en el proceso de higienización de las prendas.

\subsection{CONCLUSIONES}

La economía circular permite mejorar la situación medioambiental en la que los residuos van creciendo cada año. Para desarrollar una economía circular se hace fundamental el ecodiseño de procesos, productos y servicios. Existe la posibilidad de reintroducir los residuos en la economía a través de la reutilización, reelaboración o reciclaje. La economía circular es una nueva forma de producir en la que se utiliza la menor cantidad posible de materiales naturales y de esta manera el medioambiente tiene tiempo de regenerarse. Además de mejora de los aspectos medioambientales, la economía circular permite mejorar en aspectos económicos a través del ahorro que supone la reutilización y el reciclaje de materiales; y con la capacidad que tiene de generar nuevas oportunidades de negocio se puede crear empleo, así que también supone una fuente de beneficios sociales. La economía circular necesita del proceso de la logística inversa para recoger, reutilizar, reelaborar y reciclar los residuos que se espera que no salgan del circulo de la economía.

Koopera innovación social y ambiental es un ejemplo de entidad integrada en la red de economía alternativa y solidaria (REAS), respetando sus principios de igualdad, empleo, medioambiente, cooperación, compromiso medioambiental y carácter no lucrativo $^{8}$. Además, pertenece también a la Asociación Española de Recuperadores de

\footnotetext{
${ }^{8} \mathrm{https} / / /$ www.economiasolidaria.org/sites/default/files/CARTA_ECONOMIA_SOLIDARIA_REAS.pdf
} 
Economía Social y Solidaria (AERESS) y a la Federación de Cooperativas de Trabajo Asociado, Enseñanza y Crédito de Euskadi (ERKIDE). La organización está formada por diferentes cooperativas de iniciativa social y empresas de inserción que distribuyen en diferentes zonas por toda España (zona norte, zona este, zona centro y zona sur), y cuenta con dos proyectos de ámbito internacional (Koopera Chile y Ekorropa Romania).

Koopera tiene cinco ámbitos principales de actuación: servicios ambientales, cuidado de personas, reutilización y reciclaje, consumo responsable e inclusión social y laboral. En relación a los servicios ambientales hay que destacar que Koopera abarca temas de recogida de residuos, realiza actividades de mantenimiento y limpieza de municipios, promueve la movilidad urbana mediante un servicio público de alquiler de bicicletas eléctricas, dispone de ekohuertas solidarias, trabaja para cuidar los montes y promueve la educación ambiental.

La red Koopera es un ejemplo de economía circular, influye positivamente tanto en el ámbito medioambiental y social, como en el ámbito económico. En el ámbito medioambiental reduce residuos, reutiliza, recicla, crea energía, no genera ningún residuo, reduce emisiones de $\mathrm{CO}_{2}$ y ahorra agua y electricidad en el proceso de higienización de las prendas. En el ámbito social crea empleo e inserta a personas en riesgo o exclusión social. Por último, en el ámbito económico dispone de tiendas con el fin de obtener beneficios para seguir invirtiendo en su proyecto. 


\section{BIBLIOGRAFIA}

Ansoff, H. I. (1965): Corporate Strategy, McGraw Hill, Nueva York.

Arla Foods (2018): página web oficial de la organización, www.arla.com, accedida $08 / 09 / 2018$

Arla Foods (2018): Annual Report 2017, http://docs.arla.com/annual-report/2017/EN/, accedida 08/09/2018

Atadi (2019): página web oficial de la organización, www.atadi.es.

Báguena, M. (2016): Economía Circular - Logística Inversa: El caso de Koopera Teruel. Trabajo Fin de Grado. Facultad de Ciencias Sociales y Humanas de Teruel, Universidad de Zaragoza.

Birchall, J. (2014). The Governance of Large Co-operative Businesses. Manchester: Cooperatives UK

Bradley, K., y Gelb, A. (1987). Cooperative labor relations: Mondragon's response to recession. British Journal of Industrial Relations, 25(1): 77-99.

Bretos, I. y Errasti, A. (2016). Dinámicas de regeneración en las cooperativas multinacionales de Mondragón: La reproducción del modelo cooperativo en las filiales capitalistas. CIRIEC-España, Revista de Economía Pública, Social y Cooperativa, 86: 5-34.

Bretos, I., y Errasti, A. (2017). Challenges and opportunities for the regeneration of multinational worker cooperatives: Lessons from Mondragon Corporation - A case study of the Fagor Ederlan Group. Organization, 24(2): 154-173.

Bretos, I., y Errasti, A. (2018). La transmisión de los valores y prácticas organizacionales cooperativas en las filiales extranjeras: El caso de la cooperativa multinacional Fagor Ederlan. REVESCO-Revista de Estudios Cooperativos, 127: $45-69$.

Bretos, I. y Errasti, A. (2018). The challenges of managing across borders in worker cooperatives: Insights from the Mondragon cooperative group. Journal of Cooperative Organization and Management, 6(1): 34-42.

Bretos, I. y Marcuello, C. (2017). Revisiting globalization challenges and opportunities in the development of cooperatives. Annals of Public and Cooperative Economics, 88(1): 47-73.

Bretos, I. y Morandeira, J. (2016). La Economía Social ante la actual Crisis Económica en la Comunidad Autónoma del País Vasco. REVESCO-Revista de Estudios Cooperativos, 122, 7-33.

Bretos, I., Díaz-Foncea, M., y Marcuello, C. (2018). Cooperativas e internacionalización: Un análisis de las 300 mayores cooperativas del mundo. CIRIEC-España, Revista de Economía Pública, Social y Cooperativa, 92: 5-37.

Bretos, I., Errasti, A., y Marcuello, C. (2018). Ownership, governance and the diffusion of HRM practices in multinational worker cooperatives: Case-study evidence from the Mondragon group. Human Resource Management Journal, 28(1): 7691. 
Bretos, I., Errasti, A. y Marcuello, C. (2019). Multinational expansion of worker cooperatives and their employment practices: Markets, institutions, and politics in Mondragon. ILR Review, 72(3), 580-605..

Brundtland, G.H. (1987): Nuestro futuro común. Alianza Editorial, Madrid.

Calleja Crespo, D. (2015): La economía circular, una oportunidad estratégica para Europa. Cuadernos de energía, 46, pp. 32-35.

Catalán, P. (2018). Análisis del voluntariado en el Tercer Sector de Acción Social de Teruel: Estudio de caso: ATADI. Trabajo Fin de Grado, Facultad de Ciencias Sociales y Humanas / Campus de Teruel.

Cerelaes Teruel (2019). página web oficial de la organización, www.cerealesteruel.com

Cheshire, L. y Woods, M. (2013). Globally engaged farmers as transnational actors: Navigating the landscape of agri-food globalization. Geoforum 44, 232-242.

Comisión Europea (2014): Hacia una economía circular: un programa de cero residuos para Europa. Comunicación de la Comisión al Parlamento Europeo, al Consejo, al Comité Económico y Social Europeo y al Comité de las Regiones, Bruselas.

Coraggio, J.L. (2004), Una alternativa socioeconómica necesaria: la economía social, en Política social y economía social, Altamira, Buenos Aires.

Errasti, A., Bretos, I. y Etxezarreta, E. (2016). What do Mondragon 'coopitalist' multinationals look like? The rise and fall of Fagor Electrodomésticos S. Coop. and its European subsidiaries. Annals of Public and Cooperative Economics, 87(3): 433-456.

Errasti, A., Bretos, I. y Núnez, A. (2017). The viability of cooperatives: The fall of the Mondragon cooperative Fagor. Review of Radical Political Economics, 49(2): 181-197.

Flecha, R. y Ngai, P. (2014): The Challenge for Mondragon: Searching for the Cooperative Values in times of Internationalization. Organization, 21(5): 666682.

Franco, L. (2011): La cooperativa Cereales Teruel diversificará su actividad desarrollando parques eólicos. La sociedad, una de las más importantes de España en su género, opta a la concesión de aerogeneradores. Heraldo de Aragón, $08 / 01 / 2011$.

Groeneveld (2016): The Road Towards One Cooperative Rabobank. Accedido 08/09/2018

https://www.cooperatie.nl/sites/default/files/the road towards_one cooperative r abobank_hans_groeneveld_jianuary_2016.pdf

Grupo Arcoiris (2019). página web oficial de la organización, www.grupoarcoiris.com

Grupo UP (2018): página web oficial de la organización [https://www.up.coop/en.html], accedida $09 / 09 / 2018$

Grupo UP (2017): Informe Anual año 2017 [http://rapportannuel2016.upgroup.coop/en], accedido a 09/09/2018

Hamel, G. (1998). Strategy Innovation and the Quest for Value. Sloan Management Review 
Hamel G. (2006). Innovación estratégica y creación de valor, Harvard Deusto Business Review, 152, 18-27.

ISASS (2014). Estudio sobre el retorno social de la inversión del Servicio de Canguro de Plena inclusión Aragón y la residencia de Kalathos (Teruel). https://es.calameo.com/read/005104048310d6e8e35fa

Jiménez Lara, A. (2007): "Conceptos y tipologías de la discapacidad. Documentos y normativas de clasificación más relevantes”, en R. de Lorenzo García y L. C. Pérez Bueno (coords.), Tratado sobre Dsicapacidad, Madrid, Thomson-Aranzadi, páginas. 177-205.

Koopera (2019). página web oficial de la organización, http://koopera.org/

Ley 43/2015 (2015): de 9 de octubre, del Tercer Sector de Acción Social. Boletín Oficial del Estado, núm. 243, de 10 de Octubre de 2015.

Ley 45/2015 (2015): de 14 de octubre, de Voluntariado. Boletín Oficial del Estado, núm. 247, de 15 de Octubre de 2015.

Marcuello Servós, C. y Saz, Gil M I. (2008): Los principios cooperativos facilitadores de la innovación: un modelo teórico, REVESCO, Revista de Estudios Cooperativos, 94, 59-79

Mondrgón (2013): Modelo de gestión corporativo, https://www.mondragoncorporation.com/wp-content/uploads/2017/Modelo-de-Gesti\%C3\%B3n-

Corporativo-MONDRAGON.pdf , accedida 08/09/2018

Mondrgón (2015): Un viaje por los hitos de la historia del grupo cooperativo, https://www.mondragon-corporation.com/wpcontent/themes/mondragon/docs/History-MONDRAGON-1956-2014.pdf, accedida 08/09/2018

Mondrgón (2018): página web oficial de la organización, https://www.mondragoncorporation.com, accedida 08/09/2018

Muthu (2014): Roadmap to Sustainable Textiles and Clothing: Environmental and SocialAspects of Textiles and Clothing Supply Chain, Springer Science and Business Media, Singapore 2014. Editor Subramanian Senthilkannan Muthu, SGS Hong Kong Limited.

Newholm, T. y Shaw, D. (2007): Studying the ethical consumer: A review of research, Journal of Consumer Behaviour, 6, 253-270.

Plataforma del Voluntariado de España (2011): Manual integral de acción voluntaria. Plataforma del voluntariado en España. Madrid.

Rabobank (2018): página web oficial de la organización, https://www.rabobank.com/en/home/index.html, accedida 08/09/2018

Rabobank (2018): Informe Anual 2018, https:/www.rabobank.com/en/images/02interim-report-2018.pdf, accedida 08/09/2018

Rabobank (2018): Informe Anual 2017, https://www.rabobank.com/en/images/annualreport-2017.pdf, accedida 08/09/2018

Ramírez Orellana, A. (2006): La RSC y la triple cuenta de resultados, Estrategia financiera, 231, 54-62.

Ramón Fernández, F. y Saz Gil, M. I. (2005): El cooperativismo agrario como elemento dinamizador del desarrollo rural, en Juliá, F. J. Melía, E. y Server,R. (Eds.) 
Cooperativismo Agrario y Desarrollo, Universidad Politécnica de Valencia, pp. 465-478

Rodríguez Fernández, J.L. y Saz Gil, M.I. (2011): Una nueva frontera en organizaciones no lucrativas: el buen gobierno global, CIRIEC-España, Revista de Economía Pública, Social y Cooperativa, $\mathrm{n}^{\mathrm{o}}$ 71, agosto, pp. 229-251.

Royo, A. (2018): Cereales Teruel busca en Monreal del Campo alternativas al cultivo del cereal de secano, Diario de Teruel 3/7/2018.

Saz Gil, M. I. y Marcuello Servós, C. (2007): Introducción de la dirección estratégica en organizaciones que gestionan empleo con apoyo. Acciones e investigaciones sociales 24, 173-197.

Saz-Gil, I, Almaguer-Kalixto, P. y Gómez-Quintero, J.D. (2016): "Capital social y redes sociales: análisis del Tercer Sector en contextos rurales", CIRIEC-España, Revista de Economía Pública, Social y Cooperativa, 86, 123-154.

Saz-Gil, I. (tut.) (2012). La unión hace la fuerza. Grupo Cooperativo Arcoíris, Matarraña (Teruel), España. En Vázquez Burguete J.L. y Roriz Ferreira, M. (Eds.) IV Congreso Internacional de Casos Docentes en Marketing Público y No Lucrativo, pp. 967-976. León: Asociación Internacional de Marketing Público y No Lucrativo, Grupo de Investigación en Marketing e Investigación Operativa. ISBN: 978-84-697-0512-1

Saz-Gil, I. (tut.) (2012). Cereales Teruel. Sociedad Cooperativa. En Vázquez Burguete J.L. y Roriz Ferreira, M. (Eds.) IV Congreso Internacional de Casos Docentes en Marketing Público y No Lucrativo, pp. 449-456. León: Asociación Internacional de Marketing Público y No Lucrativo.

Saz Gil M.I y Zardoya Alegría, A. (2014): La gestión del voluntariado corporativo en las organizaciones no lucrativas, Revista Española del Tercer Sector, 28, pp. 8198.

Saz Gil, M. I. (2008): La gestión stakeholder en las organizaciones no lucrativas: una aproximación a través del estudio de casos, Estudios de Economía Aplicada, 26, 187-210.

Saz-Gil, I., Almaguer-Kalixto, P. y Gómez- Quintero, J.D. (2016): "Capital social y redes sociales: análisis del Tercer Sector en contextos rurales", CIRIEC-España, Revista de Economía Pública, Social y Cooperativa, 86, 123-154.

Storey, J., Basterretxea, I. y Salaman, G. (2014). Managing and resisting 'degeneration' in employee-owned businesses: A comparative study of two large retailers in Spain and the United Kingdom. Organization, 21(5): 626-644. 